\title{
DURAÇÃO DO PERÍODO DE MOLHAMENTO FOLIAR: ASPECTOS OPERACIONAIS DA SUA MEDIDA, VARIABILIDADE ESPACIAL EM DIFERENTES CULTURAS E SUA ESTIMATIVA A PARTIR DO MODELO DE PENMAN-MONTEITH
}

\author{
Paulo Cesar Sentelhas
}

Tese apresentada à Escola Superior de Agricultura "Luiz de Queiroz", Universidade de São Paulo, para a obtenção do título de Livre Docência em Agrometeorologia

\section{PIRACICABA}

Estado de São Paulo - Brasil

Outubro - 2004 


\title{
DURAÇÃO DO PERÍODO DE MOLHAMENTO FOLIAR: ASPECTOS OPERACIONAIS DE SUA MEDIDA, VARIABILIDADE ESPACIAL EM DIFERENTES CULTURAS E ESTIMATIVA A PARTIR DO MODELO DE PENMAN-MONTEITH
}

\author{
Paulo Cesar Sentelhas \\ Engenheiro Agrônomo \\ Mestre em Agrometeorologia \\ Doutor em Irrigação e Drenagem
}

Tese apresentada à Escola Superior de Agricultura "Luiz de Queiroz", Universidade de São Paulo, para a obtenção do título de Livre Docência em Agrometeorologia

PIRACICABA

Estado de São Paulo - Brasil

Outubro - 2004 


\section{Dedicatória}

Dedico esta tese às paixões da minha vida,

Rosana, Bárbara, Isabella e Luana,

pelo apoio e amor incondicionais que me ajudaram a chegar a mais esta fase de minha vida profissional. 


\section{Agradecimentos}

À Universidade de São Paulo (USP), à Universidade de Guelph (UofG), Canadá, e ao Conselho Nacional de Pesquisa e Desenvolvimento Tecnológico (CNPq), do Ministério de Ciência e Tecnologia (MCT), respectivamente pelo apoio, pela oportunidade e pela bolsa de estudos para a realização do programa de pósdoutoramento que me possibilitou a realização deste trabalho.

Ao Prof. Dr. Terry J. Gillespie, da Universidade de Guelph, pela amizade, ensinamentos, orientação e, principalmente, pela acolhida calorosa durante meu estágio em Guelph, Canadá, a qual nem eu e nem minha família jamais nos esqueceremos.

Ao Prof. Mark L. Gleason, da Iowa State University, pela fantástica recepção em Ames, pelo empréstimo dos sensores, pela disponibilização de boa parte dos dados utilizados neste trabalho e pela criteriosa análise dos artigos em inglês. Também a Jean C. Batzer e Sara Helland, pelo apoio com os dados meteorológicos.

Ao Prof. Dr. Luiz Roberto Angelocci, da ESALQ/USP, pelos conselhos, pela amizade incondicional e pelas longas mensagens eletrônicas que me ajudaram a matar um pouco da saudade.

Aos amigos Fábio Ricardo Marin, José Eduardo Monteiro, José Ricardo Pezzopane e Mário José Pedro Júnior, pela contribuição na coleta de dados, pelas sugestões e por estarem sempre prontos a me ajudar, mesmo a uma grande distância.

Aos amigos Gordon Drewitt, Claudia Wagner-Riddle, Jon Warland, Tracy Rawlandson, Richard Heck e Peter van Straaten, da Universidade de Guelph, pela convivência harmoniosa e pelo apoio em todos os momentos.

À minha maravilhosa família, especialmente à minha esposa Rosana, que soube suportar as dificuldades, aproveitar as oportunidades e curtir os bons momentos, tirando de tudo isso sempre importantes lições de vida. 


\section{Sumário}

Lista de Figuras.................................................................................................. vi

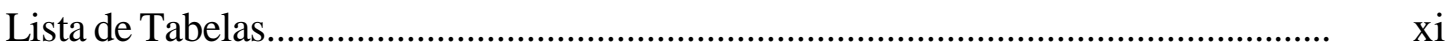

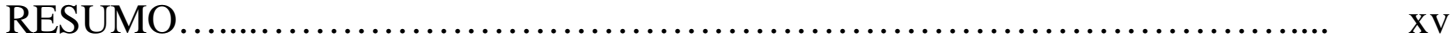

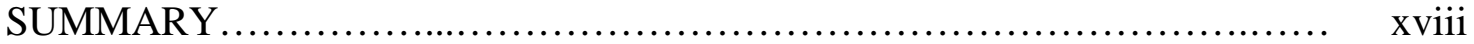

1. INTRODUÇÃO

2. REVISÃO BIBLIOGRÁFICA................................................................. 4

2.1 Agrometeorologia e doenças de plantas................................................ 4

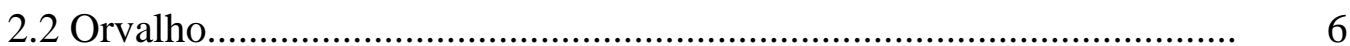

2.3 Duração do período de molhamento: medidas e estimativas................. 8

3. SENSORES ELETRÔNICOS DE MEDIDA DA DURAÇÃO DO

PERÍODO DE MOLHAMENTO FOLIAR: PORQUE ELES DEVEM SER

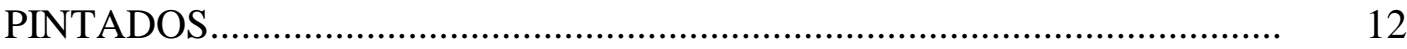

3.1 Introdução........................................................................................ 14

3.2 Material e métodos........................................................................ 17

3.3 Resultados e discussão................................................................... 20

3.4. Conclusões................................................................................... 26

4. ESTIMATIVA DA DURAÇÃO DO PERÍODO DE MOLHAMENTO

FOLIAR NA CULTURA DO ALGODÃO A PARTIR DE DADOS

METEOROLÓGICOS........................................................................... 27

4.1 Introdução.................................................................................... $\quad 30$

4.2 Material e métodos............................................................................. 33

4.3 Resultados e discussão...................................................................... 40

4.4. Conclusões.................................................................................... $\quad 50$

5. ASPECTOS OPERACIONAIS DA MEDIDA DA DURAÇÃO DO PERÍODO DE MOLHAMENTO FOLIAR COM SENSORES ELETRÔNICOS ..................................................................................... 52 
5.1. Introdução.................................................................................

5.2. Material e métodos............................................................................ 59

5.2.1 Sensores eletrônicos para medida da DPM............................... 59

5.2.2 Experimentos de campo............................................................ 61

5.2.3 Observação visual da formação e secamento do orvalho........ 64

5.2.4 Variabilidade entre sensores de DPM...................................... 66

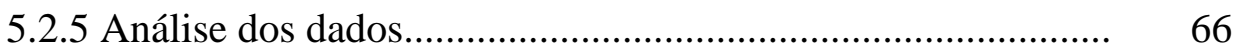

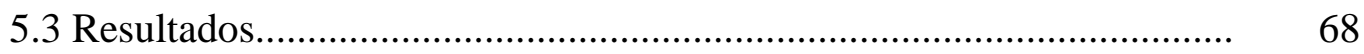

5.3.1 Posição dos sensores versus observação visual da DPM

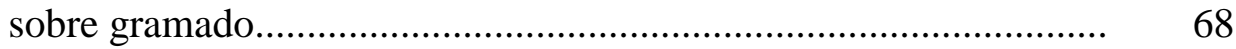

5.3.2 Variabilidade entre sensores de DPM...................................... 72

5.3.3 Efeito das diferentes alturas e ângulos dos sensores na

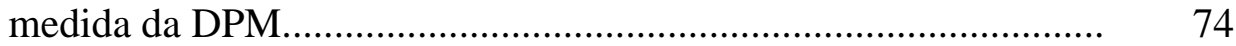

5.3.4 Relação entre a DPM medida na estação meteorológica e em três diferentes culturas.....................................................................

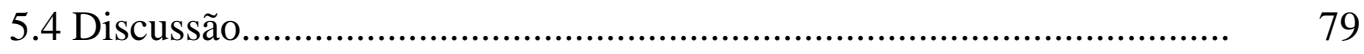

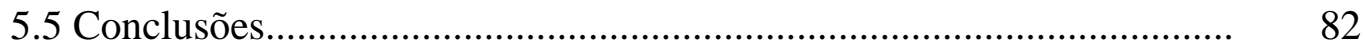

6. VARIABILIDADE ESPACIAL DA DURAÇÃO DO PERÍODO DE MOLHAMENTO FOLIAR EM DIFERENTES CULTURAS........................... 84

6.1 Introdução..........................................................................................

6.2 Material e métodos........................................................................... 89

6.2.1 Sensores eletrônicos para medida da DPM.............................. 89

6.2.2 Experimentos de campo........................................................... 90

6.2.3 Análise dos dados................................................................... 93

6.3 Resultados e discussão............................................................................ 94

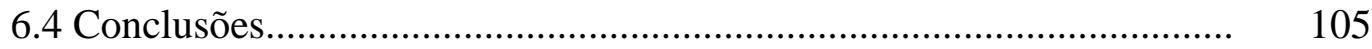

7. AVALIAÇÃO DO MODELO DE PENMAN-MONTEITH PARA ESTIMATIVA DA DURAÇÃO DO PERÍODO DE MOLHAMENTO FOLIAR EM CONDIÇÃO PADRÃO E DE CULTURA................................... 109

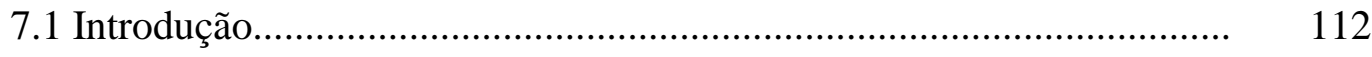


7.2 Material e métodos............................................................................... 115

7.2.1 Experimentos de campo.......................................................... 115

7.2.2 Estimativa da DPM pelo modelo de Penman-Monteith.......... 117

7.2.3 Estimativa do saldo de radiação............................................... 122

7.2.3.1 Modelo I............................................................ 122

7.2.3.2 Modelo II............................................................. 123

7.2.3.3 Modelo III............................................................. 125

7.3.3.4 Modelo IV ........................................................... 126

7.2.4 Análise dos dados............................................................... 126

7.3 Resultados e discussão....................................................................... 128

7.3.1 Estimativa da DPM em condição padrão................................. 128

7.3.2 Estimativa da DPM de referência e da cultura em diferentes

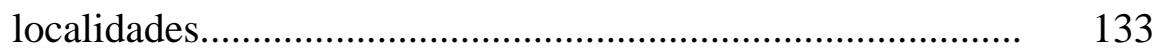

7.3.3 Efeito da redução do saldo de radiação noturno na

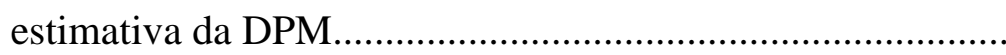

7.3.4 Efeito das estimativas do saldo de radiação na estimativa da DPM......................................................................... 142

7.4 Conclusões....................................................................................... 146

8. CONCLUSÕES GERAIS...................................................................... 147

REFERÊNCIAS BIBLIOGRÁFICAS................................................................ 151 


\section{Lista de Figuras}

Página

3.1 Detalhe da micro-estação automática, com psicrômetro aspirado para a medida da temperatura e da umidade relativa do ar e do sensor de duração do período de molhamento foliar, instalada no topo da cultura do algodão.

3.2 Representação esquemática do sensor eletrônico de medida da duração do período de molhamento foliar (DPM) utilizado nas micro-estações automáticas, mostrando o detalhe dos dois pentes intercalados...........

3.3 Coeficiente de variação (CV\%) para as medidas de DPM usando sensores eletrônicos sem (a) e com pintura (b) com tinta latex. As setas indicam os dias em que o molhamento foi promovido por orvalho e/ou chuva.

3.4 Relação entre a DPM medida pelos sensors eletrônicos (media dos seis sensores) e a DPM estimada pelo $\mathrm{NHDPO}<2^{\circ} \mathrm{C}$, para os períodos em que os sensores estavam sem pintura (a) e pintados (b)..................

3.5 Velocidade media diária do vento $\left(\mathrm{U}_{2 \mathrm{~m}}\right)$ sobre a cultura do algodão. As linhas representam a média para os dois períodos estudados: linha tracejada representa o período em que os sensores estavam sem pintura e a linha contínua representa o período em que os sensores estavam pintados

4.1 Vista geral da área experimetal, da estação meteorológica e das microestações instaladas na cultura do algodão (a) e detalhe de uma das micro-estações (b).

4.2 Árvore de classificação para a estimativa da DPM. Adaptado de Gleason et al. (1994).

4.3 Representação esquemática da altura dos sensores e da resistência aerodinâmica (ra) adicional requerida pelo modelo RES 
4.4 Relação entre a DPM medida e a estimada pelos modelos NHUR $>90 \%$ (a), DPO (b), CART (c) e RES (d) a partir de dados meteorológicos medidos sobre a cultura do algodão, considerando-se tanto os dias com como os sem chuva.

4.5 Relação entre a DPM medida e a estimada pelos modelos NHUR $>90 \%$ (a), DPO (b), CART (c) e RES (d) a partir de dados meteorológicos medidos sobre a cultura do algodão, considerando-se os dias sem chuva.

4.6 Relação entre a DPM medida e a estimada pelos modelos NHUR $>90 \%$ (a), DPO (b), CART (c) e RES (d) a partir de dados meteorológicos medidos sobre a cultura do algodão, considerando-se os dias com chuva.

4.7 Relação entre a DPM medida na estação meteorológica e nas microestações na cultura do algodão. Cada ponto representa a média de 3 medidas em cada cultivar.

4.8 Relação entre a DPM estimada com dados da estação meteorológica e a DPM estimada com dados das micro-estações na cultura do algodão, utilizando-se os modelos do NHUR $>90 \%$ (a), DPO (b), CART (c) e RES (d).

4.9 Relação entre a DPM medida e estimada com dados das micro-estações na cultura do algodão, utilizando-se o modelo RES.

5.1 Detalhe de um sensor de DPM da Campbell Sci., Modelo 237, montado em uma secção de um tudo de PVC.

5.2 Disposição dos sensores de DPM instalados em Elora, ON, Canadá, sobre o gramado (a) e na cultura do milho (b), e em Ames, IA, Estados Unidos, sobre o gramado (c) e na cultura do melão (d)....

5.3. Observação visual do orvalho: (a) observação da deposição do orvalho em gramado, com uso de uma laterna e (b) molhamento em folha de milho nas primeiras horas da manhã 
5.4 Variabilidade entre os sensores de DPM quando foram instalados à mesma altura $(30 \mathrm{~cm})$ e ângulo $\left(30^{\circ}\right)$. No eixo $X$ tem-se as posições em que esses sensores foram utilizados durante o período de medidas: $190=$ $190 \mathrm{~cm} \mathrm{e} 30^{\circ} ; 150=150 \mathrm{~cm}$ e $30^{\circ} ; 110=110 \mathrm{~cm}$ e $30^{\circ} ; 70=70 \mathrm{~cm} \mathrm{e}$ $30^{\circ} ; 30=30 \mathrm{~cm} \mathrm{e} 30^{\circ} ; 15 \mathrm{G}=30 \mathrm{~cm}$ e $15^{\circ} ; 45 \mathrm{G}=30 \mathrm{~cm}$ e $45^{\circ} ; 0 \mathrm{G}=30$ $\mathrm{cm}$ e $0^{\circ}$; e Milho $=$ no topo da cultura do milho a $30^{\circ}$. A linha contínua representa a média.

5.5 Coeficientes de variação diário (barra) e médio (linha) da medida da DPM por todos os sensores instalados na mesma altura $(30 \mathrm{~cm})$ e ângulo $\left(30^{\circ}\right)$

5.6 DPM média obtida com os sensores instalados a diferentes alturas e com um ângulo de exposição de $30^{\circ}$ em Elora (a) e Piracicaba (b) e de $45^{\circ}$ em Ames (c). As médias de DPM sobre as barras seguidas da mesma letra não diferem significativamente entre si ao nível de $1 \%$ de probabilidade

5.7 DPM média obtida com os sensores instalados com diferentes ângulos de exposição em relação à horizontal e a uma altura de 30 cm em Elora (a) e Piracicaba (b). As médias de DPM sobre as barras seguidas da mesma letra não diferem significativamente entre si ao nível de $1 \%$ de probabilidade.

5.8 Relação entre a DPM medida no topo da cultura e na posição mais alta sobre o gramado/solo em: a) Elora (gramado a $190 \mathrm{~cm}$ e milho a 240 cm), b) Piracicaba (solo nú a $170 \mathrm{~cm}$ e algodão a $100 \mathrm{~cm}$ ) e c) Ames (gramado a $150 \mathrm{~cm}$ e melão a $20 \mathrm{~cm}$ )

5.9 Relação entre a DPM medida no topo da cultura e a $30 \mathrm{~cm}$ sobre gramado em: a) Elora (milho a $240 \mathrm{~cm}$ ) e b) Ames (melão a $20 \mathrm{~cm}$ ).........

6.1 Representação esquemática da posição dos sensores em cada uma das culturas estudadas. 
6.2 Relação entre a DPM medida no topo (a), no meio (b) e na parte baixa (c) da cultura da maçã e a DPM medida a $30 \mathrm{~cm}$ de altura sobre o gramado, em Ames, IA, Estados Unidos

6.3 Relação entre a DPM medida no topo (a), no meio_alto (b), no meio_baixo (c) e na parte baixa (d) da cultura do café e a DPM medida a $30 \mathrm{~cm}$ de altura sobre o gramado, em Piracicaba, SP, Brasil

6.4 Relação entre a DPM medida no topo (a) e no interior (b) da cultura do milho e a DPM medida a $30 \mathrm{~cm}$ de altura sobre o gramado, em Elora, ON, Canadá.

6.5 Relação entre a DPM medida no topo/interior da cultura do melão e a DPM medida a $30 \mathrm{~cm}$ de altura sobre o gramado, em Ames, IA, Estados Unidos.

6.6 Relação entre a DPM medida no topo (a) e na parte baixa (b) da cultura da uva e a DPM medida a 30 cm de altura sobre o gramado, em Jundiaí, SP, Brasil

7.1 Representação esquemática da altura dos sensores e da resistência aerodinâmica (ra) adicional requerida pelo modelo de PenmanMonteith. ( $Z_{c}=$ altura da cultura e $Z_{T}=$ altura da medida de temperatura)

7.2 Representação esquemática da posição relativa dos sensores de DPM e das resistências aerodinâmicas envolvidas na estimativa do fluxo de calor latente pelo método de Penman-Monteith nas alturas de 30 e 110 cm sobre gramado.

7.3 Relação entre a DPM estimada pelo modelo de Penman-Monteith, para as alturas de $190 \mathrm{~cm}$ (a), $110 \mathrm{~cm}$ (b) e $30 \mathrm{~cm}$ (c), e a DPM medida pelos sensores eletrônicos, em Elora, ON, Canadá, de julho a outubro de 2003 
7.4 Relação entre a DPM estimada pelo modelo de Penman-Monteith, para a altura de $30 \mathrm{~cm}$ sobre a superfície gramada, e a DPM medida pelo sensor eletrônico na mesma posição em Elora, Piracicaba e Jundiaí (a) e no topo das culturas do milho, da uva e do café (b).................................

7.5 Relação entre a DPM estimada pelo modelo de Penman-Monteith (considerando-se $80 \%$ do saldo de radiação noturno), para as alturas de $190 \mathrm{~cm}$ (a), $110 \mathrm{~cm}$ (b) e $30 \mathrm{~cm}$ (c), e a DPM medida pelos sensores eletrônicos, em Elora, ON, Canadá, de julho a outubro de 2003...............

7.6 Relação entre a DPM estimada pelo modelo de Penman-Monteith (considerando-se 80\% do saldo de radiação noturno), para a altura de 30 cm sobre superfície gramada, e a DPM medida pelo sensor eletrônico na mesma posição em Elora, Piracicaba e Jundiaí (a) e no topo das culturas do milho, da uva e do café (b)...............................................................

7.7 Relação entre o saldo de radiação horário medido pelo sensor CNR1 sobre o gramado e aqueles estimados a partir das variáveis meteorológicas pelos modelos I (a), II (b), III (c) e IV (d), para Elora, ON, Canadá

7.8 Relação entre os dados horários da DPM medida por sensor eletrônico e as DPMs estimadas pelo modelo de Penman-Monteith, utilizando-se diferentes formas de obtenção do saldo de radiação: a) medido, b) estimado pelo Modelo I, c) estimado pelo Modelo II, d) estimado pelo Modelo III e e) estimado pelo Modelo IV 


\section{Lista de Tabelas}

Página

4.1 Análise de regressão e erros relacionados à estimativa da DPM pelos diferentes modelos, a partir dos dados obtidos na estação meteorológica instalada na cultura do algodão, considerando-se tanto os dias com

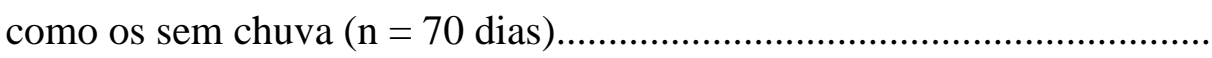

4.2 Análise de regressão e erros relacionados à estimativa da DPM pelos diferentes modelos, a partir dos dados obtidos na estação meteorológica instalada na cultura do algodão, considerando-se os dias sem chuva (n = 38 dias)

4.3 Análise de regressão e erros relacionados à estimativa da DPM pelos diferentes modelos, a partir dos dados obtidos na estação meteorológica instalada na cultura do algodão, considerando-se os dias com chuva ( $\mathrm{n}$ = 32 dias)

5.1 Condições climáticas médias durante os experimentos em Ames, IA, Estados Unidos (2003), Elora, ON, Canadá (2003), e Piracicaba, SP, Brasil (2000/01 e 2003)

5.2 Diferença entre a medida e a observação visual dos horários de deposição e do secamento do orvalho, considerando-se os sensores instalados com diferentes alturas e ângulos de exposição sobre o gramado, em Elora, ON, Canadá, durante o verão de 2003. EAM = erro absoluto médio e EM = erro médio

5.3 Diferença entre a medida e a observação visual dos horários de secamento do orvalho, considerando-se os sensores instalados com diferentes alturas e ângulos de exposição sobre o gramado, em Piracicaba, SP, Brasil, durante o inverno de 2003. EAM = erro absoluto médio e EM = erro médio 
5.4 Diferença entre a medida e a observação visual dos horários de deposição e do secamento do orvalho, considerando-se o sensor instalado no topo da cultura do milho, em Elora, ON, Canadá, durante o verão de 2003. EAM = erro absoluto médio e EM = erro médio. Diferença $=$ medido - observado.

6.1 Condições climáticas médias durante a realização dos experimentos de campo em Ames, IA, Estados Unidos (2000, 2001 e 2003), Elora, ON, Canadá (2003), Piracicaba, SP, Brasil (2003) e Jundiaí, SP, Brasil $(2003 / 04)$

6.2 Duração do período de molhamento foliar (DPM) média nas diferentes posições nas cutluras da maçã, do café, do milho, da uva, do tomate e do melão, considerando-se todo o período.

6.3 Duração do período de molhamento foliar (DPM) média nas diferentes posições nas cutluras da maçã, do café, do milho, da uva, do tomate e do melão, considerando-se apenas os dias sem chuva.....

6.4 Duração do período de molhamento foliar (DPM) média nas diferentes posições nas cutluras da maçã, do café, do milho, da uva, do tomate e do melão, considerando-se apenas os dias com chuva.

6.5 Diferença média (MD) e diferença absoluta média (DMA) entre a DPM medida pelo sensor na condição padrão (sobre o gramado, a $30 \mathrm{~cm}$ de altura e com ângulo de $30^{\circ}$ ) e nas diferentes posições nas culturas...........

7.1 Condiões climáticas médias durante a realização dos experimentos de campo em Elora, ON, Canadá (2003), Piracicaba, SP, Brasil (2003) e Jundiaí, SP, Brasil (2003/04)

7.2 Erro médio (EM) e erro absoluto médio (EAM), em minutos, para o início e para o fim do molhamento foliar estimados pelo modelo de Penman-Monteith, para alturas de 190, 110 e 30 cm acima da superfície gramada, considerando-se todo o período e os dias com e os sem chuva separadamente. 
7.3 Erro médio (EM), erro absoluto médio (EAM) e erro absoluto máximo (EMAX), em horas, da estimativa da DPM pelo modelo de PenmanMonteith para as alturas de 190, 110 e 30 cm sobre gramado, em Elora...

7.4 Erro médio (EM), erro absoluto médio (EAM) e erro absoluto máximo (EMAX), em horas, da estimativa da DPM pelo modelo de PenmanMonteith para a condição de referência (30cm sobre o gramado), em Elora, Jundiaí e Piracicaba.

7.5 Erro médio (EM), erro absoluto médio (EAM) e erro absoluto máximo (EMAX), em horas, da estimativa da DPM pelo modelo de PenmanMonteith para as culturas do milho, da uva e do café, a partir dos dados observados em uma estação meteorológica em Elora, Jundiaí e Piracicaba, respectivamente.

7.6 Erro médio (EM), erro absoluto médio (EAM) e erro absoluto máximo (EMAX), em horas, da estimava da DPM pelo modelo de PenmanMonteith para as alturas de 190, 110 e 30 cm sobre gramado, em Elora, considerando-se $80 \%$ do saldo de radiação noturno

7.7 Erro médio (EM), erro absoluto médio (EAM) e erro absoluto máximo (EMAX), em horas, da estimava da DPM pelo modelo de PenmanMonteith para a condição de referência (30 cm sobre gramado), em Elora, Jundiaí e Piracicaba, considerando-se $80 \%$ do saldo de radiação

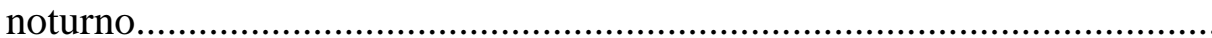

7.8 Erro médio (EM), erro absoluto médio (EAM) e erro absoluto máximo (EMAX), em horas, da estimava da DPM pelo modelo de PenmanMonteith para as culturas do milho, da uva e do café, a partir dos dados observados em estação meteorológica em Elora, Jundiaí e Piracicaba, respectivamente, e considerando-se $80 \%$ do saldo de radiação noturno.... 
7.9 Erro médio (EM), erro absoluto médio (EAM) e erro absoluto máximo (EMax), em horas, da estimativa da DPM pelo modelo de PenmanMonteith, utilizando-se diferentes métodos de determinação do saldo de radiação: medida pelo sensor CNR1 (Rn_obs) e estimada pelos modelos I (Rn_I), II (Rn_II), III (Rn_III) e IV (Rn_IV), e dados de uma estação

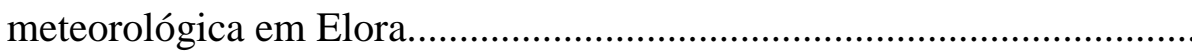




\title{
DURAÇÃO DO PERÍODO DE MOLHAMENTO FOLIAR: ASPECTOS OPERACIONAIS DA SUA MEDIDA, VARIABILIDADE ESPACIAL EM DIFERENTES CULTURAS E SUA ESTIMATIVA A PARTIR DO MODELO DE PENMAN-MONTEITH
}

\begin{abstract}
Autor: Prof. Dr. Paulo Cesar Sentelhas
RESUMO

Em razão da grande importância da duração do período de molhamento foliar (DPM) no estabelecimento de doenças fúngicas e bacterianas nas culturas agrícolas e de seu uso em grande parte dos modelos de previsão de epidemias e em sistemas de alerta fitossanitário, este estudo teve por objetivo fazer uma profunda análise dessa variável, especialmente com relação aos aspectos operacionais de sua medida, de sua variabilidade espacial em diferentes culturas e de sua estimativa por diversos métodos, com ênfase ao modelo de Penman-Monteith, de modo a se determinar uma condição de referência para sua medida e a relação dessa DPM de referência com a DPM em diferentes culturas. Para tanto, foram utilizados dados de DPM obtidos em diversos experimentos de campo conduzidos nas localidades de: Ames, IA, Estados Unidos; Elora, ON, Canadá; Jundiaí, SP, Brasil; e Piracicaba, SP, Brasil, envolvendo medidas nas culturas do algodão, do café, do milho, do melão, da maçã, do tomate e da uva, assim como sobre o gramado em diversas alturas e ângulos de inclinação, durante os anos de 2000 a 2004. Os resultados obtidos indicaram que a pintura dos sensores é um
\end{abstract}


procedimento importante para a determinação da DPM, pois ele reduz sensivelmente o coeficiente de variação entre as medidas feitas por diversos sensores, e que a posição do sensor, quando instalado sobre o gramado, tem efeito significativo nas medidas dessa variável. Foi estabelecida, a partir da comparação entre os dados medidos pelos sensores de DPM e observações visuais, uma condição de referência para a medida da DPM sobre o gramado (a $30 \mathrm{~cm}$ de altura e com inclinação de $30^{\circ}$ em relação à horizontal). A partir dessa condição de referência, determinou-se a relação entre a DPM medida sobre gramado e nas diferentes culturas, observando-se uma elevada concordância no topo das plantas. Em razão das diferenças observadas no padrão de variabilidade da DPM entre as diversas culturas, não foi possível se estabelecer relações bem definidas para a estimativa da DPM no interior das plantas a partir da DPM de referência. Analisando-se quatro diferentes modelos de estimativa da DPM a partir de dados meteorológicos, obtidos na cultura do algodão, observou que, em geral, todos os métodos de estimativa da DPM tiveram boa performance, com erros absolutos médios entre 1,27 e 2 h, porém o modelo RES, baseado na equação de Penman-Monteith, estimou a DPM ao nível da cultura com alta acurácia e regular precisão, sendo uma boa opção para a estimativa dessa variável sem o requerimento de calibração para cada cultura e local. Em uma análise mais detalhada desse modelo, observou-se que ele foi capaz de estimar a DPM sobre o gramado com boa acurácia e precisão, superestimando a DPM em 3,4\% a 190 cm, 1,1\% a $110 \mathrm{~cm}$ e 5,3\% a $30 \mathrm{~cm}$ de altura. Quando a DPM estimada para o gramado a uma altura de $30 \mathrm{~cm}$ foi correlacionada com a DPM no topo das culturas do milho, da uva e do café, uma boa concordância foi observada, com uma superestimativa média de 6,5\% e um coeficiente de determinação de 0,90. Baseando-se nesses resultados, conclui- 
se que o modelo de Penman-Monteith, aplicado a um sensor de DPM de tamanho e albedo fixos e exposto sobre gramado a $30 \mathrm{~cm}$ de altura, pode ser uma ferramenta muito útil para a estimativa dessa variável em sistemas de alerta fitossanitário, mesmo quando o saldo de radiação necessita ser estimado. 


\title{
LEAF WETNESS DURATION: OPERATIONAL EXPOSURE OF SENSORS, SPATIAL VARIABILITY IN DIFFERENT CROP CANOPIES, AND ITS ESTIMATION WITH
} PENMAN-MONTEITH MODEL

\author{
Author: Prof. Dr. Paulo Cesar Sentelhas
}

\section{SUMMARY}

How leaf wetness duration (LWD) is a very important variable for plant disease epidemiology and it is used in several plant disease warning systems, this study aimed to make a deep analysis of this variable, mainly in relation to the operational exposure of sensors, its spatial variability in different crop canopies, and its estimation using different methods, with emphasis to Penman-Monteith model, trying to determine a reference condition to its measurement and the relationship between reference LWD and crop LWD. For this purpose, LWD data from several field experiments in Ames, IA, United States, Elora, ON, Canada, Jundiaí, SP, Brazil, and Piracicaba, SP, Brazil, in different crops: cotton, coffee, corn, muskmelon, apple, tomato, and grape, were used as well as LWD data obtained over mowed turfgrass, during the years from 2000 to 2004. The results showed that for LWD measurements the treatment of the sensors with paint is desirable, since this procedure reduce the coefficient of variation among measurements obtained by several sensors, and that the position of the sensor, when installed over mowed turfagrass, has a significant effect. From the comparison of dew 
onset and dry-off between measurements and visual observations, it was established a reference position to LWD measurement (at $30 \mathrm{~cm}$ over mowed turfgrass and deployed at $30^{\circ}$ to horizontal). Based on this reference position, the relationship between turfgrass LWD and crop LWD was determined for several crops and a good agreement was observed for the top position of the canopies. Because the differences observed in the patterns of spatial variability among the crops, it was not possible to determine a define correlation between LWD inside the crops and reference LWD. The analysis of four different models to estimate LWD from meteorological data in a cotton crop showed that all of them had a good performance, with mean absolute errors ranging from 1.27 to $2 \mathrm{~h}$. However, RES model, based on a Penman-Monteith approach, showed to be a good option to estimate LWD since it does not require adjustments or calibrations for each new place and/or crop. In a deep analysis about a Penman-Monteith approach to estimate LWD, it was observed that this model was able to estimate turfgrass LWD with good accuracy and precision, overestimating this variable by $3.4 \%$ at $190 \mathrm{~cm}, 1.1 \%$ at $110 \mathrm{~cm}$, and $5.3 \%$ at $30 \mathrm{~cm}$. When reference LWD (at $30 \mathrm{~cm}$ over turfgrass) estimated by Penman-Monteith model was correlated with LWD at the top of the crops (coffee, corn, and grape) the tendency of overestimation increased to $6.5 \%\left(\mathrm{R}^{2}=0.90\right)$. Based on these results, we conclude that Penman-Monteith model for a fixed sensor size, albedo and exposure over turf may be a very useful standard tool to estimate LWD for use in plant disease management schemes, even when net radiation needs to be estimated. 


\section{INTRODUÇÃO}

A grande maioria das plantas cultivadas nas condições tropicais e subtropicais está sujeita à ação dos agentes fitopatogênicos, os quais irão se estabelecer desde que as condições ambientais sejam propícias para tal. Dentre os elementos meteorológicos que condicionam a infecção causada por patógenos, os principais são: a temperatura, que regula a velocidade das reações metabólicas tanto do patógeno como do hospedeiro, a chuva e a umidade do ar, que condicionam a presença de água na forma líquida sobre as plantas, possibilitando a germinação e a penetração dos fungos e bactérias, e o vento, responsável pelo secamento do molhamento foliar e também pela dispersão e propagação dos patógenos a grandes distâncias.

A duração do período de molhamento foliar (DPM), resultante da deposição de orvalho e/ou da chuva/irrigação sobre as plantas, é uma variável extremamente importante na relação entre o patógeno e o hospedeiro, sendo o fator crítico para o processo epidemiológico de doenças nas culturas. Isso se deve ao fato da grande maioria dos patógenos requerem a presença de água livre sobre as plantas para a germinação dos esporos e para infecção do tecido. A determinação dessa variável torna-se, portanto, fundamental para a identificação do potencial de risco de ocorrência de doenças nas 
culturas e na tomada de decisão quanto à realização dos controles, sendo esta uma das áreas mais promissoras da agrometeorologia operacional (Hoppmann e Wittich, 1997).

A determinação da DPM pode ser feita de diversas maneiras, como relatado por Getz (1991), desde medidas diretas, com sensores mecânicos ou automáticos, ou por meio de estimativas baseadas em relações empíricas, normalmente com o número de horas com a umidade relativa acima de um dado valor (Crowe et al., 1978, Sentelhas et al., 1993, Gleason et al., 1994), ou em modelos mais complexos, envolvendo o balanço de energia da cultura (Pedro Jr. e Gillespie, 1982a,b), relações mecanísticas entre o solo, a cultura e a atmosfera (Norman e Campbell, 1983; Wilson et al., 1999), empregando-se a meteorologia de mesoescala (Gleason et al., 1997) ou, ainda, o uso de radares meteorológicos (Gillespie et al., 1990).

Como na grande maioria das estações meteorológicas, sejam elas convencionais ou automáticas, é raro o uso de sensores de DPM, o monitoramento rotineiro do risco de ocorrência de doenças exige a estimativa dessa variável, a partir de dados meteorológicos. No entanto, essas estimativas apresentam inconsistências principalmente quando não são levadas em consideração as diferenças existentes entre as condições microclimáticas impostas por um gramado e pelas culturas agrícolas, o que pode resultar em erros significativos. Sendo assim, os objetivos deste trabalho foram:

a) avaliar o uso de sensores eletrônicos para a medida da DPM, com relação a diversos aspectos operacionais, como sua pintura, altura e ângulo de instalação, para a determinação de uma condição padrão de medida sobre gramado; 
b) avaliar a variabilidade espacial da DPM medida em diferentes culturas, com distintas características estruturais, e a relação dessas medidas com aquelas obtidas em condição padrão;

c) avaliar o desempenho de diversos métodos, com ênfase ao uso do modelo de Penman-Monteith, para a estimativa da DPM de referência e, a partir desta, da DPM da cultura. 


\section{REVISÃO BIBLIOGRÁFICA}

\subsection{Agrometeorologia e doenças de plantas}

A ocorrência de doenças em plantas resulta de uma complexa interação entre hospedeiro, patógeno e ambiente (Burrage, 1972, 1978). De acordo com Kranz, citado por Bergamin Filho e Amorim (1996), essa complexa interação, descrita como “o estudo de populações de patógenos em populações de hospedeiros e a doença resultante desta interação sob a influência do ambiente e da interferência humana”, é definida como epidemiologia. O ambiente assume papel fundamental, pois interfere no desenvolvimento das três populações (patógeno, hospedeiro e doença), muitas vezes de modo diferenciado e, em contrapartida, as três populações também exercem influência sobre o ambiente, especialmente no microclima (Bergamin Filho e Amorim, 1996). Portanto, as observações contínuas das condições ambientais, da cultura e do patógeno são indispensáveis para o entendimento e quantificação dessas relações (Sutton et al., 1984).

Vários são os trabalhos que evidenciam a importância e a influência das variáveis ambientais, especialmente da DPM causada por orvalho ou chuva, no 
estabelecimento e desenvolvimento de doenças nas culturas agrícolas. O orvalho e/ou a chuva propiciam longos períodos com a presença de água na forma líquida sobre as folhas e frutos, permitindo a germinação dos esporos dos fungos e servindo como veículo para o processo de penetração do tubo germinativo, sendo que quanto maior a DPM maior é a taxa de infecção (Melching et al., 1989; Pedro Jr., 1989; Grove, 1991; Buttler e Jadhav, 1991; Jacome e Schua, 1992; Sentelhas, 1992; Schuh, 1993; Deshpande et al., 1995; Sentelhas et al., 1996; Byrne et al., 1998; Camihos et al., 1999; Ciarisse et al., 2000).

Apesar da duração do molhamento foliar ser a variável mais importante para as doenças, na realidade é o binômio temperatura-DPM que irá condicionar efetivamente o estabelecimento e desenvolvimento dos patógenos (Pereira et al., 2002). Schuh (1992), estudando a ocorrência de Cercospora kikuchii em soja, verificou que apesar da DPM de pelo menos 24 h ser fundamental para a proliferação do patógeno, nenhum sintoma foi observado em plantas submetidas a temperaturas inferiores a $15^{\circ} \mathrm{C}$ ou superiores a $35^{\circ} \mathrm{C}$. Schuh e Adamowicz (1993), também com soja, observaram que com DPM entre 6 e 36 h, a ocorrência de septosporiose apresentou uma relação quadrática com a temperatura do ar, sendo que a máxima infecção ocorreu com $25^{\circ} \mathrm{C}$. Apesar dessas constatações, a interrelação entre DPM e temperatura irá depender também da concentração de inóculo e da idade das folhas, como observado por Zheng e Sutton (1994), para a cultura do morango, e por Turechek e Stevenson (1998), em plantas de nogueira pecã.

O conhecimento dessas informações permite se estabelecer os limites críticos das condições ambientais a partir das quais as doenças terão plenas condições para um rápido desenvolvimento, quando, então, o uso de fungicidas passa ser indispensável 
(Gillespie et al., 1993). Essa é uma importante e promissora contribuição da agrometeorologia para o setor produtivo, possibilitando a otimização da produção, a produção de alimentos mais saudáveis, a racionalização do uso de defensivos nas áreas agrícolas, a redução dos custos de produção e a diminuição da contaminação dos recursos naturais.

\subsection{Orvalho}

O orvalho é definido como a água condensada sobre a superfície, quando a temperatura dessa atinge o ponto de orvalho, devido ao resfriamento intenso, por perda de radiação de ondas longas, em noite de céu limpo, sem vento e com alta umidade no ar próximo à superfície (Pereira et al., 2002). A temperatura do ponto de orvalho, por sua vez, é a temperatura na qual uma dada parcela de ar deve ser resfriada sob pressão e teor de vapor constantes a fim de que haja saturação (Monteith, 1973).

O orvalho, que ocorre em superfícies naturais, especialmente nas plantas, pode ser proveniente de dois processos distintos: a "precipitação de orvalho”, quando ocorre condensação do vapor proveniente da camada imediatamente superior, adjacente à superfície, e a “destilação de orvalho”, quando ocorre condensação do vapor proveniente de uma superfície evaporante inferior à folha, sendo ambos função do gradiente de pressão de vapor existente (Burrage, 1972; Sharma, 1976). No entanto, de acordo com Raman et al. (1973), a condensação na face inferior é, geralmente, insignificante quando comparada ao processo que promove a condensação na face superior das plantas. 
O orvalho na vegetação se forma como resultado da perda radiativa de calor das superfícies das plantas, que se resfriam, fazendo com que haja transferência de calor sensível do ar adjacente para a superfície, processo pelo qual o ar se resfria até que seja atingida a temperatura do ponto de orvalho e o vapor se condense sobre as folhas; porém, a formação de orvalho pode se dar muito antes que a umidade relativa do ar (UR) atinja $100 \%$, desde que haja presença de partículas hidrofílicas no ar. Nesses casos, de acordo com Klemm et al. (2002), a formação de orvalho pode se dar com UR entre 60 e 100\%, iniciando-se, em média, duas a três horas após o por do sol (Baier, 1966).

Segundo Montheith (1961), o potencial de condensação sobre uma superfície vegetal não depende somente das suas propriedades aerodinâmicas, mas também de outras características das superfícies como: estrutura (estágio de desenvolvimento, posição no dossel, ângulo e geometria da folha), tamanho e propriedades térmicas, além das condições micrometeorológicas (Sharma, 1976; Sutton et al., 1984). Já a permanência da água sobre as folhas, ou outras partes da planta, irá depender também do ângulo de inclinação e do formato dessas.

Burrage (1972) e Van der Wal (1978) salientam que a duração com que o orvalho permanece sobre as plantas, denominado de duração do período de molhamento foliar (DPM), é muito mais importante que a quantidade total de água depositada sobre elas, especialmente com relação ao desenvolvimento de doenças. Assim a medida ou estimativa dessa variável é de extrema importância nos estudos epidemiológicos. 


\subsection{Duração do período de molhamento foliar: medidas e estimativas}

Apesar do orvalho, e sua duração, ser uma variável de difícil observação e registro (Wallin, 1967; Getz, 1991), e de serem quase que inexistentes os estudos que relatem a sua climatologia, à exceção de Klemm et al. (2002), existem diversos tipos de sensores para sua medida.

Atualmente, os sensores utilizados para a medida da DPM podem ser classificados, basicamente, em dois grupos: os mecânicos, que medem mudanças de peso, tamanho ou comprimento do elemento sensor com a umidade, e os eletrônicos, que detectam mudanças na resistência ou capacitância do elemento sensor em função da presença de água (Gillespie e Kidd, 1978; Getz, 1991). Com o advento da microeletrônica e o desenvolvimento e a popularização dos sistemas automáticos de aquisição de dados, os sensores eletrônicos passaram a ser os mais empregados.

A partir da década de setenta, os sensores eletrônicos começaram a ser desenvolvidos (Davis e Hughes, 1970; Gillespie e Kidd, 1978), com o uso de circuitos eletrônicos, sendo classificados como folha artificial ou “clips”, este último utilizado diretamente em folhas, troncos e frutos (Miranda et al., 2000). Esses sensores foram testados para várias condições (Gillespie \& Kidd, 1978; Weiss \& Lukens, 1981; Gillespie \& Duan, 1987; Armstrong et al., 1993; Wittich, 1995; Giesler et al., 1996; Miranda et al., 2000), apresentando excelentes resultados quando comparados com observações visuais, passando, assim, a serem comercializados juntamente com as estações meteorológicas automáticas. 
Apesar disso, poucas são as estações meteorológicas que dispõe de sensores de DPM e, muitas vezes, sua operação requer cuidados que, se não forem levados em consideração, poderão gerar erros significativos (Monteiro et al., 2002). Desse modo, a estimativa da DPM, a qual pode ser baseada tanto em modelos empíricos (Gillespie et al., 1993; Gleason et al., 1994), como em modelos mais complexos, envolvendo os princípios físicos da formação e da evaporação do orvalho (Pedro Jr e Gillespie, 1982a,b; Rao et al., 1998), passa a ser a opção mais viável.

Dentre os modelos mais complexos, os desenvolvidos por Pedro Jr. \& Gillespie (1982a,b), baseados na equação do balanço de energia aplicado a uma superfície vegetada, apresentaram significativa contribuição à estimativa da DPM. Os autores consideraram como o horário de início da formação do orvalho o momento em que o fluxo de calor latente (LE) passa a ser negativo e o momento de seu secamento quando a mesma quantidade de água condensada durante a noite é consumida pelo processo de evaporação pela manhã. Os autores testaram esse método utilizando dados micrometeorológicos de três culturas: milho, soja e maçã (Pedro Jr. \& Gillespie, 1982a) e dados meteorológicos de uma estação padrão (Pedro Jr.\& Gillespie, 1982b), observando excelentes resultados, sendo os erros médios da DPM, em relação aos dados observados, da ordem de 30 a 60 minutos quando empregou-se dados micrometeorológicos e da ordem de 60 a 90 minutos quando utilizou-se dados meteorológicos.

O modelo desenvolvido por Pedro Jr. \& Gillespie (1982a,b) também foi aplicado na cultura da cebola por Gillespie \& Barr (1984), para folhas de bananeira por Lhomme \& Jimenez (1992) e para a cultura do trigo por Francl \& Panigrahi (1997), apresentando 
bons resultados, porém, requerendo a medida da temperatura ao nível da cultura. Wittich (1995) também empregou esse modelo com sucesso na cultura da maçã, porém, testando três diferentes formas de se considerar a diferença entre a temperatura da folha e a do ar. O autor verificou que as melhores estimativas, com erros da ordem 15 minutos, foram obtidas quando se considerou a temperatura de ambos os lados da folha, a umidade específica e os coeficientes de transporte iguais. Lou \& Goudriaan (2000) empregaram um método físico de multi-camadas, baseado na equação de Penman-Monteith, desenvolvido por Goudriaan (1977), para a estimativa da DPM em arroz inundado, obtendo resultados satisfatórios. Modelo similar foi testado por Rao et al. (1998), o qual apresentou desempenho satisfatório, porém, sendo similar aos modelos mais simples, dentre eles os que consideram somente a umidade relativa ou a depressão do ponto de orvalho.

Entre os diversos modelos físicos utilizados para estimar a deposição e evaporação do molhamento, aquele baseado na equação de Penman-Monteith (Monteith e Unsworth, 1990) parece ter algumas vantagens em relação àqueles baseados na equação geral do balanço de energia, como o modelo apresentado por Pedro Jr. e Gillespie (1982a,b). A principal vantagem do modelo de Penman-Monteith é a de que este não exige dados de temperatura ao nível da cultura. Para isso, assume-se que a temperatura do ar, a uma dada altura acima do gramado em uma estação meteorológica, é representativa das condições à mesma altura acima da cultura e que uma resistência adicional nesse modelo, denominada resistência aerodinâmica, é suficiente para contabilizar a camada de ar entre a altura considerada e o topo da cultura (Rao et al., 1998). Resultados apresentados por Luo e Goudriaan (1999, 2000), na região tropical 
das Filipinas, por Jacobs et al. (2002), na região árida do Mediterrâneo, e por Rao et al. (1998), no sul de Ontário, Canadá, demonstraram que o modelo de Penman-Monteith teve uma boa performance sob uma grande diversidade de condições climáticas. 


\section{SENSORES ELETRÔNICOS DE MEDIDA DA DURAÇÃO DO PERÍODO DE MOLHAMENTO FOLIAR: PORQUE ELES DEVEM SER PINTADOS}

\section{Resumo}

A proposta deste estudo foi comparar e avaliar a performance de sensores eletrônicos de medida da duração do período de molhamento foliar (DPM) utilizados na medida dessa variável na cultura do algodão, usando-se sensores com e sem pintura. A DPM foi medida com sensores eletrônicos e os dados foram divididos em dois períodos de 24 dias: de 18 de dezembro de 2001 a 10 de janeiro de 2002, quando os sensores estavam sem pintura, e de 20 de janeiro a 13 de fevereiro de 2002, quando os sensores encontravam-se pintados com duas camadas de tinta latex. A análise dos dados levou em consideração o Coeficiente de Variação (CV\%), entre as medidas diárias obtidas por seis sensores instalados no terço superior da cultura, e a relação entre a DPM medida (média dos seis sensores) e o número de horas com a depressão do ponto de orvalho (DPO) abaixo de $2^{\circ} \mathrm{C}$, usada como um indicador da presença de orvalho. Os resultados mostraram que a pintura dos sensores reduziu sensivelmente os valores do CV\%. Para o período em que os sensores não estavam pintados o CV\% foi da ordem de $67 \%$, contra 
9\% para o período em que os sensores se encontravam pintados. Para os dias sem chuva, essa redução foi ainda maior. Comparando-se as medidas dos sensores de DPM com as estimativas, feitas a partir da depressão do ponto de orvalho menor que $2{ }^{\circ} \mathrm{C}$, observou-se que a pintura dos sensores melhorou não só a precisão das medidas como também a sua sensibilidade, já que a tinta proporcionou uma melhor detecção e medida do molhamento promovido pelas pequenas gotículas.

\section{ELECTRONIC LEAF WETNESS DURATION SENSOR: WHY IT SHOULD BE PAINTED}

\section{Summary}

The purpose of this study was to compare and evaluate the performance of electronic leaf wetness duration (LWD) sensors to measure LWD in a cotton crop canopy using unpainted and painted sensors. LWD was measured with flat, printedcircuit wetness sensors, and the data were divided into two periods of 24 days: from December 18, 2001 to January 10, 2002, when the sensors were unpainted, and from January 20 to February 13, 2002, when the sensors were painted with white latex paint (two coats of paint). The data analysis included evaluating the Coefficient of Variation (CV\%) among the six sensors for each day, and the relationship between the measured LWD (mean for the six sensors) and the number of hours with dew point depression (DPD) under $2^{\circ} \mathrm{C}$, used as an indicator of dew presence. The results showed that the painting markedly reduced the CV\% values. For the unpainted sensors the CV\% was on 
average $67 \%$ against $9 \%$ for painted sensors. For the days without rainfall this reduction was greater. Comparing the sensor measurements to another estimator of LWD, in this case the number of hours with dew point depression under $2^{\circ} \mathrm{C}$, it was also observed that painting improved not only precision of the sensors but also their sensitivity, because it increases the ability of the sensor to detect and measure the wetness promoted by small water droplets.

\subsection{Introdução}

A duração do período de molhamento foliar (DPM), promovida pelo orvalho, chuva, neblina e irrigação, é um dos mais importantes fatores que influenciam a propagação e a severidade das doenças de plantas causadas por fungos e bactérias, já que a presença de água na forma líquida sobre a superfície das plantas permite a germinação e penetração dos agentes fitopatogênicos nos tecidos foliares. Essa variável é usada como dado de entrada em diversos sistemas de aviso fitossanitário (Huber and Gillespie 1992; Kim et al. 2002), os quais possibilitam o uso mais racional dos fungicidas, assim como apresentado por Gillespie et al. (1993).

A medida da DPM é normalmente problemática. De acordo com Magarey (1999) e Madeira et al. (2002), a DPM é uma variável de difícil medida e não pode ser considerada uma variável exclusivamente atmosférica, já que ela depende das propriedades estruturais e ópticas da superfície e também do microclima. Entretanto, o uso de sensores para sua medida é uma boa opção quando estes estão disponíveis, já que 
as estimativas da DPM por meio de modelos empíricos ou físicos requerem diversas variáveis meteorológicas, sendo algumas vezes muito complexos.

Os sensores usados para a medida da DPM podem ser classificados em três grupos (Gillespie and Kidd 1978; Getz 1991): instrumentos estáticos, quando dão apenas indicação se houve ou não molhamento durante o período noturno; mecânicos, os quais medem a mudança no comprimento, peso ou tamanho do elemento sensor causada pela deposição do molhamento; e eletrônicos, nos quais o molhamento promove mudanças na impedância, resistência ou capacitância.

Com a expansão das redes governamentais e não governamentais de estações meteorológicas automáticas em todo o mundo e mais especificamente no Brasil, o uso dos sensores eletrônicos - normalmente os de placa de circuito impresso - tem aumentado. Entretanto, o uso desses sensores requer especial atenção para alguns detalhes para que dados confiáveis sejam obtidos, tais como: formato, tamanho, altura e ângulo de instalação, orientação, calibração, número de sensores utilizados e pintura do sensor (Gillespie e Kidd 1978; Gillespie e Duan 1987; Armstrong et al. 1993; Wei et al. 1995; Lau et al. 2000; Miranda et al. 2000; Madeira et al. 2002).

O tamanho e o formato dos sensores normalmente dependem das características da planta em que eles serão instalados (Wei et al. 1995). Gillespie e Duan (1987) compararam dois tipos de sensores e verificaram que a DPM foi mais longa nos sensores cilíndricos do que nos sensores planos. Baseados nisso, esses autores recomendaram que o uso de sensores cilíndricos para o monitoramento da DPM seja feito com certa ressalva quando o objetivo for monitorar a DPM em culturas com folhas planas. 
De acordo com Lau et al. (2000), o ângulo de inclinação e a orientação do sensor plano tem menos influência na medida da DPM do que a aplicação de tinta na sua superfície. Esses autores observaram que os sensores sem pintura falharam em medir a presença de molhamento em 15,4\% e 30,8\% dos casos para os sensores instalados com ângulos de $30^{\circ}$ e $45^{\circ}$, respectivamente. Por outro lado, os sensores pintados responderam à presença de molhamento para todos os eventos e para todos os ângulos de instalação utilizados. Gillespie e Kidd (1978) usaram diferentes cores na pintura de sensores eletrônicos de DPM e verificaram que aqueles pintados com tinta branca e cinza claro foram os que mais se aproximaram da taxa real de secamento observada em folhas, especialmente em comparação aos sensores sem pintura. Usando as recomendações de Gillespie e Kidd (1978), Pedro Jr. (1980) observou que os sensores eletrônicos de DPM mediram a deposição de orvalho com erros menores que 15 minutos e mediram seu secamento a cerca de 30 minutos mais tarde do que as observações realizadas visualmente em folhas da macieira. Para folhas de milho e soja, as diferenças foram da ordem de 15 minutos tanto para a formação como para o secamento do orvalho. De acordo com esse autor, diferenças de 15 minutos entre as observações visuais e as medidas não são significativas por causa das dificuldades relacionadas à mensuração dessa variável, particularmente aos erros de amostragem espacial.

Por outro lado, Wei et al. (1995), trabalhando com sensores eletrônicos de DPM flexíveis para detectar condensação em plantas e frutos de tomate cultivados no interior de ambientes protegidos, encontraram resultados diferentes quanto à pintura dos sensores. Esses autores verificaram que a cobertura de tinta latex acríclica produziu resultados irreais e que o uso de latex de vinil-acetato, em várias concentrações, não 
detectou com precisão a formação e o secamento do molhamento, não permitindo a obtenção de resultados acurados em termos de repetitibilidade para o tipo de sensor testado. Portanto, eles sugeriram o uso de sensores sem pintura.

Baseando-se na discussão apresentada acima, a proposta deste estudo foi a de se comparar e avaliar a performance dos sensores planos de placa de circuito impresso para a medida da DPM na cultura do algodão, utilizando-se sensores com e sem pintura com tinta latex.

\subsection{Material e métodos}

O experimento de campo foi conduzido durante a safra das águas de 2001/02, de dezembro a março, na área experimental da Fazenda Areão, pertencente à Escola Superior de Agricultura "Luiz de Queiroz" da Universidade de São Paulo (ESALQ/USP), no município de Piracicaba, Estado de São Paulo, Brasil (Lat.: $22^{\circ} 42^{\prime}$ S,

Long.: $47^{\circ} 30^{\prime} \mathrm{W}$, Alt.: $546 \mathrm{~m}$ ), onde foram semeadas duas cultivares de algodoeiro (IAC23 e Coodetec).

Seis micro-estações automáticas, equipadas com sensores de temperatura e umidade do ar (psicrômetros aspirados) e de DPM (Figura 3.1), foram instaladas no topo da cultura. Além disso, medidas de chuva e da velocidade do vento a $2 \mathrm{~m}$ também foram feitas, respectivamente com um pluviômetro de báscula (Texas Eletronics, Modelo TE525M) e anemômetro (Met One, Modelo 014A). As micro-estações foram programadas para medir as variáveis a cada 10 segundos e armazenar suas médias a 
intervalos de 15 minutos, usando para tanto um sistema automático de aquisição de dados (Campbell Scientific, Modelo CR23X).

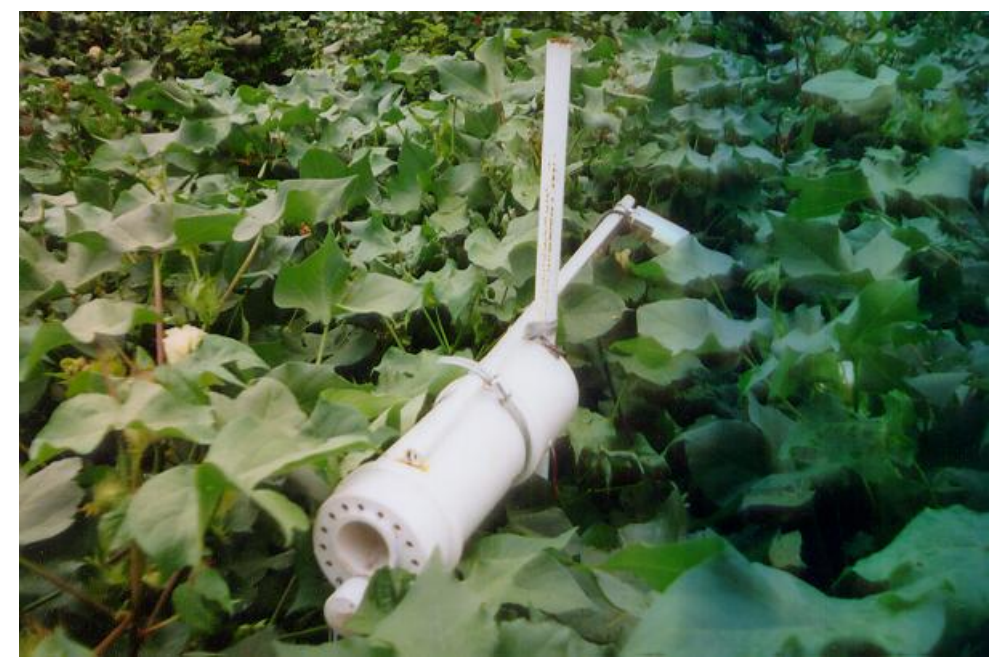

Figura 3.1 - Detalhe da micro-estação automática, com psicrômetro aspirado para a medida da temperatura e da umidade relativa do ar e do sensor de duração do período de molhamento foliar, instalada no topo da cultura do algodão.

A DPM foi medida com sensores planos de placa de circuito impresso (Campbell Scientific, Modelo 237). Cada sensor de DPM foi montado numa estrutura metálica (0.015 m de diâmetro), com um ângulo de 20 em relação à horizontal (Gillespie e Kidd, 1978) e com sua face voltada para o norte. Esse sensor, que simula uma seção de uma folha artificial, consiste de uma placa de circuito impresso, de $1 \mathrm{~mm}$ de espessura, com dois pentes intercalados (Figura 3.2), o qual é descrito com mais detalhes por Gillespie e Kidd (1978) e Campbell Sci. (1996). A condensação sobre a placa do sensor faz com 
que a impedância entre os dentes dos pentes diminua e a medida é registrada pelo sistema de aquisição de dados.

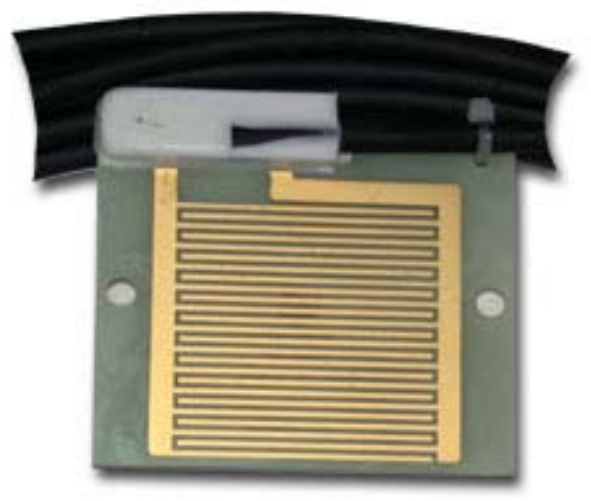

Figura 3.2 - Sensor eletrônico de medida da duração do período de molhamento foliar (DPM), sem pintura, utilizado nas micro-estações automáticas, mostrando o detalhe dos dois pentes intercalados. Fonte: www.campbellsci.com.

Os dados obtidos das micro-estações foram divididos em dois períodos de 24 dias: a) de 18 de dezembro de 2001 a 10 de janeiro de 2002, quando os sensores de DPM se encontravam sem pintura na sua face superior e b) de 20 de janeiro a 13 de fevereiro de 2002, após os sensores de DPM terem sido pintados com duas camadas de tinta latex branca e tratados termicamente, como recomendado por Gillespie e Duan (1987), para a remoção de componentes higroscópicos da tinta. Os sensores foram calibrados antes de cada período para a determinação do ponto de transição entre úmido e seco.

A análise dos dados incluiu a avaliação do Coeficiente de Variação (CV\%) entre os seis sensores, considerando-se as medidas diárias: 


$$
C V \%=\left(\frac{S D}{\bar{X}}\right) * 100
$$

em que SD é o desvio padrão da DPM e $\bar{X}$ a DPM média. Além disso, avaliou-se a relação, por meio da regressão linear simples, entre a DPM média diária dos seis sensores e a DPM estimada a partir do número de horas com a depressão do ponto de orvalho (DPO) menor do que $2^{\circ} \mathrm{C}\left(\mathrm{NHDPO}<2^{\circ} \mathrm{C}\right)$, sendo DPO dada pela diferença entre a temperatura do ar e a temperatura do ponto de orvalho.

\subsection{Resultados e Discussão}

Os coeficientes de varaição (CV\%) para as medidas diárias de DPM entre os seis sensores são apresentados na Figura 3.3, onde é possível se verificar a grande diferença entre os sensores com e sem pintura. Para o período quando os sensores estavam sem pintura (Figura 3.3a), os valores diários de CV\% variaram de 2,3 a 139,3\%, com uma média para o período de 67,4\%. Nesse caso, valores de CV\% menores que 20\% somente ocorreram em dias com chuva, indicados pelas setas, quando a DPM foi maior do que 15 h. Assim como observado por Lau et al. (2000), os sensores sem pintura neste estudo também falharam como um todo durante alguns eventos de baixa DPO, o que contribuiu para o aumento dos valores de CV\%.

Para o período quando os sensores estavam pintados (Figura 3.3b), os valores de CV\% foram consideravelmente menores, especialmente durante os dias com o molhamento promovido por orvalho, variando de 0 a 31,2\%, com uma média de 9,3\%. Neste caso, a pintura aumentou a sensibilidade dos sensores para detectar as pequenas 
gotículas de água que se formam nos primeiros instantes de deposição do orvalho (Gillespie e Kidd, 1978), reduzindo a subestimativa da DPM.

Para os sensores pintados, o número de camadas de tinta latex é uma outra fonte de variação para as medidas de DPM. Lau et al. (2000), estudando sensores de DPM pintados com 3 e 9 camadas de tinta, observaram diferenças entre esses dois tipos de tratamento, tanto na deposição como no secamento do molhamento, quando compararam as medidas com observações visuais. De acordo com esses autores, os sensores com 3 camadas de tinta foram os que apresentaram os melhores resultados. Gillespie e Kidd (1978) e Pedro Jr. (1980) usaram duas camadas de tinta, o mesmo número utilizado neste estudo, obtendo resultados muito bons em comparação às observações visuais.

Uma outra forma de se avaliar a importância da pintura dos sensores eletrônicos de DPM é pela comparação de suas medidas a outro indicador da DPM. A Figura 3.4 apresenta a relação entre os dados diários do $\mathrm{NHDPO}<2^{\circ} \mathrm{C}$ e as medidas de $\mathrm{DPM}$ obtidas pelos sensores, assim como a regressão linear forçando-se a origem em zero para essa relação. Para os sensores sem pintura (Figura 3.4a), essa relação resultou em um coeficiente angular de 0,85, representando uma subestimativa de cerca de $15 \%$, e em uma baixa precisão $\left(\mathrm{R}^{2}=0,45\right)$, a qual foi conseqüência da alta variabilidade entre a DPM medida pelos sensores. Por outro lado, quando os sensores encontravam-se pintados (Figura 3.4b), a subestimativa foi de apenas $5 \%(b=0,95)$ e o coeficiente de determinação $\left(\mathrm{R}^{2}\right)$, que representa a precisão das medidas, aumentou para 0,89 . Nesse caso, a tinta aplicada na superfície dos sensores fez as medidas serem mais precisas em razão da sua habilidade de distribuir a água proveniente do orvalho por toda a superfície do sensor, permitindo, com isso, que pequenas gotículas, com diâmetro inferior a $1 \mathrm{~mm}$, 
depositadas sobre o sensor fossem detectadas (Gillespie e Kidd, 1978). Uma pequena subestimativa da DPM pelos sensores ainda foi observada quando se comparou as medidas e as estimativas obtidas pelo critério $\mathrm{NHDPO}<2^{\circ} \mathrm{C}$ (Figura 3.4b), o que, no entanto, era esperado porque o orvalho pode não se formar em algumas ocasiões quando a DPO esteja por volta de $2^{\circ} \mathrm{C}$, especialmente durante noites com ventos intensos, como pode ser visto na Figura 3.5, quando a formação de orvalho somente ocorre com DPO próximo de zero. Entretanto, o uso do $\mathrm{NHDPO}<2{ }^{\circ} \mathrm{C}$ como um estimador da DPM é embasado em resultados prévios apresentados por Gillespie et al. (1993) e Rao et al. (1998), que observaram que as estimativas da DPM feitas por este método, baseado na temperatura e na umidade relativa do ar, foram tão boas quanto aquelas obtidas por modelos físicos mais complexos.

Os resultados aqui apresentados, que mostram uma melhoria na performance dos sensores pintados, concordam com os resultados obtidos por Gillespie e Kidd (1978), Pedro Jr. (1980) e Lau et al. (2000). Por outro lado, eles discordam daqueles obtidos por Wei et al. (1995) em condição de ambiente protegido (estufa). A melhor performance do sensor sem pintura, obtida por Wei et al. (1995), pode estar relacionada ao espaçamento entre os eletrôdos, que foi de apenas $0,25 \mathrm{~mm}$ contra $1 \mathrm{~mm}$ nos sensores comerciais usados neste estudo e pelos demais autores citados acima. Um menor espaçamento entre os eletrôdos pode eliminar a necessidade da pintura dos sensores, a não ser quando a cor do sensor necessite ser ajustada para simular melhor a DPM em partes das plantas onde o secamento é fortemente influenciado pela radiação solar. 

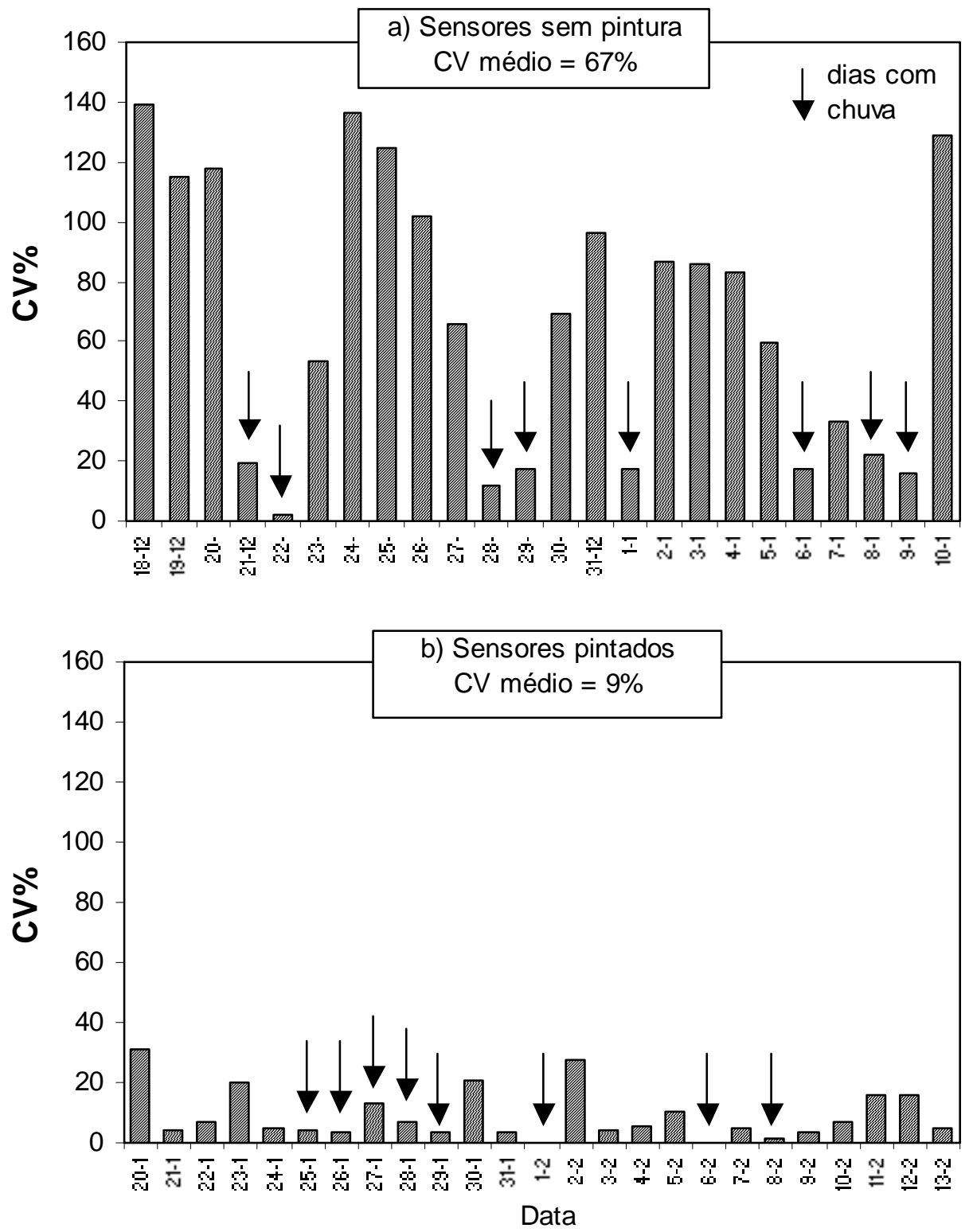

Figura 3.3 - Coeficiente de variação (CV\%) para as medidas de DPM usando sensores eletrônicos sem (a) e com pintura (b) com tinta latex. As setas indicam os dias em que o molhamento foi promovido por orvalho e/ou chuva. 

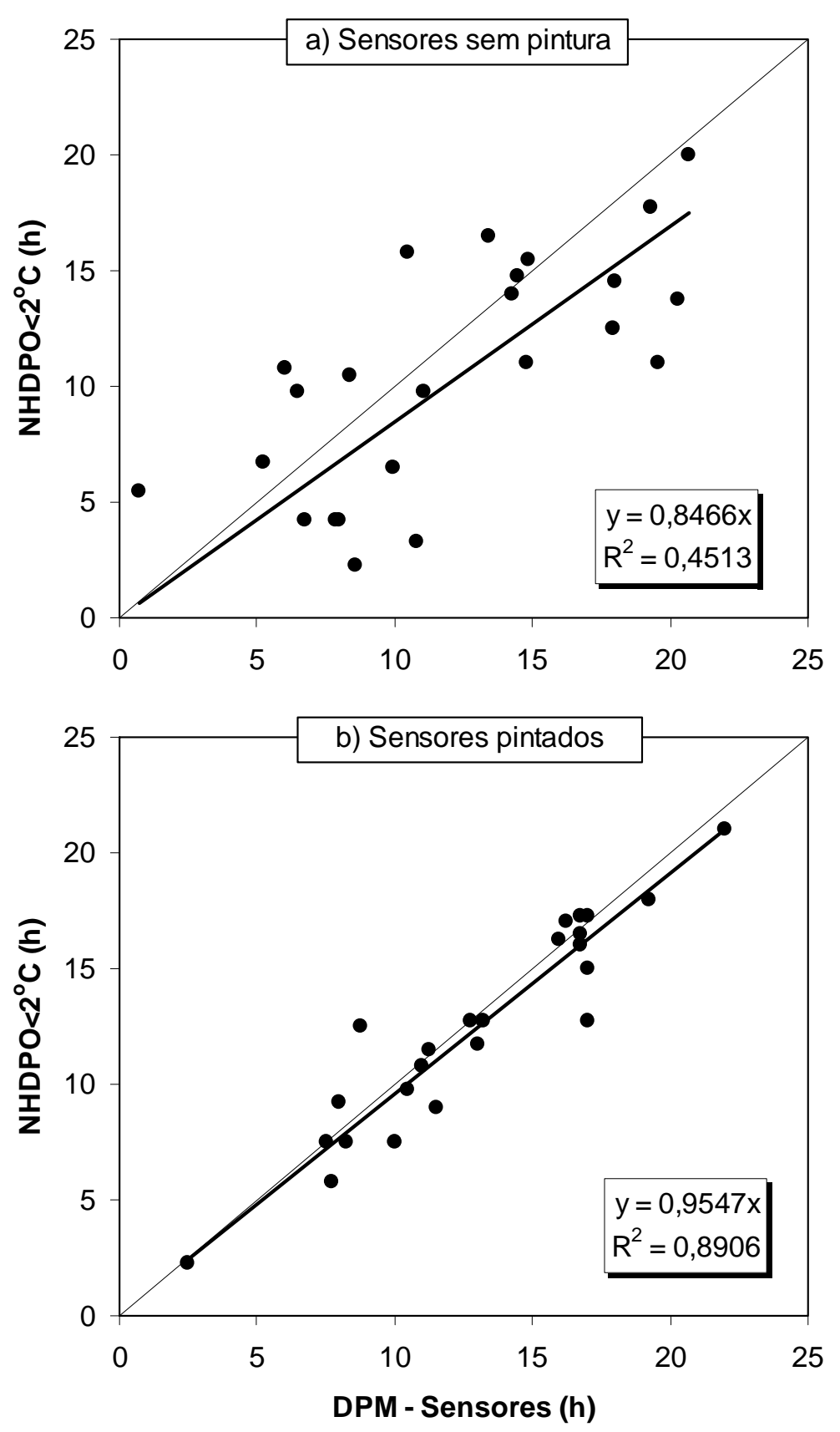

Figura 3.4 - Relação entre a DPM medida pelos sensores eletrônicos (média dos seis sensores) e a DPM estimada pelo $\mathrm{NHDPO}<2^{\circ} \mathrm{C}$, para os períodos em que os sensores estavam sem pintura (a) e pintados (b). 


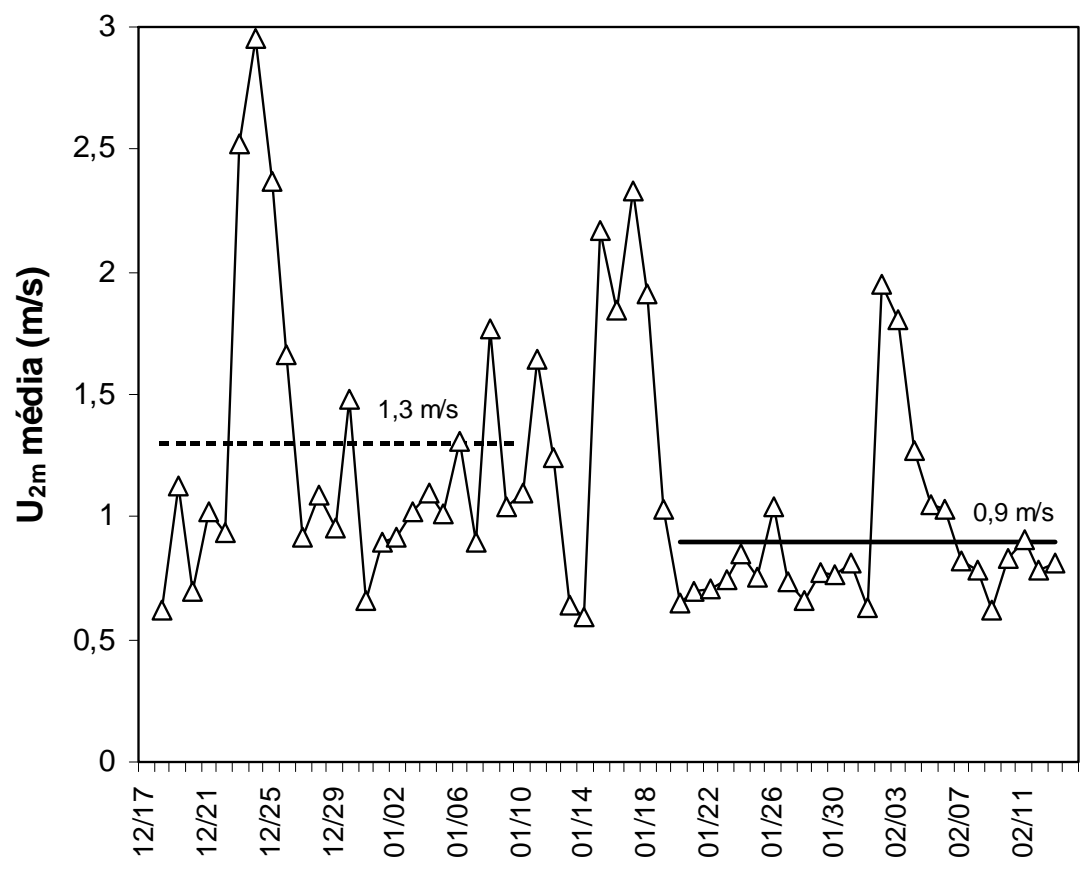

Figura 3.5 - Velocidade média diária do vento $\left(\mathrm{U}_{2 \mathrm{~m}}\right)$ sobre a cultura do algodão. As linhas representam a média para os dois períodos estudados: a linha tracejada representa o período em que os sensores estavam sem pintura e a linha contínua representa o período em que os sensores estavam pintados.

A formação precoce do orvalho e o secamento tardio obtidos pelo sensores usados por Wei et al. (1995), podem ter ocorrido porque esses autores indicaram em seu trabalho que após a pintura dos sensores o secamento se deu em condições naturais (seco ao ar). Previamente, Gillespie e Duan (1987) relataram que o secamento da tinta aplicada aos sensores de DPM deve ser feito a altas temperaturas de modo a se remover ou desativar componentes higroscópicos da tinta latex, visando a se evitar a detecção antecipada e o secamento tardio do molhamento. 


\subsection{Conclusões}

Os resultados apresentados neste estudo com a cultura do algodão mostraram que os sensores eletrônicos para medida da DPM, com espaçamento típico de $1 \mathrm{~mm}$ entre os eletrôdos, devem ser pintados. Esse procedimento é útil para reduzir as subestimativas e aumentar a precisão das medidas. A pintura aumenta a habilidade do sensor em detectar e medir o molhamento promovido por pequenas gotículas (com diâmetros menores do que $1 \mathrm{~mm}$ ), reduzindo assim a variabilidade entre os sensores. Verificou-se neste estudo que duas camadas de tinta foram suficientes para reduzir o CV\% das medidas de DPM de $67 \%$ para $9 \%$, quando seis sensores foram utilizados. Assim, recomenda-se que os sensores comerciais de DPM utilizem o procedimento de pintura aqui apresentado, principalmente quando o objetivo for o seu uso em sistemas de alerta fitossanitário. 


\section{ESTIMATIVA DA DURAÇÃO DO PERÍODO DE MOLHAMENTO FOLIAR NA CULTURA DO ALGODOEIRO A PARTIR DE DADOS METEOROLÓGICOS}

\section{Resumo}

Este trabalho teve por objetivo comparar o desempenho de quatro diferentes métodos de estimativa da duração do período de molhamento (DPM) em folhas do algodoeiro, usando dados provenientes de uma estação automática, em intervalos de 15 minutos, instalada na área da cultura, e também mostrar as diferenças entre a DPM medida a 1,7 m, na estação meteorológica, e próximo das plantas. Para tanto, uma estação automática foi instalada na área da cultura, onde as seguintes variáveis foram medidas a 1,7 m: temperatura e umidade relativa do ar, saldo de radiação, velocidade do vento, chuva e DPM. Seis micro-estações foram instaladas na parte superior da cultura, tendo sensores para a medida da temperatura e umidade relativa do ar e DPM. Esses dados foram usados para se estimar a DPM de acordo com os seguintes métodos: Número de Horas com Umidade Relativa acima de 90\% (NHRH>90\%); Depressão do Ponto de Orvalho (DPO); modelo da Árvore de Classificação e Regressão (CART); e 
modelo da Resistência Aerodinâmica (RES), este último baseado no modelo de PenmanMonteith. Os resultados mostraram que, em geral, todos os métodos de estimativa da DPM tiveram boa performance. Para os modelos DPO, CART e RES foram observadas, respectivamente, superestimativas da ordem de $2 \%, 6 \%$ e $7 \%$, enquanto que para o método do NHUR>90\% foi observada sub-estimativa da ordem de 6\%. Essa análise resultou numa alta acurácia das estimativas feitas por esses métodos, mas, apesar disso, a precisão não foi tão elevada, permanecendo entre 0,75 e 0,90 , resultando em erros absolutos médios entre 1,27 e 2 h. Quando foram usados somente dias sem chuva para a estimativa da DPM foi observada uma pequena melhoria na acurácia, enquanto que para os dias chuvosos a precisão diminuiu muito. Comparando-se os dados de DPM obtidos na estação meteorológica com aqueles obtidos junto à parte superior da cultura verificou-se uma grande diferença, especialmente para os dias com DPM $<17$ h. Isso mostra que a medida ou estimativa de DPM deve ser feita especificamente para o local e a cultura de interesse ou ajustada por coeficientes empíricos. Para os dias com DPM $\geq$ 17h, normalmente causada por chuva, as diferenças entre a DPM na estação e na cultura foram pequenas, o mesmo sendo observado entre os sensores utilizados. O modelo RES estimou a DPM ao nível da cultura com alta acurácia e regular precisão, sendo uma boa opção para a estimativa dessa variável sem o requerimento de calibração para cada cultura e local. 


\section{ESTIMATING LEAF WETNESS DURATION ON A COTTON CROP FROM METEOROLOGICAL DATA}

\section{Summary}

The purpose of this study was to use and compare four different models to estimate leaf wetness duration (LWD) on cotton leaves, using 15 min data from an automatic weather station installed inside the crop area, and also to show the differences between the LWD measured at $1.7 \mathrm{~m}$ in the weather station, and close to the plants. For this purpose, an automatic weather station was installed inside the crop area, where the following meteorological variables were measured at $1.7 \mathrm{~m}$ : air temperature and relative humidity, net radiation, wind speed, rainfall, and LWD. Six automatic micro-stations were installed at the top of the crop having sensors of air temperature, relative humidity, and LWD. These meteorological data were used to estimate LWD according to the following methods: Number of Hours with Relative Humidity above 90\% (NHRH>90\%); Dew Point Depression (DPD); Classification and Regression Tree model (CART); and Aerodynamic Resistance model (RES). The results showed that in general, all methods of LWD estimation performed quite well. For the DPD, CART and RES models an overestimation of around $2 \%, 6 \%$, and $7 \%$ respectively was observed, whereas the $\mathrm{NHRH}>90 \%$ method showed an underestimation of $6 \%$. This analysis resulted in high accuracy of these methods, however the precision of the estimations was not as high, remaining between 0.75 and 0.90 , and resulting in mean absolute errors between 1.27 and $2 \mathrm{~h}$. When only dry days were used to estimate LWD a little improvement on 
accuracy was observed, while for rainy days the precision decreased considerably. Comparing the LWD data obtained in the weather station with those close to the crop canopy, it was verified that a large difference existed between them, mainly for periods with less than $17 \mathrm{~h}$ of wetness. This shows that LWD should be measured or estimated site-specifically, or adjusted by empirical coefficients. For LWD $\geq 17 \mathrm{~h}$, normally promoted by rain, the differences are smaller both between the LWD measured/estimated in the crop and in the weather station, and among the sensors. Therefore the RES model estimated LWD at crop level with high accuracy and regular precision, and is a good option to estimate this variable without the requirement of calibration for each crop and place.

\subsection{Introdução}

A duração do período de molhamento foliar (DPM), promovida pela deposição de água sobre as folhas pelo orvalho, chuva, neblina ou irrigação, é o fator mais importante a influenciar a ocorrência de doenças nas plantas, tanto em termos de distribuição como também de severidade (Huber e Gillespie, 1992; Kim et al., 2002). A água na forma líquida sobre o tecido foliar tem importante papel durante vários dos processos epidemiológicos, afetando principalmente a infecção e a esporulação (Huber e Gillespie, 1992). Na cultura do algodão, a DPM e a temperatura do ar são responsáveis pela ocorrência de várias doenças importantes nas lavouras conduzidas nas regiões Sudeste e Centro-Oeste do Brasil (Monteiro, 2002). 
A medida da DPM é normalmente difícil de ser realizada (Gillespie e Kidd, 1978; Madeira et al., 2002), mesmo com os sensores automáticos que foram desenvolvidos ao longo dos últimos 35 anos. De acordo com Kim et al. (2002), o uso de sensores automáticos de medida da DPM e de sistemas automáticos de aquisição de dados não é atrativo para muitos produtores devido às dificuldades para a instalação, manutenção e manipulação desses instrumentos, como também é descrito por Monteiro et al. (2002). Além desse fato, a maioria das redes de estações meteorológicas oficiais não tem sensores de DPM disponíveis, o que exige que essa variável seja estimada, especialmente quando o propósito é o uso de sistemas de alerta fitossanitários para a racionalização do uso de defensivos.

O desenvolvimento de métodos de estimativa da DPM vem sendo objeto de estudo de vários trabalhos. Muitos desses são apresentados e discutidos por Huber e Gillespie (1992). Esses métodos variam desde simples relações empíricas, baseadas em uma ou mais variáveis meteorológicas como a umidade relativa do ar, velocidade do vento e temperatura (Sentelhas et al., 1993; Gleason et al., 1994), até modelos mais complexos, baseados nos aspectos físicos da deposição de orvalho e de sua evaporação, como apresentado por Pedro Jr. e Gillespie (1982a, 1982b), Rao et al. (1998), Magarey (1999) e Madeira et al. (2002), os quais usam os princípios do balanço de energia e da resistência aerodinâmica.

Entre os métodos empíricos de estimativa da DPM, o número de horas com umidade realtiva do ar acima de 90\% (NHUR>90\%) é o mais comum. Entretanto, os resultados apresentados na literatura têm sido contraditórios. Gleason et al. (1994), comparando a DPM medida por sensores e estimada pelo NHUR $>90 \%$, encontraram que 
o erro associado com esse método empírico foi $40 \%$ maior do que o erro obtido com o uso do modelo da Árvore de Classificação e Regressão (CART), o qual também usa as variáveis depressão do ponto de orvalho (DPO) e velocidade do vento (U). Resultados similares foram encontrados por Francl e Panigrahi (1997) para a DPM estimada para a cultura do trigo. Por outro lado, RAO et al. (1998) observaram que as estimativas de DPM a partir de métodos mais simples, baseados na umidade relativa (UR), tiveram acurácia tão boa quanto as estimativas feitas com modelos físicos complexos, quando esses métodos foram testados para se determinar a DPM em espigas de milho em Ridgetown, Ontario, Canadá. Entretanto, esses autores enfatizam que os modelos baseados nos princípios físicos do processo de molhamento foliar tem aplicação universal, ao passo que os métodos empíricos necessitam ser testados e validados para cada nova condição (cultura e local).

Gillespie e Barr (1984) utilizaram o modelo de base física desenvolvido para a estimativa da DPM, causada por orvalho, nas culturas da maçã, do milho e da soja por Pedro Jr. e Gillespie (1982a, 1982b), para a cultura da cebola e verificaram que esse procedimento pode ser aplicado para uma nova cultura e local, resultando em estimativas de DPM de grande utilidade para o controle de doenças. O mesmo foi concluido por Rao et al. (1998), quando estes usaram o procedimento citado acima para a estimativa da DPM em espigas de milho.

Como a escolha apropriada de um método de estimativa da DPM para fins operacionais depende basicamente da disponibilidade de dados meteorológicos (Rao et al., 1998), os objetivos do presente trabalho foram comparar o desempenho de quatro métodos, que diferem em suas complexidades, na estimativa da DPM na cultura do 
algodão, usando-se dados de uma estação meteorológica automática instalada na área da cultura, e de mostrar as diferenças na DPM entre as medidas feitas a 1,7 m na estação meteorológica e junto ao topo da cultura.

\subsection{Material e métodos}

O experimento de campo foi conduzido durante a safra das águas de 2001/02, de dezembro a março, em área cultivada com duas cultivares de algodoeiro (IAC23 e Coodetec), na Fazenda Experimental Areão, pertencente à Escola Superior de Agricultura "Luiz de Queiroz” da Universidade de São Paulo, no município de

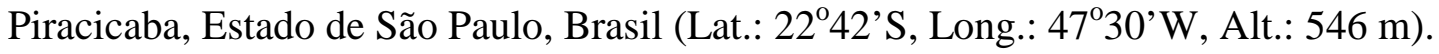

Uma estação meteorológica automática foi instalada na área da cultura do algodão, onde as seguintes variáveis meteorológicas foram medidas a 1,7 m: temperatura (T) e umidade relativa do ar (UR), velocidade do vento (U), precipitação pluvial (P), saldo de radiação (Rn) e DPM. A DPM foi medida com sensor automático da Campbell Sci., modelo 237, pintado com duas mãos de tinta latex branca e tratado termicamente para a remoção de componentes higroscópicos, instalado com um ângulo de $20^{\circ}$ em relação à horizontal. Outras seis micro-estações foram instaladas no terço superior da cultura, sendo três em cada cultivar, com sensores de T, UR e DPM. Esses tiveram suas alturas ajustadas periodicamente para acompanhar o crescimento das plantas. A Figura 4.1 apresenta uma vista geral da área experimental e também detalhe de uma microestação. 

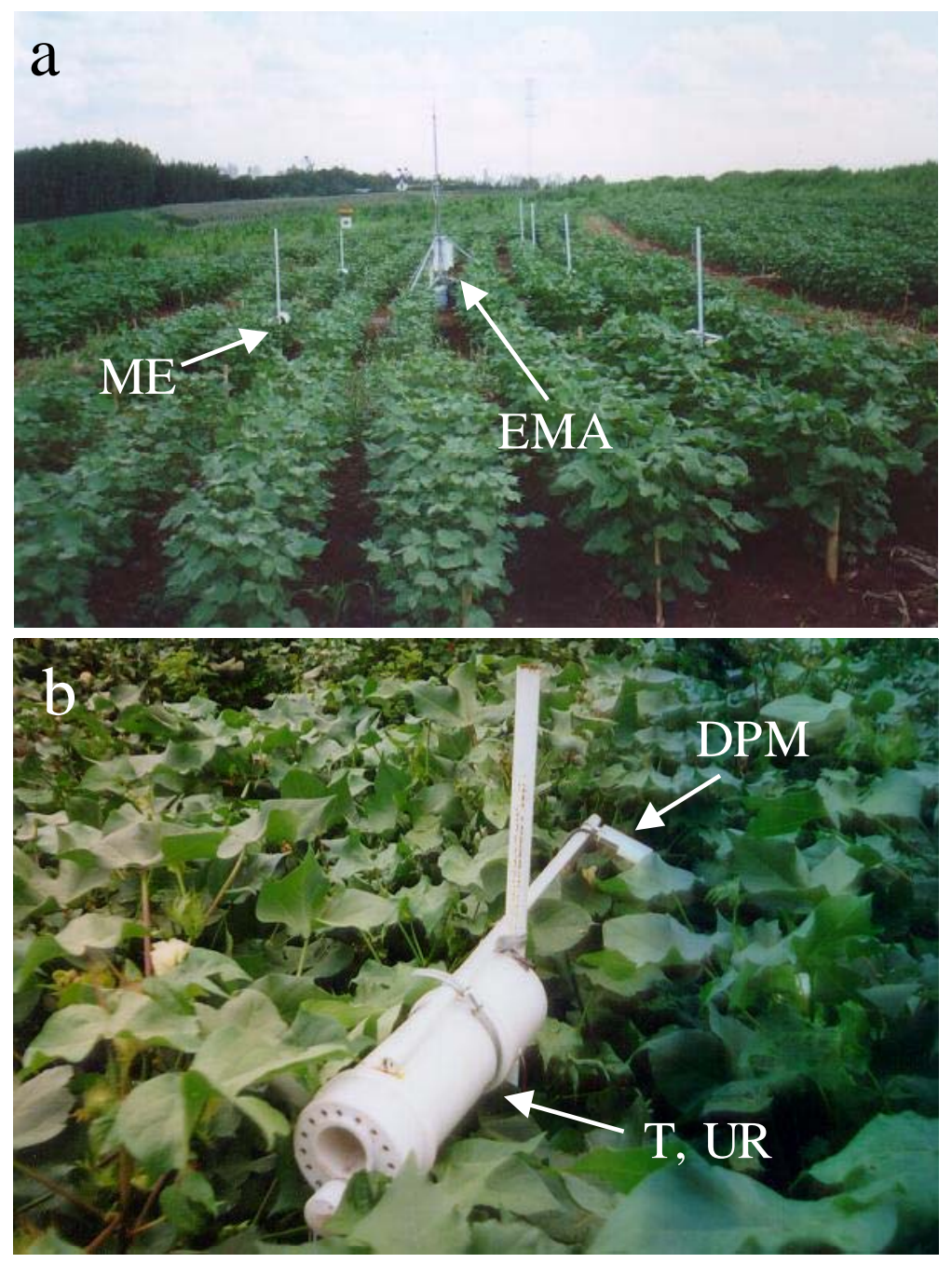

Figura 4.1 - Vista geral da área experimetal, da estação meteorológica e das microestações instaladas na cultura do algodão (a) e detalhe de uma das micro-estações (b).

A estação meteorológica e as micro-estações foram programadas para medir as variáveis a cada 10 segundos e armazenar as médias a cada 15 minutos, usando-se para tanto dois sistemas automáticos de aquisição de dados da Campbell Sci, modelos CR10 e CR23X. 
Os dados meteorológicos obtidos foram usados para estimar a DPM de acordo com os seguintes métodos:

a) Número de Horas com Umidade Relativa do ar acima de 90\% (NHUR $>90 \%)$ : a UR = 90\% no abrigo meteorológico foi considerada como o limite para o início da deposição do orvalho. O número de intervalos de 15 minutos com UR acima de 90\% dividido por 4 foi considerado como a DPM, expressa em horas.

b) Depressão do Ponto de Orvalho (DPO): a diferença entre a temperatura do ar (T) e a temperatura do ponto de orvalho (To) foi sugerida como um método de estimativa da DPM por Gillespie et al. (1993). A DPM, neste caso, é estimada como sendo o intervalo de tempo em que DPO permanece entre dois limites específicos. O critério mais satisfatório para este estudo com relação aos limites para que o molhamento foliar ocorra foram $2,0^{\circ} \mathrm{C}$ para a deposição do orvalho e $3,8^{\circ} \mathrm{C}$ para o seu secamento.

c) Modelo da Árvore de Classificação e Regressão (CART): o procedimento nãoparamétrico de classificação para estimativa da DPM, sugerido por Gleason et al. (1994), foi adaptado para dados coletados a cada 15 minutos e aplicado para o intervalo das $12: 15 \mathrm{~h}$ do dia 1 às 12:00 h do dia 2. Esse modelo foi desenvolvido para estimar a DPM a partir da DPO, da velocidade do vento a 10m (U) e da UR, utilizando-se uma árvore de classificação binária, que apresenta nós (categorias) e ramos para distinguir se um intervalo de 15 minutos apresenta ou não molhamento, como apresentado na Figura 4.2, empregando-se as Equações 1 e 2: 
$\left(1,6064 \mathrm{~T}^{0,5}+0,0036 \mathrm{~T}^{2}+0,1531 \mathrm{UR}-0,4599 \mathrm{U} * \mathrm{DPO}-0,0035 \mathrm{~T} * \mathrm{UR}\right)>14,46$

$\left(0,7921 \mathrm{~T}^{0,5}+0,0046 \mathrm{UR}-2,3889 \mathrm{U}-0,039 \mathrm{~T} * \mathrm{U}+1,0613 \mathrm{U} * \mathrm{DPO}\right)>37,00$

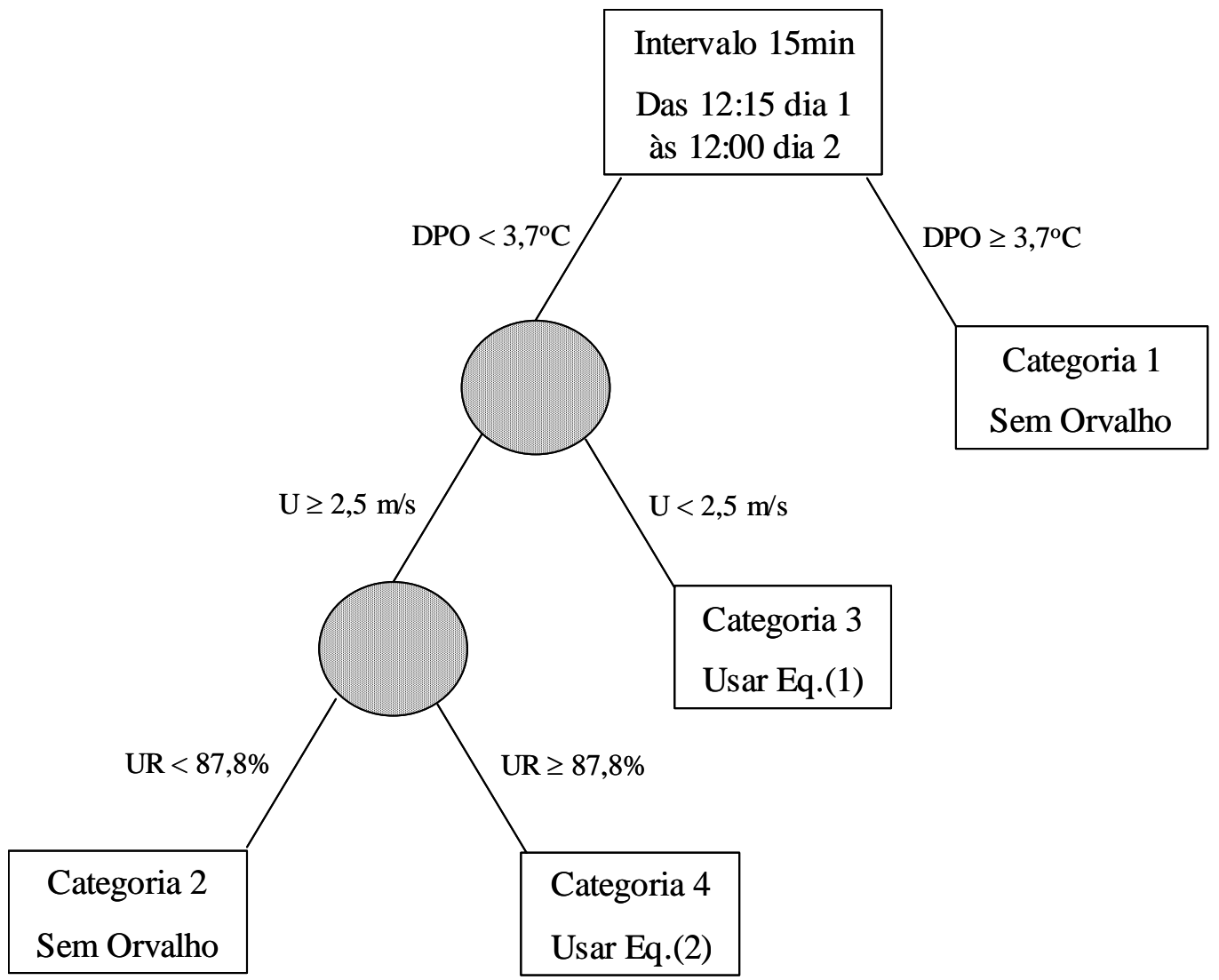

Figure 4.2 - Árvore de classificação para a estimativa da DPM. Adaptado de Gleason et al. (1994).

d) Modelo da resistência aerodinâmica (RES): como apresentado por Rao et al. (1998), esse modelo elimina a necessidade da medida da temperatura do ar na altura da cultura por assumir que a temperatura do ar medida sobre o gramado, em uma estação meteorológica padrão, normalmente entre 1,5 e 2,0 m de altura, representa a temperatura 
do ar à mesma altura sobre a cultura. Para isso, uma nova resistência é adicionada ao modelo (Figura 4.3), a qual assume-se como a resistência aerodinâmica (ra), descrita por Monteith e Unsworth (1990) como sendo:

$r a=\frac{\ln \left[\frac{\left(z_{T}-0,65 z_{c}\right)}{\left(0,13 z_{c}\right)}\right]}{\left(0,4 u^{*}\right)}$

em que: $\mathrm{z}_{\mathrm{C}}$ é a altura da cultura $(\sim 1,0 \mathrm{~m}), \mathrm{z}_{\mathrm{T}}$ a altura da medida da temperatura $(\sim 1,7 \mathrm{~m})$ e u* a velocidade de fricção, dada pelo perfil logarítmico do vento (Pedro Jr. e Gillespie, 1982b):

$u *=\frac{\left(0,4 U z_{T}\right)}{\left\{\ln \left[\frac{\left(z_{T}-0,65 z_{c}\right)}{\left(0,13 z_{c}\right)}\right]\right\}}$

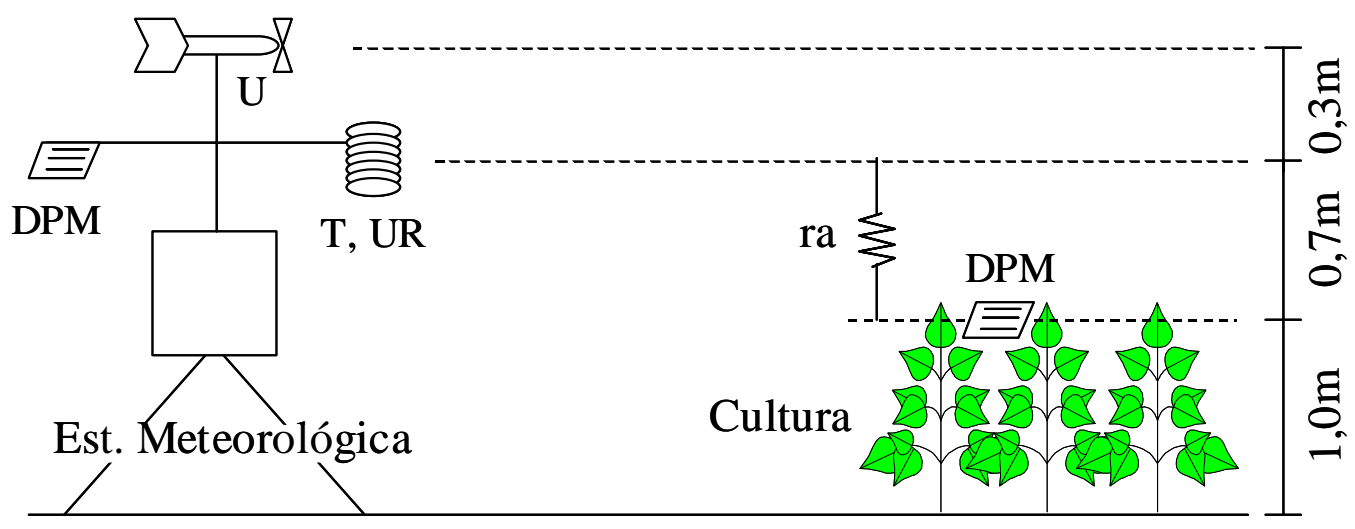

Figura 4.3 - Representação esquemática da altura dos sensores e da resistência aerodinâmica (ra) adicional requerida pelo modelo RES. 
Usando as relações apresentadas acima, o fluxo de calor latente (LE) para uma folha artificial pode ser estimado para cada intervalo de tempo (no caso 15 minutos) empregando-se a equação de Penman-Monteith (Monteith e Unsworth, 1990):

$L E=-\frac{\left\{s R n+\left[\frac{1200\left(e s_{T a}-e a\right)}{(r a+r b)}\right]\right\}}{\left(s+\gamma^{*}\right)}$

em que: s é a tangente à curva de pressão de saturação de vapor, es Ta $_{\text {a }}$ a pressão de saturação de vapor à temperatura do ar medida na estação meteorológica, e a pressão atual de vapor, $\gamma^{*}$ a constante psicrométrica modificada $\left(=\gamma r_{V} / r_{H}\right)$, assumida como sendo 0,64 para período com orvalho $\left(\mathrm{r}_{\mathrm{V}}=\mathrm{r}_{\mathrm{H}}\right.$, os dois lados da folha com molhamento), e 1,28 para períodos com chuva ( $\mathrm{r}_{\mathrm{V}}=2 \mathrm{r}_{\mathrm{H}}$, apenas um lado da folha com molhamento), e rb a resistência da camada limite para o transporte de calor, dado por Campbell e Norman (1998) como sendo:

$r b=\frac{\left[307 *\left(\frac{d}{U z c}\right)^{1 / 2}\right]}{2}$

em que: d é a dimensão efetiva da folha artificial, ou seja, do sensor de DPM (= 0,07 m) e Uzc a velocidade do vento no topo da cultura $\left(\mathrm{ms}^{-1}\right)$. A máxima capacidade de retenção de água pela folha artificial (sensor) foi considerada igual a 0,8 mm para 
eventos com orvalho. O modelo admite que quando há ocorrência de chuva, esta inicia ou aumenta o molhamento e, portanto, é adicionada ao valor acumulado de LE (valores positivos) até um máximo de 0,6 mm. Para a estimativa da DPM na condição da estação meteorológica, onde o sensor de DPM está na mesma altura dos sensores de T e UR (Figura 4.3), a resistência aerodinâmica adicional (ra) não é necessária e a Equação (5) pode então ser escrita da seguinte forma:

$L E=-\frac{\left\{s R n+\left[\frac{1200\left(e s_{T a}-e a\right)}{(r b)}\right]\right\}}{\left(s+\gamma^{*}\right)}$

Seguindo-se o mesmo procedimento adotado por Pedro Jr. e Gillespie (1982a), a DPM por esse modelo foi considerada como sendo o intervalo de tempo entre a deposição de molhamento, quando LE > 0 (orvalho) ou quando inicia-se uma chuva, e o seu secamento, considerado quando a condensação e/ou chuva acumuladas pelo modelo são consumidas pela quantidade equivalente de evaporação. O intervalo de tempo considerado para se obter a DPM diária foi entre as 12:15 h do dia n e as 12:00 h do dia $\mathrm{n}+1$.

Os dados de DPM estimados pelos diferentes modelos e os medidos pelos sensores eletrônicos foram comparados pela análise de regressão (coeficiente de determinação - $\mathrm{R}^{2}$ e índice de concordância de Willmott - D) e pela avaliação dos erros (erro médio - EM, erro absoluto médio - EAM e erro máximo -EMAX), como sugerido 
por Willmott et al. (1995), utilizando-se todo o conjunto de dados e também separandose os dados em dias com e sem chuva:

$$
\begin{aligned}
& D=1,0-\left\{\frac{\sum\left(O_{i}-P_{i}\right)^{2}}{\sum\left(\left|P_{i}-O m\right|+\left|O_{i}-O m\right|\right)^{2}}\right\} \\
& E M=\frac{\sum\left(P_{i}-O_{i}\right)}{N} \\
& E A M=\frac{\sum\left(\left|P_{i}-O_{i}\right|\right)}{N} \\
& E M A X=M A X\left(P_{i}-O_{i}\right)
\end{aligned}
$$

em que: Pi é a DPM estimada, Oi a DPM medida e Om a DPM média medida, sendo todas as variáveis dadas em horas.

\subsection{Resultados e Discussão}

Considerando-se todo o conjunto de dados, as relações entre a DPM medida na estação meteorológica (1,7 m) e aquelas estimadas pelos 4 modelos são apresentadas na Figura 4.4. Em geral, todos os modelos de estimativa da DPM tiveram uma boa performance. Para os modelos DPO, CART e RES (Figuras 4b, 4c e 4d) foram observadas superestimativas da ordem de 2, 6 e 7\% respectivamente, enquanto que o NHUR $>90 \%$ (Figura 4.4a) apresentou uma subestimativa de 6\%. Essa análise resultou em valores elevados de $\mathrm{D}$, indicando que todos os modelos apresentaram boa exatidão 
ou acurácia (Tabela 4.1). Entretanto, a precisão das estimativas, expressa pelo $\mathrm{R}^{2}$, não foi muito elevada, variando de 0,75 a 0,90, resultando em EAMs entre 1,27 e 2 h. O método que apresentou a maior precisão (NHUR>90\%) também apresentou o menor EMAX (-4,75 h), seguido pelos modelos DPO (5,75 h), CART (7,5 h) e RES (9,75 h).

Os dois primeiros métodos, NHUR>90\% e DPO, sendo empíricos e bastante simples, são uma ferramenta muito prática para a estimativa da DPM na cultura do algodão, especialmente onde dados de radiação solar ou saldo de radiação não estão disponíveis. Esses dois métodos simples, baseados na temperatura e na umidade relativa do ar, tiveram desempenho tão bom quanto os outros métodos mais complexos, os quais requerem dados de saldo de radiação e/ou velocidade do vento. Resultados similares também foram observados por Rao et al. (1998), para a estimativa da DPM em espigas de milho, mas, por outro lado, diferem dos apresentados por Gleason et al. (1994) e Francl e Panigrahi (1997), talvez devido às condições de clima seco nas quais esses trabalhos foram desenvolvidos, no meio-oeste dos Estados Unidos. Sob essas condições, somente a UR não pode ser usada para estimar diretamente a DPM, sendo que a velocidade do vento, a cobertura de nuvens e a umidade do solo também devem ser consideradas (Gleason et al., 1994; Pedro Jr. e Gillespie, 1982a; Wilson et al., 1999).

Quando o banco de dados foi analisado considerando-se os dias sem (Figura 4.5 e Tabela 4.2) e com chuva (Figura 4.6 e Tabela 4.3) separadamente, foi observado que a tendência apresentada pelos modelos na estimativa da DPM foi a mesma, com o NHUR $>90 \%$ apresentando subestimativas e os demais modelos apresentando superestimativas. Entretanto, a precisão e a exatidão das estimativas mudou. Para os dias sem chuva (Figura 4.5 e Tabela 4.2), as precisões das estimativas pelos modelos 
NHUR>90\%, DPO e CART diminuíram enquanto que as exatidões permaneceram praticamente as mesmas, com subestimativas de $7,5 \%$ para o NHUR $>90 \%$ e de $1,4 \%$ para o DPO, e superestimativa de $10 \%$ pelo modelo CART. Por outro lado, para o modelo RES foi observada uma melhoria, com a superestimativa da DPM caindo para $5,3 \%$ e o $\mathrm{R}^{2}$ e $\mathrm{D}$ aumentando respectivamente para 0,78 e 0,96 .
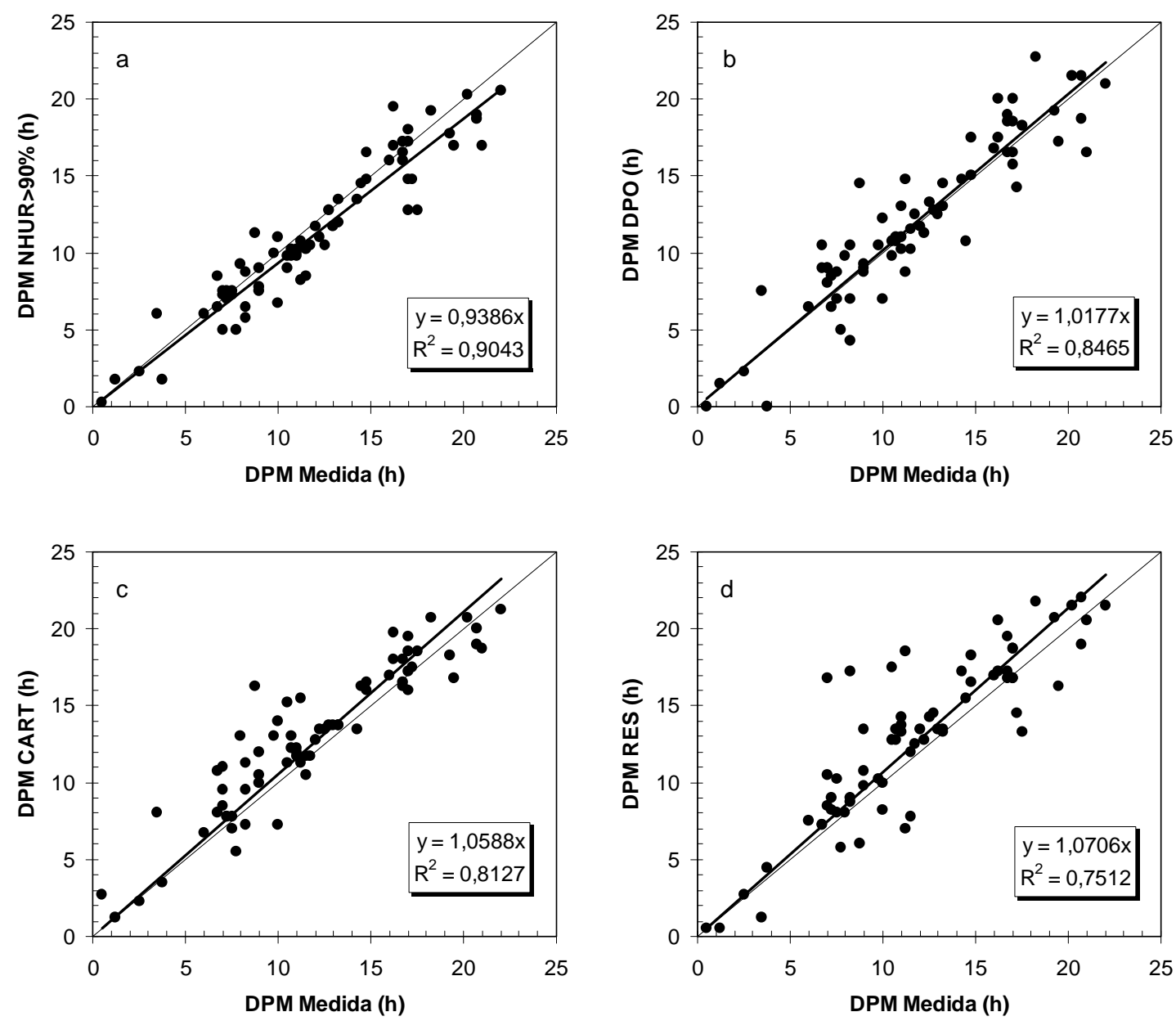

Figura 4.4 - Relação entre a DPM medida e a estimada pelos modelos NHUR $>90 \%$ (a), DPO (b), CART (c) e RES (d) a partir de dados meteorológicos medidos sobre a cultura do algodão, considerando-se tanto os dias com como os sem chuva. 
Para os dias com chuva (Figura 4.6 e Tabela 4.3), poucas mudanças foram observadas nas exatidões das estimativas feitas pelos modelos NHUR>90\%, DPO e CART, porém as precisões dessas estimativas foram substancialmente afetadas, com os valores de $\mathrm{R}^{2}$ caindo para 0,82, 0,68 e 0,52, respectivamente. Para o modelo RES, a performance em dias chuvosos foi ainda pior, especialmente em relação à precisão $\left(\mathrm{R}^{2}=\right.$ 0,11), resultando em um EAM de 2,58 h e em um EMAX de 9,75 h. Foi observado que os maiores erros ocorreram durante noites com chuvas de alta intensidade acompanhadas de ventos fortes. Durante essas noites, o modelo RES indicou a presença de molhamento por toda noite enquanto que os sensores acusaram intervalos de secamento.

Tabela 4.1 - Análise de regressão e erros relacionados à estimativa da DPM pelos diferentes modelos, a partir dos dados obtidos na estação meteorológica instalada na cultura do algodã, considerando-se tanto os dias com como os sem chuva ( $\mathrm{n}=70$ dias).

\begin{tabular}{lcccccc}
\hline Modelos & $\mathrm{b}$ & $\mathrm{R}^{2}$ & $\mathrm{D}$ & $\mathrm{EM}$ & EAM & EMAX \\
\cline { 5 - 7 } & & & & & (Horas) & \\
\hline NHUR $>90 \%$ & 0,94 & 0,90 & 0,97 & $-0,70$ & 1,27 & $-4,75$ \\
DPO & 1,02 & 0,85 & 0,96 & 0,32 & 1,54 & 5,75 \\
CART & 1,06 & 0,81 & 0,95 & 1,07 & 1,63 & 7,50 \\
RES & 1,07 & 0,75 & 0,92 & 1,11 & 2,00 & 9,75 \\
\hline
\end{tabular}

Essa diminuição na precisão das estimativas de DPM durante os dias com chuva era esperada com o uso do modelo CART, já que este foi desenvolvido para estimar a DPM somente em dias sem chuva, assim como descrito em Gleason et al. (1994). Por outro lado, era esperado que o modelo RES tivesse um melhor desempenho nos dias chuvosos em razão desse modelo considerar em seu procedimento o molhamento 
proporcionado pelas chuvas. Entretanto, mesmo com essa performance insatisfatória durante alguns dias chuvosos, os erros observados permaneceram dentro dos intervalos descritos por diversos autores (Gleason et al., 1984; Rao et al., 1998; Kim et al., 2002) e obtidos pelas medidas dos sensores de DPM quando comparadas às observações visuais (Magarey, 1999; Magarey et al., 2001). De acordo com Magarey (1999) e Magarey et al. (2001), os sensores de medida da DPM apresentam 95\% de chance de incertezas da ordem de 2 h, o que sugere que todos os métodos de estimativa de DPM aqui testados tiveram um desempenho tão bom quanto as medidas diretas dessa variável.

Comparando-se os dados de DPM obtidos na estação meteorológica dentro da cultura do algodão (1,7 $\mathrm{m}$ de altura e em média $0,7 \mathrm{~m}$ acima do topo da cultura) com aqueles observados no terço superior da cultura, entre as folhas, foi verificado que uma grande diferença existe entre eles, principalmente para períodos com DPM $<17$ h (Figure 4.7). Isso mostra que a DPM deve ser medida ou estimada para uma posição específica ou então ajustada por coeficientes empíricos, assim como apresentado pela regressão linear da Figura 4.7. Para os períodos com longas DPMs ( $\geq 17$ h), normalmente causadas por chuva, as diferenças são muito pequenas tanto entre a DPM medida no topo da cultura e na estação meteorológica, como também entre os seis sensores espalhados na cultura do algodão (Figura 3.3, Capítulo 3).

Para ilustrar a estimativa da DPM ao nível da cultura, os quatro modelos foram usados com dados da estação meteorológica e das micro-estações no interior da cultura. A Figura 4.8 apresenta a relação entre essas duas estimativas, a qual mostra o mesmo padrão observado na Figura 4.7. 

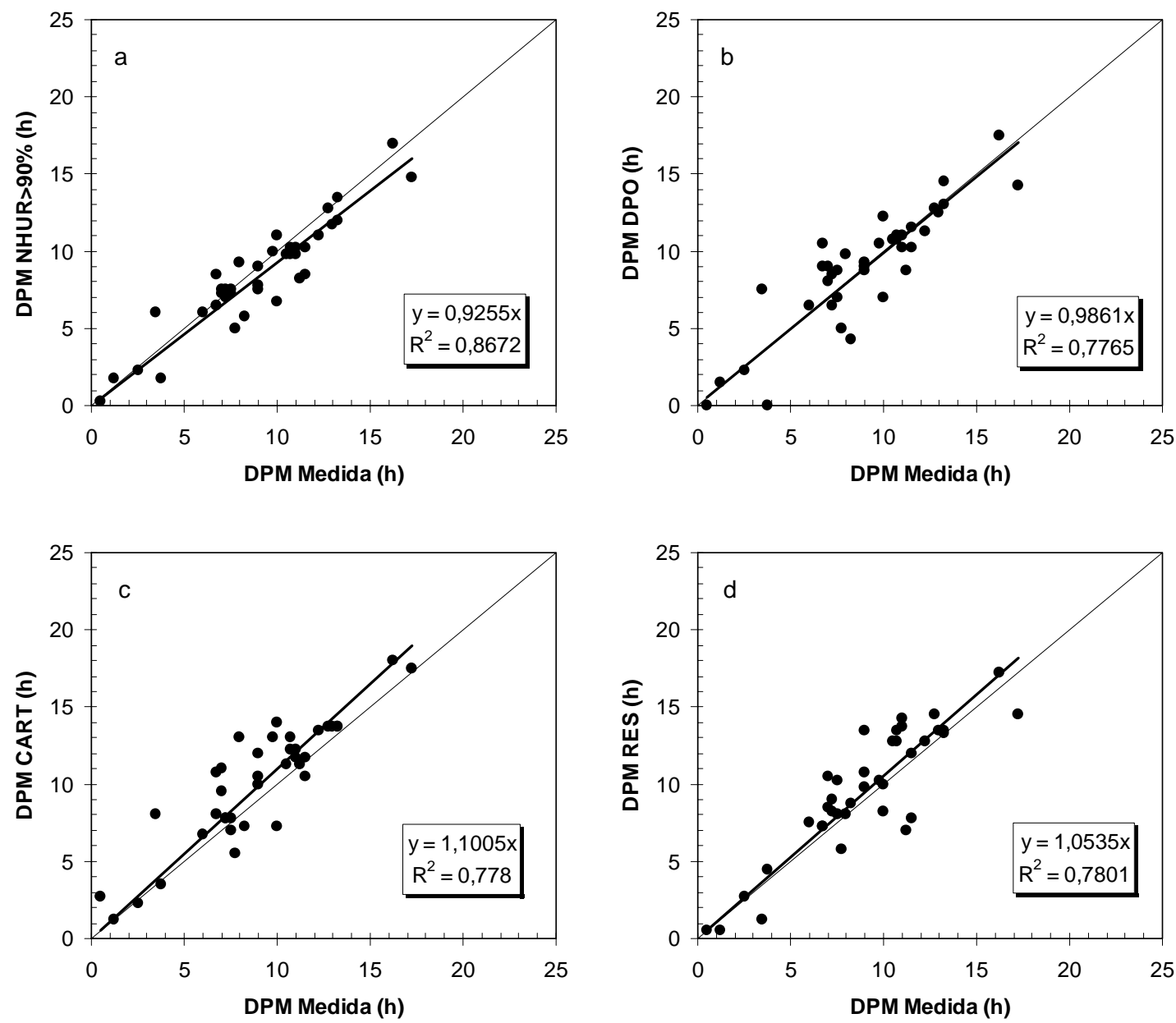

Figura 4.5 - Relação entre a DPM medida e a estimada pelos modelos NHUR>90\% (a), DPO (b), CART (c) e RES (d) a partir de dados meteorológicos medidos sobre a cultura do algodão, considerando-se os dias sem chuva. 
Entre os modelos utilizados, a relação dada pelo modelo RES (Figura 4.8d) é aquela que mais se aproxima da relação obtida com os dados observados (Figura 4.7). Isso ocorre por causa da concordância observada entre a DPM estimada pelo modelo RES e a DPM medida ao nível da cultura, como pode ser observado na Figura 4.9. Esse resultado dá uma maior confiabilidade ao modelo RES, o qual é um modelo físico transferível para outros locais e culturas sem a necessidade de calibrações, e suporta a hipótese de que sob condições de chuvas intensas o vento é o grande responsável pelo mau desempenho desse método (Figura 4.6d).

O modelo DPO também mostrou manter o mesmo padrão da relação entre a DPM no topo da cultura e na estação meteorológica apresentada pelos dados medidos (Figura 4.8b), mas esse modelo foi empiricamente calibrado para esta condição e, portanto, não é transferível para outras culturas e locais, assim como é o caso do modelo RES.

Tabela 4.2 - Análise de regressão e erros relacionados à estimativa da DPM pelos diferentes modelos, a partir dos dados obtidos na estação meteorológica instalada na cultura do algodão, considerando-se os dias sem chuva ( $\mathrm{n}=38$ dias).

\begin{tabular}{lcccccc}
\hline Modelos & $\mathrm{b}$ & $\mathrm{R}^{2}$ & $\mathrm{D}$ & $\mathrm{EM}$ & EAM & EMAX \\
\cline { 5 - 7 } & & & & & (Horas) & \\
\hline NHUR $>90 \%$ & 0,92 & 0,87 & 0,98 & $-0,60$ & 1,09 & $-3,25$ \\
DPO & 0,97 & 0,78 & 0,96 & 0,02 & 1,30 & 4,00 \\
CART & 1,10 & 0,78 & 0,95 & 1,13 & 1,55 & 5,00 \\
RES & 1,05 & 0,78 & 0,96 & 0,59 & 1,51 & 4,50 \\
\hline
\end{tabular}



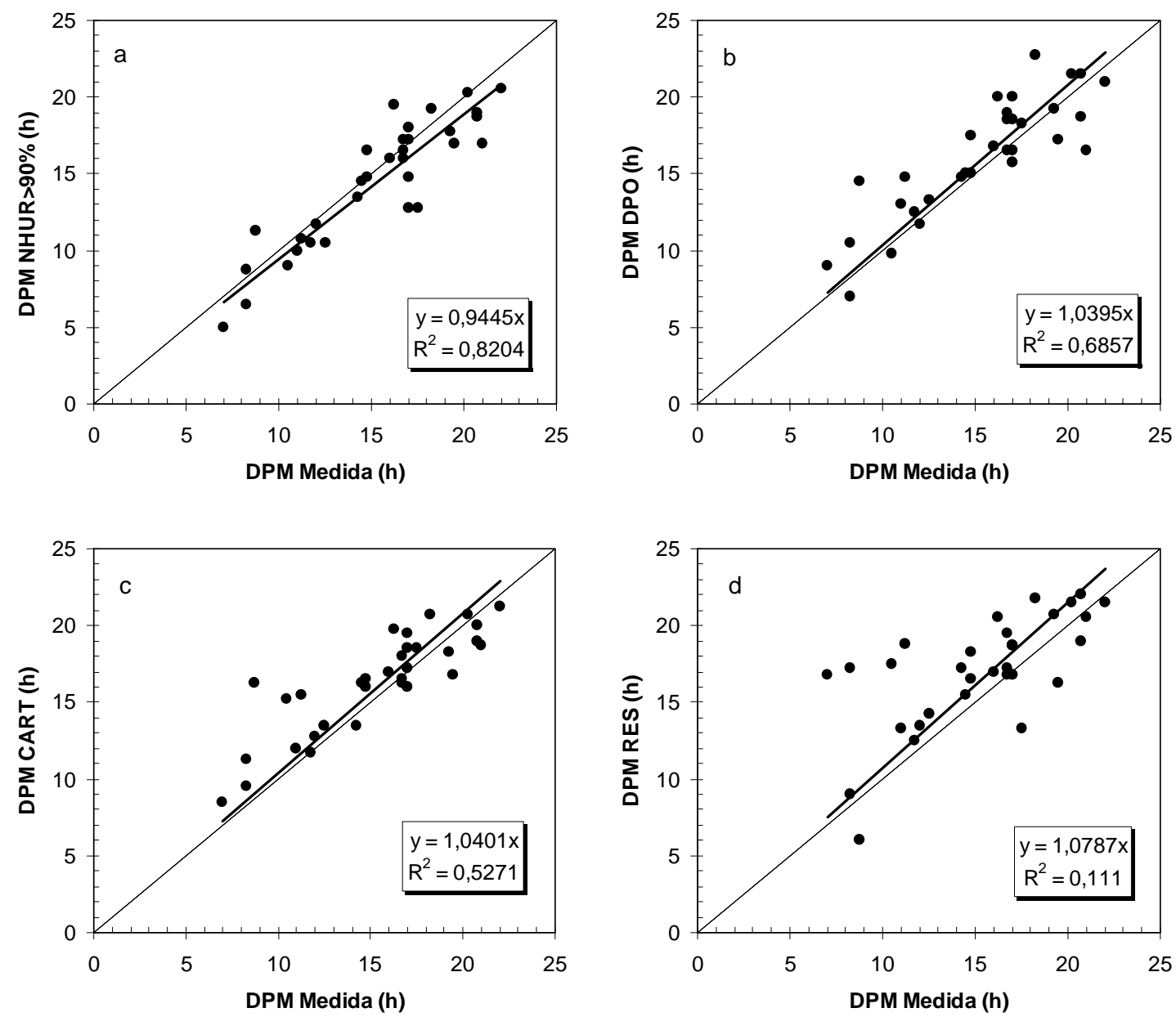

Figura 4.6 - Relação entre a DPM medida e a estimada pelos modelos NHUR>90\% (a), DPO (b), CART (c) e RES (d) a partir de dados meteorológicos medidos sobre a cultura do algodão, considerando-se os dias com chuva. 
Tabela 4.3 - Análise de regressão e erros relacionados à estimativa da DPM pelos diferentes modelos, a partir dos dados obtidos na estação meteorológica instalada na cultura do algodão, considerando-se os dias com chuva ( $\mathrm{n}=32$ dias).

\begin{tabular}{lcccccc}
\hline Modelos & $\mathrm{b}$ & $\mathrm{R}^{2}$ & $\mathrm{D}$ & $\mathrm{EM}$ & EAM & EMAX \\
\cline { 5 - 7 } & & & & & (Horas) & \\
\hline NHUR $>90 \%$ & 0,94 & 0,82 & 0,96 & $-0,80$ & 1,48 & $-4,75$ \\
DPO & 1,04 & 0,68 & 0,96 & 0,85 & 1,73 & 5,75 \\
CART & 1,04 & 0,52 & 0,95 & 1,00 & 1,73 & 7,50 \\
RES & 1,08 & 0,11 & 0,90 & 1,73 & 2,58 & 9,75 \\
\hline
\end{tabular}

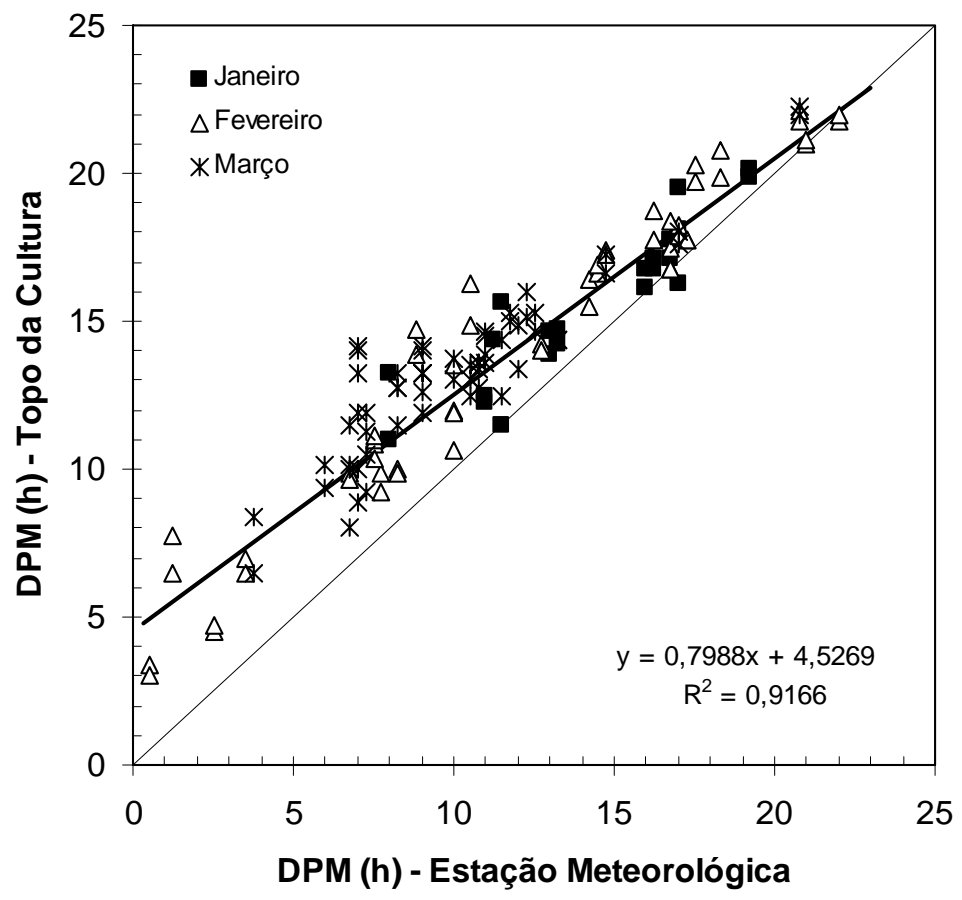

Figure 4.7 - Relação entre a DPM medida na estação meteorológica e nas microestações, na cultura do algodão. Cada ponto representa a média de 3 medidas em cada cultivar. 

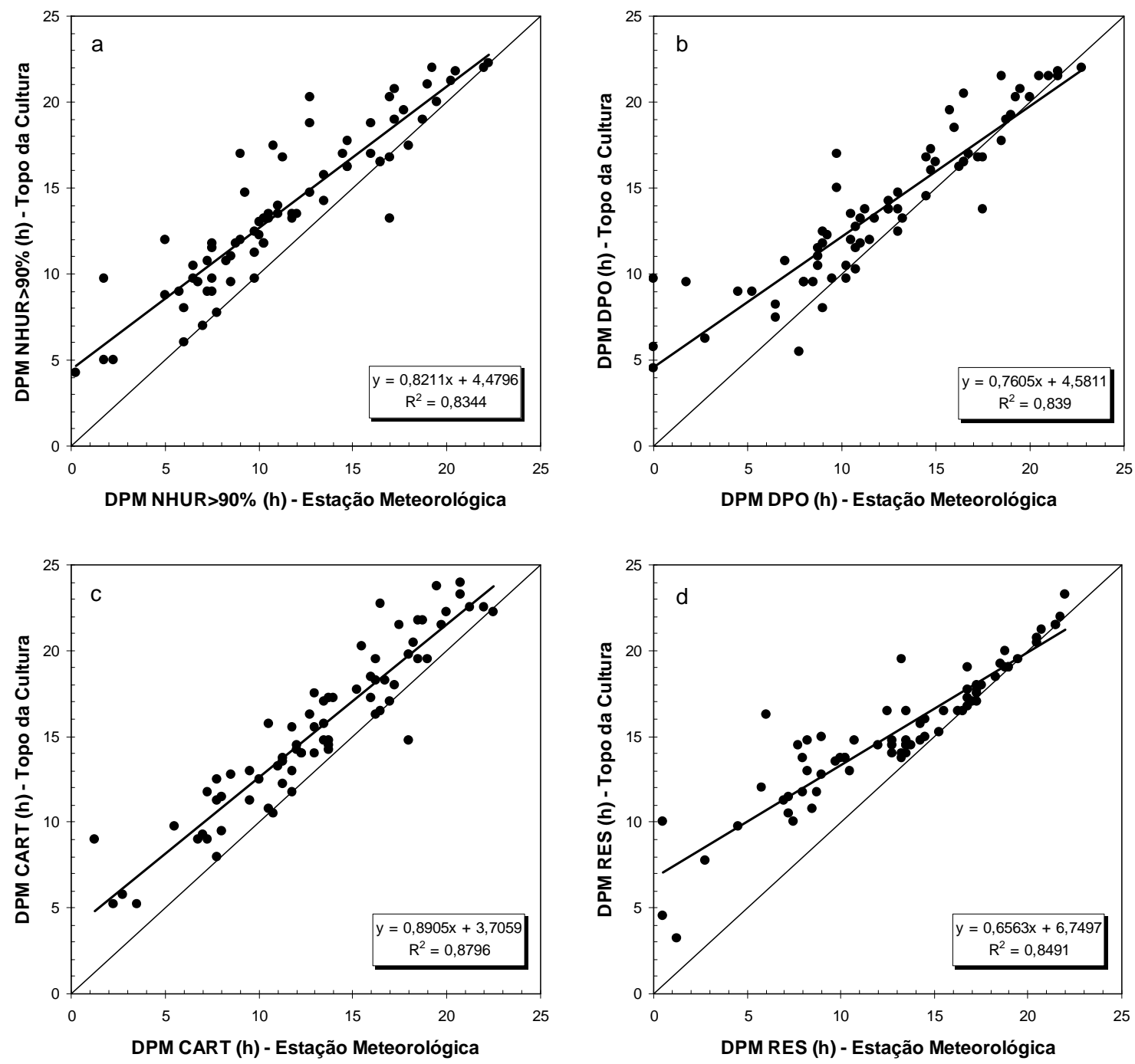

Figura 4.8 - Relação entre a DPM estimada com dados da estação meteorológica e a DPM estimada com dados das micro-estações, na cultura do algodão, utilizando-se os modelos do NHUR>90\% (a), DPO (b), CART (c) e RES (d). 


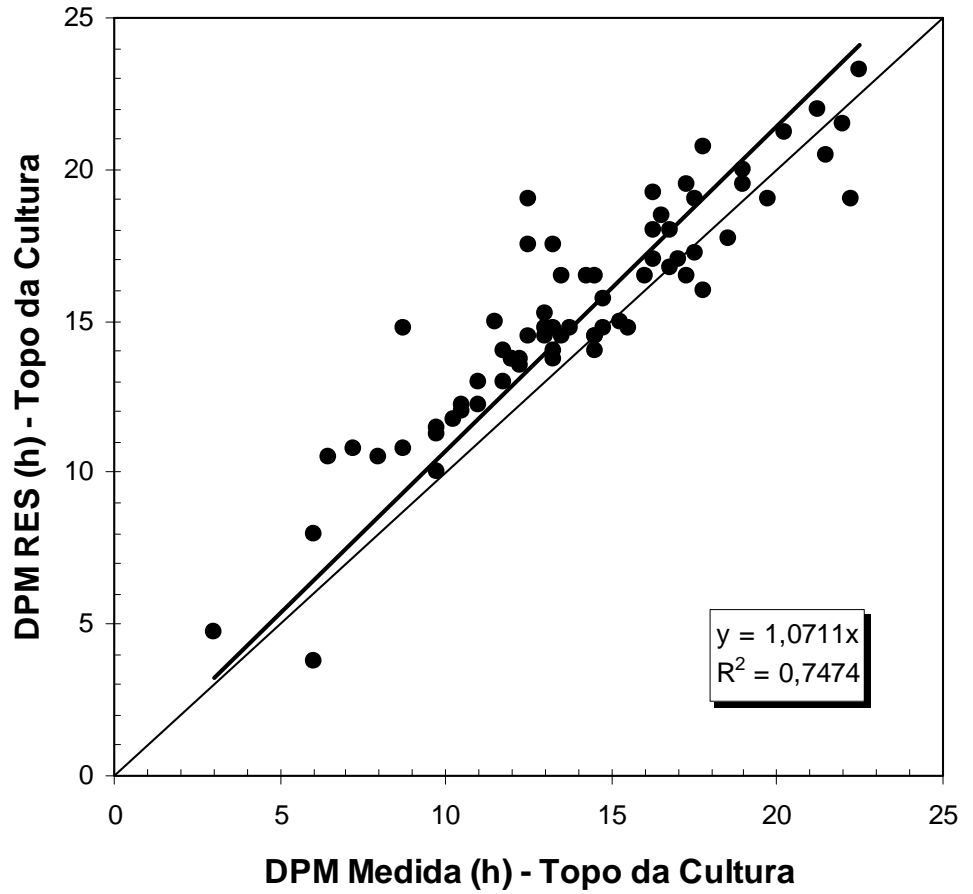

Figura 4.9 - Relação entre a DPM medida e estimada com dados das micro-estações, na cultura do algodão, utilizando-se o modelo RES.

\subsection{Conclusões}

Os resultados obtidos neste estudo permitem concluir que:

a) Em geral, todos os modelos de estimativa da DPM tiveram um bom desempenho, apresentando em média pequenas subestimativas pelo modelo do NHUR $>90 \%$ e superestimativas pelos modelos DPO, CART e RES.

b) Os modelos do NHUR>90\% e da DPO, sendo empíricos e de fácil aplicação, são uma ferramenta prática para a estimativa da DPM na cultura do algodão, 
especialmente quando dados de radiação solar e velocidade do vento não estão disponíveis.

c) Todos os modelos apresentaram diferentes performances quando usados em dias com e sem chuva, com a pior performance ocorrendo nos dias chuvosos, especialmente quando acompanhados de alta velocidade do vento.

d) Existe uma grande diferença entre os dados de DPM obtidos na estação meteorológica, a 1,7 m de altura, e aqueles observados no terço superior da cultura do algodão, principalmente para os dias com DPM $<17 \mathrm{~h}$.

e) Para os dias com DPM $\geq 17 \mathrm{~h}$, normalmente provocadas por chuva, as diferenças entre a DPM medida na cultura e na estação meteorológica foram muito pequenas.

f) O modelo RES mostrou ser uma boa opção para a estimativa da DPM ao nível da cultura, tendo as estimativas boa concordância com as medidas obtidas pelas microestações. Além disso, o modelo RES foi capaz de reproduzir a mesma relação entre a DPM medida ao nível da cultura e na estação meteorológica.

g) O modelo da DPO também apresentou capacidade de reproduzir a relação de DPM entre a cultura e a estação meteorológica, porém, este método necessita de ajustes empíricos dependentes das condições climáticas do local e da cultura. 


\section{ASPECTOS OPERACIONAIS DA MEDIDA DA DURAÇÃO DO PERÍODO DE MOLHAMENTO FOLIAR COM SENSORES ELETRÔNICOS}

\section{Resumo}

A duração do período de molhamento foliar (DPM) é um fator chave na ocorrência de doenças em plantas em diversos fitopatosistemas e, conseqüentemente, uma variável importante nos sistemas de alerta fitossanitário. A medida da DPM é freqüentemente problemática devido à falta de uma condição e sensor padrão para tal. Buscando-se entender melhor os aspectos operacionais relacionados à exposição dos sensores eletrônicos para a medida da DPM, este trabalho foi realizado avaliando-se dados de três diferentes locais: Elora, ON, Canadá; Ames, IA, Estados Unidos; e Piracicaba, SP, Brasil. Sensores eletrônicos de DPM (Campbell Sci., Modelo 237) foram instalados em diferentes alturas e ângulos de exposição em relação à horizontal, acima e/ou no interior de diferentes culturas: gramado e milho em Elora; gramado e melão em Ames; e gramado e algodão em Piracicaba. Observações visuais de deposição e secamento do orvalho foram feitas para se comparar com as medidas feitas pelos sensores nas diferentes posições. Em Elora e Piracicaba, os sensores instalados a $30 \mathrm{~cm}$ 
acima do gramado e entre $15^{\circ}$ e $45^{\circ}$ em relação à horizontal apresentaram os menores erros quando comparados às observações visuais, tanto para a formação quanto para o secamento do orvalho. Assumindo-se o sensor a $30 \mathrm{~cm}$ de altura e com um ângulo de $30^{\circ}$ como referência para a medida da DPM sobre o gramado, foi possível se identificar diferenças significativas entre as medidas feitas nas diversas alturas e ângulos de instalação dos sensores, o que mostrou que a posição do sensor tem efeito considerável na medida da DPM. Sensores instalados a $190 \mathrm{~cm}$ de altura mediram em média DPM mais curta - 97 min em Elora e 54 min em Piracicaba - do que os sensores instalados a $30 \mathrm{~cm}$. Nenhuma diferença significativa foi observada entre os sensores a 30 e $70 \mathrm{~cm}$, nos dois locais. Em Ames, a diferença média da DPM entre os sensores a $30 \mathrm{~cm}$ e a 150 cm de altura, ambos com um ângulo de $45^{\circ}$, foi de 33 min. Com relação ao ângulo de instalação dos sensores, aqueles com inclinação de $0^{\circ}$ e $15^{\circ}$ mediram em média DPM mais longa - 38 min em Elora e 56 min em Piracicaba - do que os sensores a $30^{\circ}$ e $45^{\circ}$. A DPM medida pelo sensor próximo da altura do abrigo meteorológico sobre o gramado diferiu consideravelmente da DPM medida junto ao topo das culturas, especialmente durante períodos com menos do que 15 h de molhamento. Por outro lado, os sensores instalados a $30 \mathrm{~cm}$ sobre o gramado mostraram um grande potencial para serem utilizados em sistemas operacionais de manejo de doenças em plantas por suas medidas terem sido bastante próximas da DPM das culturas, apesar das diferenças estruturais entre elas. 


\section{OPERATIONAL EXPOSURE OF LEAF WETNESS ELECTRONIC SENSORS}

\section{Summary}

Leaf wetness duration (LWD) is a key factor in plant disease occurrence in many phytopathosystems and, consequently, an important variable in disease warning systems. Measurement of LWD is often problematic because of the lack of a standard sensor, and lack of a standard exposure protocol. Accordingly, operational aspects of LWD exposure were evaluated using data from experiments in three different locations: Elora, ON, Canada; Ames, IA, U.S.A.; and Piracicaba, SP, Brazil. LWD sensors (flat, printedcircuit) were installed at different heights and angles, and above or inside different crops: turfgrass and corn in Elora; turfgrass and muskmelon in Ames; and turfgrass and cotton in Piracicaba. Visual observations of dew onset and dry-off were made for comparison with the different sensor positions. At Elora and Piracicaba, sensors deployed $30 \mathrm{~cm}$ above turfgrass and between $15^{\circ}$ and $45^{\circ}$ to horizontal showed the smallest errors in relation to visual observations of turfgrass wetness, for both dew onset and dry-off. Assuming the sensor at $30 \mathrm{~cm}$ and $30^{\circ}$ as a reference for LWD measurements over turfgrass it was possible to identify significant differences among the different sensor heights and angles, showing that the position of the sensor had a strong effect on LWD measurements. Sensors at $190 \mathrm{~cm}$ measured shorter average LWD - 97 min for Elora and $54 \mathrm{~min}$ for Piracicaba - than sensors at $30 \mathrm{~cm}$. No significant difference was observed between the sensors at $30 \mathrm{~cm}$ and $70 \mathrm{~cm}$ in both places. In Ames, the average difference in LWD between the sensors at $30 \mathrm{~cm}$ and $150 \mathrm{~cm}$ (both 
deployed at $45^{\circ}$ ) was $33 \mathrm{~min}$. In relation to the angle of deployment, sensors at $0^{\circ}$ and $15^{\circ}$ measured longer average LWD - 38 min for Elora and 56 min for Piracicaba - than sensors at $30^{\circ}$ and $45^{\circ}$. LWD measured by sensors near the standard screen height over turfgrass differed considerably from LWD measured by sensors in the canopy, especially during periods with less than $15 \mathrm{~h}$ of wetness. In contrast, sensors at $30 \mathrm{~cm}$ over the turfgrass showed potential for use in operational plant disease management systems because they provided much more accurate estimates of crop LWD despite large differences in crop height and structure.

\subsection{Introdução}

A duração do período de molhamento foliar (DPM) é uma das mais importantes variáveis agrometeorológicas que influenciam a epidemiologia de doenças de plantas. Em geral, a presença de molhamento sobre a superfície das plantas provê a água requerida pelos patógenos para o processo de germinação e infecção do tecido foliar. Essa variável é usada como dado de entrada em vários sistemas de alerta fitossanitário (Huber e Gillespie, 1992; Kim et al., 2002), os quais permitem o uso mais racional dos fungicidas (Gillespie et al., 1993), e permite também a análise de risco de uma dada doença quando aplicada em modelos de previsão (Hijmans et al., 2000).

A DPM é uma variável de difícil medida já que não há um padrão para sua observação, tanto em termos de sensor como em termos de sua instalação (Magarey, 1999; Madeira et al., 2002). Entretanto, o uso de sensores de DPM pode ser necessário para fins operacionais, especialmente onde a estimativa por modelos empíricos ou 
físicos se torna problemática. Tais estimativas podem requerer variáveis meteorológicas que não são normalmente medidas, como por exemplo, o saldo de radiação, ou ainda necessitar ajustes e calibrações para diferentes locais e culturas (Gillespie e Barr, 1984).

Os sensores de DPM são divididos em três classes (Gillespie e Kidd, 1978; Getz, 1991): estáticos, que apenas dão uma indicação se houve ou não molhamento durante um dado período, porém sem quantificar o volume de água e a duração do molhamento; mecânicos, que registram mudanças de comprimento, tamanho ou peso do elemento sensor causado pelo molhamento; e eletrônicos, que promovem mudança na resistência ou impedância do sensor.

Os sensores estáticos são aqueles que não dispoem de qualquer artifício mecânico ou eletrônico, como o sensor de Duvdevani (Getz, 1991). Esse tipo de equipamento é muito rudimentar e suas medidas são pouco úteis, já que os mesmos não têm correlação com a DPM (Getz, 1991). Os instrumentos mecânicos foram intensamente usados para a medida da DPM até 1970 (Lomas, 1965; Lomas e Shashoua, 1970) e apesar de suas limitações, esses sensores ainda têm sido usados recentemente em vários locais (Zangvil, 1996).

Seguindo algumas tentativas prévias de se medir a DPM a partir da mudança da resistência elétrica, Davis e Hughes (1970) introduziram a idéia de se tratar os sensores de placa de circuito impresso com tinta a base de água de côr cinza para aumentar a sensibilidade do sensor ao molhamento. Preocupados com essa questão, Gillespie e Kidd (1978) avaliaram em sensores de circuito impresso, que simulava uma secção plana de uma folha, tratados com diferentes cores de tinta latex e confirmaram que a coloração 
cinza claro resultou na melhor acurácia para a simulação da deposição e do secamento do molhamento na cultura da cebola.

Em seguida, diversos autores desenvolveram e/ou compararam a performance de diferentes tipos de sensores eletrônicos de DPM (Smith e Gilpatrick, 1980; Weiss e Lukens, 1981; Weiss e Hagen, 1983; Barthakur, 1985; Gillespie e Duan, 1987; Weiss et al., 1988; Armstrong et al., 1993; Wei et al., 1995; Giesler et al., 1996; Miranda et al., 2000). Em geral, a performance dos sensores foi adequada, porém diferenças entre os sensores foram detectadas, o que dependeu das características de cada um deles e dos aspectos operacionais de sua instalação e exposição.

Gillespie e Duan (1987) desenvolveram e testaram sensor cilíndrico, tentando-se simular culturas com folhas cilíndricas, como a da cebola. Esses autores encontraram que os sensores cilíndricos registraram o início do molhamento por orvalho mais tarde e o seu secamento mais cedo do que os sensores de placa de circuito impresso com similar largura. Desse modo, eles sugeriram precaução no uso dos sensores cilíndricos para monitorar a DPM em culturas que apresentam folhas planas. Weiss e Lukens (1981) e Weiss e Hagen (1983) também encontraram diferenças entre sensores eletrônicos de DPM com diferentes características. O sensor de placa de circuito impresso foi menos efetivo em medir a DPM do que um sensor cujo elemento de medida era uma gaze de algodão branca entre uma rede de fios finos. Além desses, sensores de posicionamento específico também foram desenvolvidos (Weiss et al., 1988; Barthakur, 1985; Armstrong et al. (1993); Giesler et al, 1996; Miranda et al., 2000). Apesar da aparente vantagem desses sensores, por serem montados diretamente sobre as folhas, alguns 
problemas operacionais, tais como: contato entre os fios e a folha, o tamanho e a deterioração da folha, têm limitado sua utilização para medidas rotineiras.

Apesar do enorme esforço para se desenvolver sensores eletrônicos para a medida da DPM, os aspectos operacionais de sua medida não têm sido extensivamente discutidos. Assim como relatado por Davis e Hughes (1970), a performance de um sistema eletrônico para monitoramento da DPM sobre os vegetais depende basicamente da correta exposição do sensor nas condições de campo.

Alguns estudos têm se concentrado nos aspectos operacionais do monitoramento da DPM de modo a se estabelecer a melhor maneira de se fazer tais medidas. A primeira tentativa de se estabelecer um padrão para a medida da DPM foi feita por Gillespie e Kidd (1978). Esses autores encontraram que um ângulo de instalação de $20^{\circ}$ em relação à horizontal foi o melhor para a medida da DPM na cultura da cebola, usando um sensor de placa de circuito impresso com uma distância entre os eletrôdos de 1 mm. Mais tarde, Wei et al. (1995) desenvolveram um sensor similar, adaptado para a medida da DPM em frutos cultivados no interior de ambientes protegidos. Esses autores concluíram que para o sensor desenvolvido por eles, com uma distância entre os eletrôdos de 0,25 mm, o tratamento com tinta não foi necessário para se obter uma boa correlação entre a DPM medida e observada visualmente. Por outro lado, Lau et al. (2000) e Sentelhas et al. (2004a) observaram que a pintura com tinta latex é desejável nos sensores comerciais de DPM, quando utilizados nas cutluras do tomate e do algodão, respectivamente. De acordo com esses autores, o uso de duas ou três camadas de tinta latex branca, seguida de tratamento térmico dos sensores, foi suficiente para reduzir a variabilidade entre os sensores. Lau et al. (2000) também verificaram que o ângulo de instalação do sensor 
pode afetar significativamente a acurácia e a precisão das medidas de DPM, devido à sua influência na capacidade de retenção de água do sensor, e que a direção da orientação de instalação não teve efeito significativo tanto em termos da formação como do secamento do molhamento. Apesar da importância dessas informações para a medida da DPM, pouco tem sido feito para investigar o efeito das várias posições de medida da DPM em condição padrão sobre gramado em uma estação meteorológica e para correlacionar essas medidas com a DPM em diferentes culturas.

Baseado nas considerações apresentadas anteriormente, os objetivos deste trabalho foram os de se estabelecer uma condição padrão para a medida da DPM em uma estação meteorológica sobre gramado, avaliando-se as medidas obtidas por sensores em diferentes alturas e ângulos de exposição, e de se avaliar a correlação destas com a DPM observada em três diferentes culturas (milho, algodão e melão), conduzidas nas proximidades das áreas gramadas.

\subsection{Material e métodos}

\subsubsection{Sensores eletrônicos para medida da DPM}

Para a medida da DPM neste estudo foram utilizados sensores eletrônicos de placa de circuito impresso (Campbell Scientific, Modelo 237). Esses sensores consistem de uma placa de circuito impresso de $1 \mathrm{~mm}$ de espessura com dois pentes de cobre intercalados. Todos os sensores foram tratados com duas ou três camadas de tinta latex branca, assim como sugerido por Gillespie e Kidd (1978), Lau et al. (2000) e Sentelhas 
et al. (2004a), para se aumentar a habilidade do sensor em detectar pequenas quantidades de molhamento, ou seja, gotículas com menos de $1 \mathrm{~mm}$ de diâmetro. Esses sensores foram testados em laboratório em uma câmara conectada a um gerador de ponto de orvalho (Li-cor, Modelo LI 610) para avaliar a possível, mas indesejável, influência da umidade relativa (UR) nas medidas. Inicialmente, como todos os sensores estavam respondendo à UR $>80 \%$, eles foram submetidos a um tratamento térmico em estufa (60-70 ${ }^{\circ} \mathrm{C}$ por $\left.12 \mathrm{~h}\right)$ para remoção ou desativação de componentes higroscópicos da tinta. Após esse tratamento, os sensores não mais apresentaram resposta a altas UR na ausência de água livre. Assim, somente a condensação sobre os sensores pode ser responsável pela redução da impedância entre os dentes dos pentes de cobre intercalados, o que foi medido por um sistema de aquisição de dados.

O limiar de leitura no sistema de aquisição de dados para se considerar o sensor com molhamento foi determinado em laboratório pela aplicação de uma gota de água de diâmetro de cerca de $1 \mathrm{~mm}$ sobre o sensor, utilizando-se para tanto uma seringa com agulha e observando-se a relação entre a voltagem de medida (Vs) e a voltagem de excitação do sensor (Vx). Cada um dos sensores foi montado em uma secção de tudos de PVC ou de metal (Figura 5.1) e todos foram instalados no campo em diversas posições, assim como será descrito a seguir. 


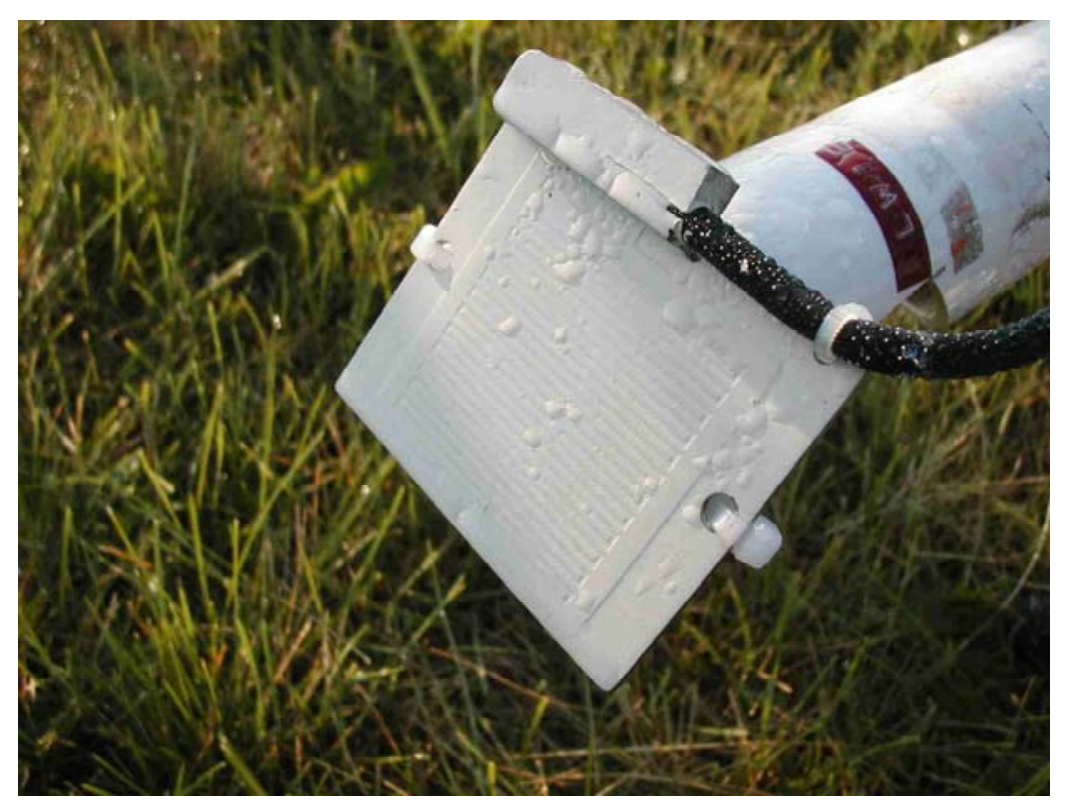

Figura 5.1 - Detalhe de um sensor de DPM da Campbell Sci., Modelo 237, montado em uma secção de um tudo de PVC.

\subsubsection{Experimentos de campo}

Os experimentos de campo foram conduzidos em três localidades sob diferentes condições climáticas (Tabela 5.1). Os três locais foram utilizados de modo a se poder comparar a DPM medida na estação meteorológica sobre o gramado com a DPM em diversas culturas instaladas nas proximidades. Este estudo não teve por intensão comparar a DPM entre as diferentes localidades, mas sim ter uma maior diversidade de dados de modo a se obter resultados consistentes. Portanto, o fato de os experimentos não terem exatamente o mesmo tipo de distribuição dos sensores não foi levado em consideração. 
Em Elora, ON, Canadá $\left(43^{\circ} 49^{\prime} \mathrm{N}, 80^{\circ} 35^{\prime} \mathrm{W}\right)$, os sensores de DPM foram instalados sobre um gramado ( 1 ha) e também no topo de uma cultura de milho, que se localizava a aproximadamente $200 \mathrm{~m}$ a noroeste da área gramada. As medidas foram realizadas entre 28 de julho e 07 de outubro de 2003, totalizando 71 dias. No gramado, oito sensores de DPM foram instalados a cinco alturas (30, 70, 110, 150 e $190 \mathrm{~cm}) \mathrm{com}$ um ângulo de exposição de $30^{\circ}$ em relação à horizontal e voltados para o norte. Além disso, os sensores a $30 \mathrm{~cm}$ de alturta e voltados para o norte foram instalados com quatro diferentes ângulos $\left(0^{\circ}, 15^{\circ}, 30^{\circ}\right.$ e $\left.45^{\circ}\right)$. Na cultura do milho, o sensor de DPM foi instalado junto às folhas superiores, com sua altura sendo ajustada periodicamente para acompanhar o crescimento das plantas. As Figuras 5.2a e 5.2b ilustram a disposição dos sensores de DPM instalados em Elora.

Em Ames, IA, Estados Unidos (42 $01^{\prime}$ N, $\left.93^{\circ} 46^{\prime} \mathrm{W}\right)$, os sensores de DPM foram instalados sobre uma área gramada a 30 e $150 \mathrm{~cm}$ de altura, voltados para o norte e com um ângulo de $45^{\circ}$ em relação à horizontal, e também na parte superior de uma cultura de melão com o mesmo tipo de exposição, de 23 de julho a 07 de outubro de 2003, totalizando 69 dias de medidas. As Figuras 5.2c e 5.2d ilustram a disposição dos sensores de DPM instalados em Ames.

Em Piracicaba, SP, Brasil ( $22^{\circ} 42^{\prime}$ S, $\left.47^{\circ} 30^{\prime} \mathrm{W}\right)$, os experimentos foram divididos em duas fases. A primeira fase foi conduzida na cultura do algodão de 17 de dezembro de 2000 a 02 de abril de 2001, totalizando 69 dias de medidas. Nessa fase, seis sensores de DPM foram instalados no terço superior da cultura do algodão, com suas alturas sendo ajustadas periodicamente para acompanhar o crescimento das plantas. Um outro sensor de DPM foi instalado a $170 \mathrm{~cm}$ de altura em uma estação meteorológica 
assentada sobre solo desnudo, nas adjacências da área da cultura. A segunda fase do experimento se deu de 07 de julho a 24 de setembro de 2003, totalizando 50 dias de medidas. Nesse período, medidas de DPM foram feitas sobre um gramado em cinco diferentes alturas (30, 70, 110, 150 e $190 \mathrm{~cm})$, com todos os sensores expostos a $30^{\circ} \mathrm{em}$ relação à horizontal e voltados para o norte. Outros dois sensores instalados a $150 \mathrm{~cm}$ de altura foram expostos a diferentes ângulos $\left(0^{\circ}\right.$ e $\left.45^{\circ}\right)$, ambos voltados para o norte.

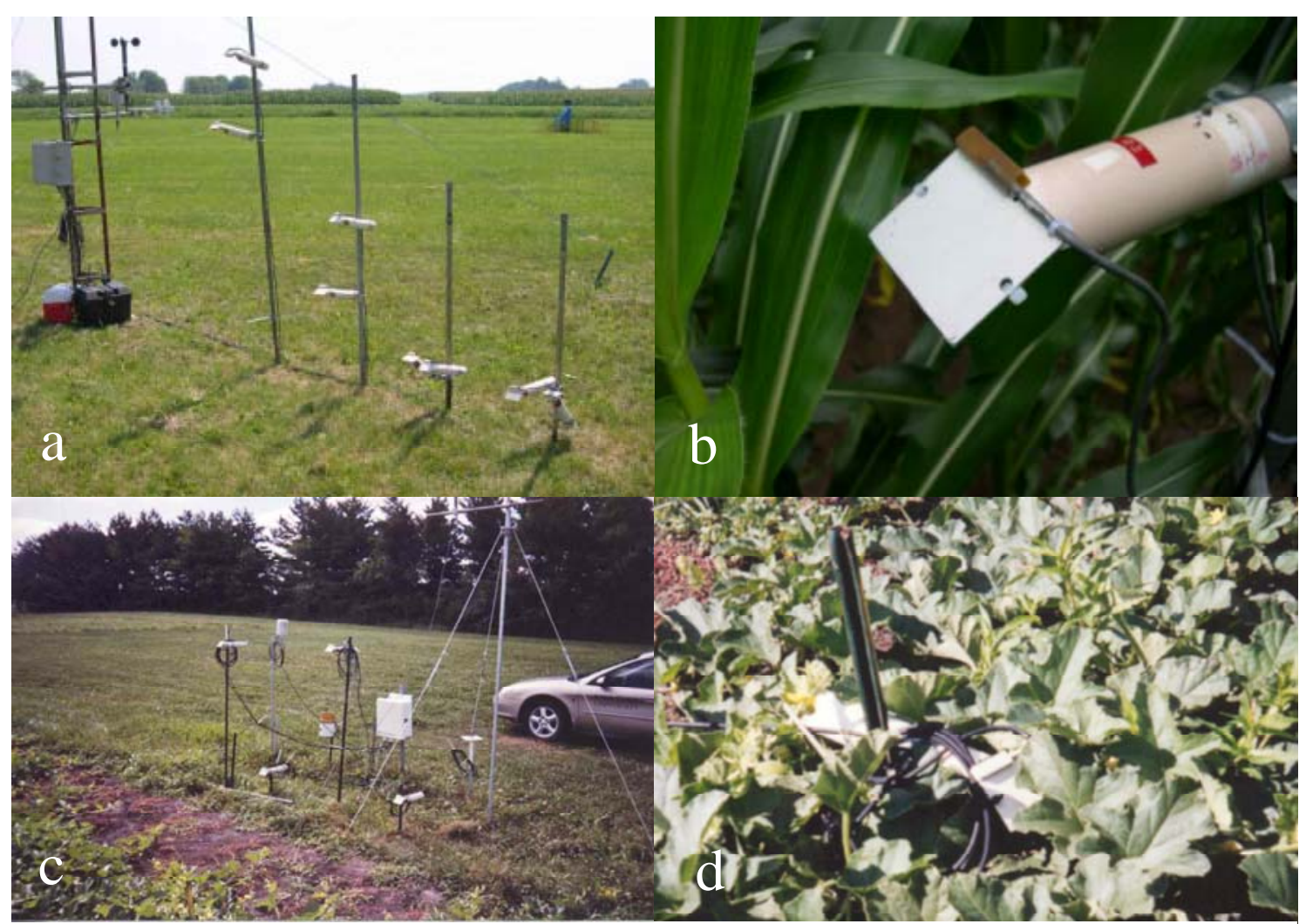

Figura 5.2 - Disposição dos sensores de DPM instalados em Elora, ON, Canadá, sobre o gramado (a) e na cultura do milho (b), e em Ames, IA, Estados Unidos, sobre o gramado (c) e na cultura do melão (d). 
Tabela 5.1 - Condições climáticas médias durante os experimentos em Ames, IA, Estados Unidos (2003), Elora, ON, Canadá (2003), e Piracicaba, SP, Brasil (2000/01 e 2003).

\begin{tabular}{lcccc}
\hline Local & $\begin{array}{c}\mathrm{T} \\
\left({ }^{\circ} \mathrm{C}\right)\end{array}$ & $\begin{array}{c}\mathrm{UR} \\
(\%)\end{array}$ & $\begin{array}{c}\mathrm{P} \\
(\mathrm{mm})\end{array}$ & $\begin{array}{c}\mathrm{U}^{*} \\
\left(\mathrm{~m} \mathrm{~s}^{-1}\right)\end{array}$ \\
\hline Ames (2003) & 20,5 & 75,1 & 197 & 3,0 \\
Elora (2003) & 16,0 & 83,1 & 344 & 1,8 \\
Piracicaba (2000/01) & 22,5 & 83,2 & 1016 & 1,0 \\
Piracicaba (2003) & 18,6 & 65,7 & 45 & 1,4 \\
\hline
\end{tabular}

$\mathrm{T}$ = temperatura média, $\mathrm{UR}=$ umidade relativa média, $\mathrm{P}$ = chuva e $\mathrm{U}$ = velocidade média do vento.

* A velocidade do vento foi medida a 2 m em Elora e Piracicaba, e a 3 m em Ames.

Baseando-se em Lau et al. (2000), todos os sensores utilizados nos experimentos foram instalados voltados para o norte. Esses sensores foram conectados a sistemas de aquisição de dados (Campbell Scientific, Modelos CR10, 21X ou CR23X), os quais foram programados para realizar medidas a cada 1, 5 ou 10 segundos, dependendo do local e do número de sensores, e armazenar a percentagem de tempo em que o sensor esteve úmido no intervalo estipulado: 10 minutos em Piracicaba, 15 minutos em Elora e 60 minutos em Ames.

\subsubsection{Observação visual da formação e do secamento do orvalho}

Observações visuais do ínício da deposição e do secamento do orvalho em gramado foram feitas em Elora e Piracicaba, desde o final de julho até 24 de setembro de 
2003, de modo a se avaliar a performance dos sensores de DPM. Um total de sete noites de céu limpo e pouco vento foi selecionado para a observação da deposição de orvalho e onze manhãs foram selecionadas para observar o secamento do orvalho ou da chuva em Elora. Em Piracicaba, somente o secamento do orvalho foi observado durante quatorze manhãs. A deposição do orvalho não foi observada em Piracicaba devido ao fato de que durante o inverno, nessa região, a condensação inicia-se normalmente após a meia-noite por causa da baixa umidade do ar. A observação visual da deposição do orvalho foi baseada no aparecimento das primeiras gotículas de água sobre a lâmina das folhas de grama e não foram confundidas com gutação ou exudação. Uma lanterna foi usada para detectar a presença de condensação pela mudança da reflectância das folhas (Figura 5.3). As observações foram feitas a intervalos de 15 minutos, utilizando-se pelo menos 5 repetições, com amostras de 10 folhas por repetição. Para o secamento do orvalho, utilizou-se observação visual e tátil com o mesmo número de amostras e repetições (Giesler et al., 1996). Quando as superfícies das folhas foram consideradas secas usando-se essa técnica, pelo menos $80 \%$ da cobertura estava sem água na fase líquida. Simultaneamente, a observação visual do orvalho foi feita na cultura do milho em Elora. Para as observações da deposição e do secamento do orvalho na cultura do milho, um total de nove noites e treze manhãs foi selecionado. O mesmo procedimento usado nas observações feitas no gramado para deposição e evaporação do orvalho foi utilizado na cultura do milho. 


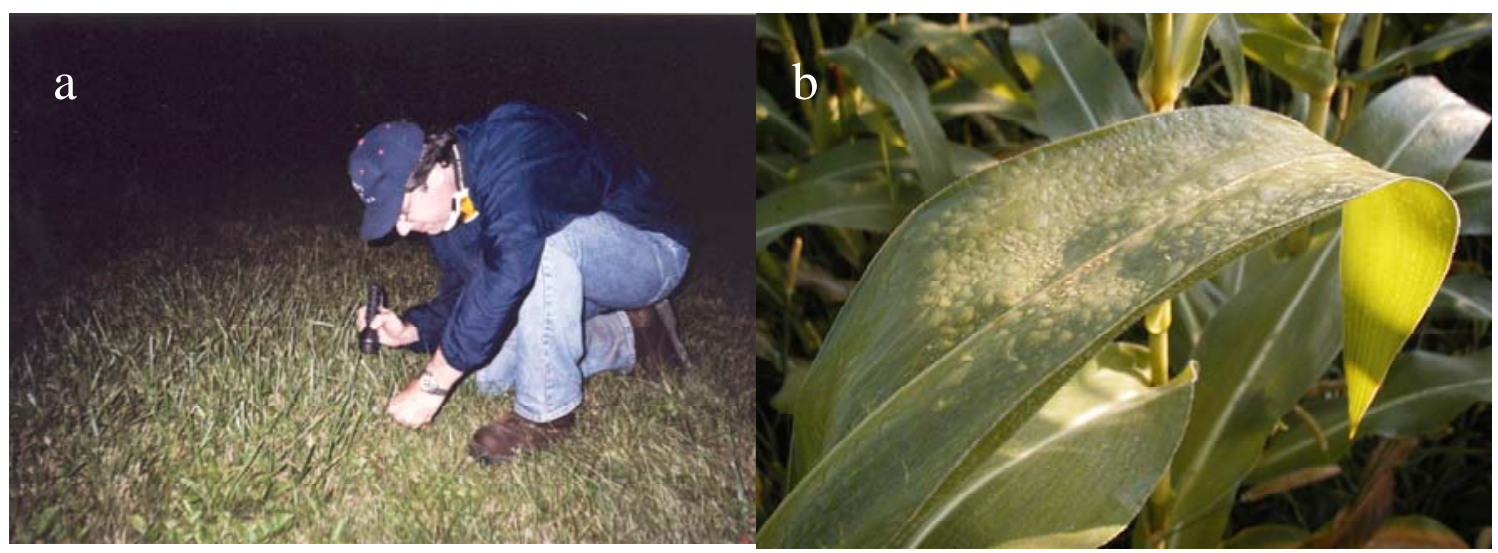

Figura 5.3 - Observação visual do orvalho: (a) observação da deposição do orvalho em gramado, com uso de uma laterna e (b) molhamento em folha de milho nas primeiras horas da manhã.

\subsubsection{Variabilidade entre sensores de DPM}

Para quantificar a magnitude da variabilidade entre os sensores eletrônicos de DPM, todos os nove sensores utilizados nos experimentos de Elora foram instalados sobre o gramado à mesma altura $(30 \mathrm{~cm})$ e com o mesmo ângulo $\left(30^{\circ}\right)$ por 10 dias, seguindo-se os mesmos procedimentos descritos anteriormente. O horário da deposição e do secamento do orvalho, assim como a DPM, foram analizadas durante esse período.

\subsubsection{Análise dos dados}

Os dados das observações visuais de deposição e secamento do orvalho foram comparados com os dados obtidos pelos sensores. A diferença entre as observações e as medidas foi calculada e então o erro médio (EM), que descreve a direção do erro 
predominante, e o erro absoluto médio (EAM), que indica a magnitude do erro médio, foram determinados para cada um dos nove sensores (oito a diferentes alturas e ângulos e um na cultura do milho). Os dados obtidos em Elora para o período de 10 dias com todos os sensores instalados na mesma posição (altura e ângulo) foram avaliados de modo a se determinar a magnitude da variabilidade entre eles. O coeficiente de variação (CV\%), e as diferenças média (DM) e absoluta média (DAM), em relação à média geral da DPM obtida pelos sensores durante esse período, foram determinadas e os resultados foram levados em consideração quando as DPMs médias dos sensores em diferentes posições foram comparadas, como será descrito a seguir. Para os experimentos em Ames e em Piracicaba, dados da comparação de todos os sensores à mesma altura não estavam disponíveis. Apesar disso, todos os sensores usados nesses experimentos passaram pelos mesmos procedimentos de pintura e tratamento térmico, o que leva a crer que o mesmo padrão de variabilidade apresentado pelos sensores usados em Elora seja esperado para os sensores utilizados nas demais localidades.

Uma segunda fase da análise dos dados foi avaliar o efeito das diferentes alturas e ângulos de instalação dos sensores durante todos os períodos de medida da DPM. Para esse propósito, os dados de DPM de Elora, Ames e Piracicaba foram usados para o cálculo das médias $(\bar{X})$. A análise de variância e de dados pareados foram feitas para a comparação das médias de DPM obtidas pelos sensores nas diferentes posições.

Finalmente, os dados de DPM obtidos sobre o gramado com os sensores a $30 \mathrm{~cm}$ e na posição mais elevada, próxima dos sensores de T, UR e U (190 cm em Elora, 150 
cm em Ames e 170 cm em Piracicaba), foram correlacionados, por regressão linear simples, com os dados obtidos no topo das culturas do milho, melão e algodão.

\subsection{Resultados}

\subsubsection{Posição dos sensores versus observação visual da DPM sobre o gramado}

Em Elora, a altura de medida da DPM teve efeito mais pronunciado na deposição e evaporação do orvalho do que o ângulo de exposição do sensor em relação à horizontal (Tabela 5.2). Para os sensores instalados com ângulo de $30^{\circ}$, o EAM entre as observações visuais no gramado e as medidas de deposição do orvalho decresceu de 42,5 minutos, para o sensor a $190 \mathrm{~cm}$ de altura, para 23,6 minutos, para o sensor a 30 cm. Para o secamento do orvalho, essa variação foi ainda maior, com o EAM variando de 46,5 minutos, para o sensor a $190 \mathrm{~cm}$, a 20,4 minutos, para o sensor a $30 \mathrm{~cm}$. O mesmo padrão foi observado para o secamento do orvalho em Piracicaba (Tabela 5.3), onde o EAM variou de 55,8 minutos, para o sensor a $190 \mathrm{~cm}$, a 42,5 minutos, para o sensor a $30 \mathrm{~cm}$. A tendência dos sensores, com exceção para aquele a $70 \mathrm{~cm}$ de altura em Elora e Piracicaba e a $110 \mathrm{~cm}$ de altura em Piracicaba, foi de responder mais tarde à deposição do orvalho (EM positivo) e mais cedo ao secamento (EM negativo) do que o observado visualmente (Tabelas 5.2 e 5.3).

Para os diferentes ângulos de exposição dos sensores, instalados a 30 cm sobre o gramado em Elora, a comparação entre as observações visuais e as medidas não mostraram uma clara diferença, especialmente entre os sensores com 15, 30 e $45^{\circ}$ em 
relação à horizontal (Table 5.2). Para a deposição do orvalho, o EAM variou de 19,3 a 23,6 minutos e para o seu secamento o EAM variou de 19,1 a 23,2 minutos. O sensor instalado com ângulo de $0^{\circ}$ teve um EAM similar aos demais ângulos para a deposição do orvalho, porém com o secamento sendo consistentemente mais cedo (EAM = 31,4 minutos e $\mathrm{EM}=-31,4$ minutos), o que está relacionado ao fato do sensor com esse ângulo ficar mais exposto à radiação solar durante o período da manhã.

Em Piracicaba, o sensor com ângulo de $45^{\circ}$ foi aquele que apresentou o menor EAM durante o secamento em comparação aos sensores instalados com ângulos de $0^{\circ} \mathrm{e}$ $30^{\circ}$. As diferenças entre os EAMs dos sensores instalados em diferentes ângulos também foram pequenas, no entanto, as diferenças entre os valores do EM mostraram que o sensor a $0^{\circ}$ teve tendência de medir o secamento do orvalho consistentemente mais tarde enquanto que os sensores com ângulo de $30^{\circ}$ e $45^{\circ}$ normalmente mediram o secamento do orvalho respectivamente 25 e 33 minutos mais tarde. Esse padrão, mais uma vez, está relacionado à exposição do sensor à radiação solar durante o período da manhã. Em Piracicaba (Lat $=22^{\circ} 42^{\prime} \mathrm{S}$ ), durante o inverno, os sensores instalados voltados para o norte a $30^{\circ}$ e $45^{\circ}$ receberam mais energia solar do que o sensor com $0^{\circ}$. Exatamente o oposto foi observado em Elora (Lat $=43^{\circ} 49^{\prime} \mathrm{N}$ ), onde durante o verão o sensor com ângulo de $0^{\circ}$ foi o que recebeu mais energia em comparação aos demais sensores instalados voltados para o norte.

Considerando os resultados apresentados acima, o sensor instalado sobre uma área gramada a $30 \mathrm{~cm}$ de altura e com um ângulo de $30^{\circ}$ em relação à horizontal foi selecionado, por conveniência, como referência para se comparar as medidas da DPM pelos demais sensores, durante as demais análises deste estudo. 
Tabela 5.2 - Diferença entre a medida e a observação visual dos horários de deposição e do secamento do orvalho, considerando-se os sensores instalados com diferentes alturas e ângulos de exposição sobre o gramado, em Elora, ON, Canadá, durante o verão de 2003. $\mathrm{EAM}=$ erro absoluto médio e EM = erro médio.

\begin{tabular}{|c|c|c|c|c|c|c|c|c|c|c|}
\hline \multicolumn{11}{|c|}{ Deposição do orvalho } \\
\hline \multirow{3}{*}{ Dia } & \multicolumn{10}{|c|}{ Diferença = medido - observado (min) } \\
\hline & Horário* & \multicolumn{5}{|c|}{ Altura dos sensores $\left(\right.$ a $\left.30^{\circ}\right)$ - cm } & \multicolumn{4}{|c|}{ Ângulo dos sensores $($ a $30 \mathrm{~cm})$} \\
\hline & & 190 & 150 & 110 & 70 & 30 & $0^{\circ}$ & $15^{\circ}$ & $30^{\circ}$ & $45^{\circ}$ \\
\hline $30 / 08$ & 20:15 & 30,0 & 30,0 & 30,0 & 15,0 & 0,0 & 0,0 & 0,0 & 0,0 & 0,0 \\
\hline 05/09 & 19:45 & - & 30,0 & 60,0 & 15,0 & 15,0 & 0,0 & 0,0 & 15,0 & 0,0 \\
\hline 06/09 & 20:15 & 30,0 & 0,0 & 0,0 & $-15,0$ & $-15,0$ & $-15,0$ & $-15,0$ & $-15,0$ & $-15,0$ \\
\hline $11 / 09$ & 20:15 & 60,0 & 60,0 & 45,0 & 45,0 & 60,0 & $-30,0$ & $-15,0$ & 60,0 & 45,0 \\
\hline $12 / 09$ & 20:15 & 45,0 & 0,0 & $-15,0$ & $-30,0$ & 45,0 & $-30,0$ & $-30,0$ & 45,0 & $-15,0$ \\
\hline 13/09 & 20:15 & $-60,0$ & $-60,0$ & $-60,0$ & $-75,0$ & $-15,0$ & $-60,0$ & $-75,0$ & -15 & $-60,0$ \\
\hline \multirow[t]{3}{*}{$14 / 09$} & 19:00 & 30,0 & 30,0 & $-15,0$ & $-15,0$ & 15,0 & 15,0 & 0,0 & $-15,0$ & 0,0 \\
\hline & EAM & 42,5 & 30,0 & 32,1 & 30,0 & 23,6 & 21,4 & 19,3 & 23,6 & 19,3 \\
\hline & EM & 22,5 & 12,9 & 6,4 & $-8,6$ & 15,0 & $-17,1$ & $-19,3$ & 15,0 & $-6,4$ \\
\hline \multicolumn{11}{|c|}{ Secamento do orvalho } \\
\hline \multirow{3}{*}{ Dia } & \multirow{3}{*}{ Horário* } & \multicolumn{9}{|c|}{ Diferença = medido - observado (min) } \\
\hline & & \multicolumn{5}{|c|}{ Altura dos sensores $\left(\mathrm{a} 30^{\circ}\right)-\mathrm{cm}$} & \multicolumn{4}{|c|}{ Ângulo dos sensores (a 30cm) } \\
\hline & & 190 & 150 & 110 & 70 & 30 & $0^{\circ}$ & $15^{\circ}$ & $30^{\circ}$ & $45^{\circ}$ \\
\hline $31 / 08$ & 10:15 & $-45,0$ & $-60,0$ & $-30,0$ & $-45,0$ & $-45,0$ & $-45,0$ & 0,0 & $-45,0$ & $-15,0$ \\
\hline 04/09 & 09:45 & 0,0 & $-45,0$ & 0,0 & 15,0 & 0,0 & 0,0 & 45,0 & 0,0 & 0,0 \\
\hline 06/09 & 10:00 & - & 0,0 & 15,0 & 30,0 & $-15,0$ & $-30,0$ & 30,0 & $-15,0$ & $-45,0$ \\
\hline 08/09 & 09:30 & $-90,0$ & $-90,0$ & $-60,0$ & $-45,0$ & $-15,0$ & $-30,0$ & $-15,0$ & $-15,0$ & $-30,0$ \\
\hline 09/09 & 10:00 & $-75,0$ & $-75,0$ & $-45,0$ & $-30,0$ & $-30,0$ & $-30,0$ & 0,0 & $-30,0$ & 0,0 \\
\hline $10 / 09$ & 10:30 & $-45,0$ & $-60,0$ & $-30,0$ & $-15,0$ & $-45,0$ & $-30,0$ & 30,0 & $-45,0$ & $-45,0$ \\
\hline $12 / 09$ & & $-45,0$ & $-45,0$ & $-45,0$ & $-45,0$ & 0,0 & $-30,0$ & 0,0 & 0,0 & $-15,0$ \\
\hline $13 / 09$ & $10: 00$ & $-45,0$ & $-45,0$ & -15 & 0,0 & $-30,0$ & $-30,0$ & 15,0 & $-30,0$ & 15,0 \\
\hline $17 / 09$ & 10:30 & $-45,0$ & $-60,0$ & $-15,0$ & $-15,0$ & $-15,0$ & $-45,0$ & 30,0 & $-15,0$ & $-45,0$ \\
\hline 20/09 & $10: 00$ & $-45,0$ & $-45,0$ & $-45,0$ & $-45,0$ & $-15,0$ & $-30,0$ & $-15,0$ & $-15,0$ & $-30,0$ \\
\hline \multirow[t]{3}{*}{$24 / 09$} & $10: 30$ & $-30,0$ & $-30,0$ & $-30,0$ & $-30,0$ & $-15,0$ & $-45,0$ & $-30,0$ & $-15,0$ & $-15,0$ \\
\hline & EAM & 46,5 & 50,4 & 30,0 & 25,9 & 20,4 & 31,4 & 19,1 & 20,4 & 23,2 \\
\hline & EM & $-46,5$ & $-50,4$ & $-27,3$ & $-20,4$ & $-20,4$ & $-31,4$ & 5,4 & $-20,4$ & $-20,4$ \\
\hline
\end{tabular}

* Horário quando a deposição ou o secamento do orvalho foram observados visualmente.

A performance do sensor de DPM instalado na cultura do milho (no topo da cultura e com ângulo de $30^{\circ}$ ) também foi avaliada, pela comparação das medidas com as observações visuais (Tabela 5.4). As diferenças entre a observação visual e as medidas foram similares àquelas obtidas com os sensores instalados sobre o gramado, com EAM 
de 25,0 minutos, para a deposição do orvalho, e de 10,4 minutos, para o seu secamento. Nesse caso, entretanto, o EM mostrou uma tendência clara de detecção antecipada do orvalho no início da noite e uma fraca tendência de secamento precoce durante a manhã pelo sensor em relação à observação visual. Esses resultados são similares às diferenças da ordem de 15 a 30 minutos entre as medidas pelos sensores e as observações visuais obtidas por Pedro Jr. (1980), para folhas de milho e soja, e por Lau et al. (2000), para folíolos de tomate, o que confirma a capacidade do sensor estudado para medir a DPM em diferentes culturas.

Tabela 5.3 - Diferença entre a medida e a observação visual dos horários de secamento do orvalho, considerando-se os sensores instalados com diferentes alturas e ângulos de exposição sobre o gramado, em Piracicaba, SP, Brasil, durante o inverno de 2003. EAM = erro absoluto médio e EM = erro médio.

\begin{tabular}{|c|c|c|c|c|c|c|c|c|c|c|}
\hline \multicolumn{11}{|c|}{ Secamento do orvalho } \\
\hline \multirow{3}{*}{ Dia } & \multirow{3}{*}{ Horário* } & \multicolumn{9}{|c|}{ Diferença = medido - observado (min) } \\
\hline & & \multicolumn{5}{|c|}{ Altura dos sensores (a $30^{\circ}$ ) - cm } & \multicolumn{4}{|c|}{ Ângulo dos sensores (a 150cm) } \\
\hline & & 190 & 150 & 110 & 70 & 30 & $0^{\circ}$ & $15^{\circ}$ & $30^{\circ}$ & $45^{\circ}$ \\
\hline $31 / 07$ & $8: 10$ & 20,0 & 20,0 & 10,0 & $-10,0$ & 40,0 & 30,0 & - & 20,0 & 20,0 \\
\hline $01 / 08$ & 8:40 & 40,0 & 20,0 & 30,0 & 40,0 & 40,0 & 40,0 & - & 20,0 & 10,0 \\
\hline 07/08 & 9:20 & 40,0 & 40,0 & 10,0 & 20,0 & 20,0 & 100,0 & - & 40,0 & 30,0 \\
\hline $13 / 08$ & 10:30 & $-30,0$ & 10,0 & $-50,0$ & 0,0 & $-10,0$ & 30,0 & - & 10,0 & $-40,0$ \\
\hline $14 / 08$ & 8:30 & 30,0 & 50,0 & 10,0 & 30,0 & 60,0 & 110,0 & - & 50,0 & 20,0 \\
\hline $27 / 08$ & 9:30 & $-120,0$ & $-130,0$ & - & $-80,0$ & $-80,0$ & - & - & $-130,0$ & $-120,0$ \\
\hline $28 / 08$ & 9:00 & $-240,0$ & $-180,0$ & - & $-110,0$ & $-110,0$ & - & - & $-180,0$ & $-180,0$ \\
\hline $29 / 08$ & $8: 10$ & $-50,0$ & $-40,0$ & 150,0 & $-20,0$ & $-10,0$ & - & - & $-40,0$ & $-50,0$ \\
\hline 03/09 & 8:45 & $-25,0$ & $-35,0$ & 55,0 & 125,0 & $-5,0$ & - & - & $-35,0$ & $-35,0$ \\
\hline 04/09 & 8:20 & 0,0 & 0,0 & 60,0 & 70,0 & 20,0 & - & - & 0,0 & $-10,0$ \\
\hline 05/09 & 8:00 & $-100,0$ & $-100,0$ & 20,0 & 30,0 & $-60,0$ & - & - & $-100,0$ & $-70,0$ \\
\hline $17 / 09$ & 8:00 & 10,0 & 0,0 & 20,0 & 20,0 & 30,0 & 20,0 & - & 0,0 & $-10,0$ \\
\hline $18 / 09$ & $7: 50$ & 20,0 & 20,0 & 30,0 & 30,0 & 30,0 & 30,0 & - & 20,0 & 10,0 \\
\hline \multirow[t]{3}{*}{$19 / 09$} & 8:00 & - & - & $-90,0$ & $-50,0$ & $-80,0$ & - & - & - & - \\
\hline & EAM & 55,8 & 49,8 & 44,6 & 45,4 & 42,5 & 51,4 & - & 49,8 & 46,5 \\
\hline & EM & $-31,2$ & $-25,0$ & 21,3 & 6,8 & $-8,2$ & 51,4 & - & $-25,0$ & $-32,7$ \\
\hline
\end{tabular}

* Horário quando a deposição ou o secamento do orvalho foram observados visualmente. 
Tabela 5.4 - Diferença entre a medida e a observação visual dos horários de deposição e do secamento do orvalho, considerando-se o sensor instalado no topo da cultura do milho, em Elora, ON, Canadá, durante o verão de 2003. EAM = erro absoluto médio e EM = erro médio. Diferença = medido - observado.

\begin{tabular}{|c|c|c|c|c|c|}
\hline \multicolumn{3}{|c|}{ Deposição de orvalho } & \multicolumn{3}{|c|}{ Secamento do orvalho } \\
\hline Dia & Horário* & $\begin{array}{l}\text { Diferença** } \\
\text { (min) }\end{array}$ & Dia & Horário* & $\begin{array}{l}\text { Diferença** } \\
\text { (min) }\end{array}$ \\
\hline 27/08 & $20: 30$ & $-15,0$ & 28/08 & $10: 45$ & 0,0 \\
\hline $28 / 08$ & 21:00 & $-45,0$ & $29 / 08$ & $12: 00$ & $-30,0$ \\
\hline $30 / 08$ & 21:15 & 0,0 & $31 / 08$ & 10:30 & 0,0 \\
\hline 05/09 & 19:45 & 15,0 & 04/09 & 10:15 & $-15,0$ \\
\hline 06/09 & 20:15 & $-15,0$ & 06/09 & $10: 30$ & 15,0 \\
\hline $11 / 09$ & 21:15 & $-30,0$ & 08/09 & 9:30 & $-15,0$ \\
\hline $12 / 09$ & $20: 15$ & $-30,0$ & 09/09 & $10: 30$ & $-15,0$ \\
\hline $13 / 09$ & 20:00 & $-45,0$ & $10 / 09$ & 11:00 & $-15,0$ \\
\hline \multirow[t]{7}{*}{$14 / 09$} & 19:45 & $-30,0$ & $12 / 09$ & 10:15 & $-15,0$ \\
\hline & & & $13 / 09$ & 10:15 & 0 \\
\hline & & & $17 / 09$ & $10: 45$ & 15,0 \\
\hline & & & 20/09 & 9:45 & 0,0 \\
\hline & & & $24 / 09$ & 10:30 & 0,0 \\
\hline & EAM & 25,0 & & EAM & 10,4 \\
\hline & EM & $-21,7$ & & EM & $-5,8$ \\
\hline
\end{tabular}

* Horário quando a deposição ou o secamento do orvalho foram observados visualmente.

\subsubsection{Variabilidade entre os sensores de DPM}

A Figura 5.4 apresenta a variabilidade entre os sensores de DPM em termos das diferenças absolutas e relativas entre a medida de cada sensor e a média de todos eles para o horário da deposição e do secamento do orvalho. A diferença absoluta média (DAM) para a deposição do orvalho foi de 7 minutos e para o secamento foi de 15 minutos. O CV\% para a DPM foi de 2,35\% (Figura 5.5), ou aproximadamente 22 minutos, considerando-se a DPM média diária medida pelos sensores, igual a 15,93 h. De acordo com Pedro (1980) e Magarey (1999), diferenças de 15 a 30 minutos entre a observação visual e as medidas não são significativas para fins operacionais, em razão 
dos erros inerentes à medida e à observação, que são conseqüência da variabilidade espacial da ocorrência do molhamento na vegetação. Essa variabilidade entre os sensores foi empregada para se interpretar os dados de DPM obtidos em diferentes posições, considerando-se as diferenças desprezíveis quando elas foram inferiores a 22 minutos.
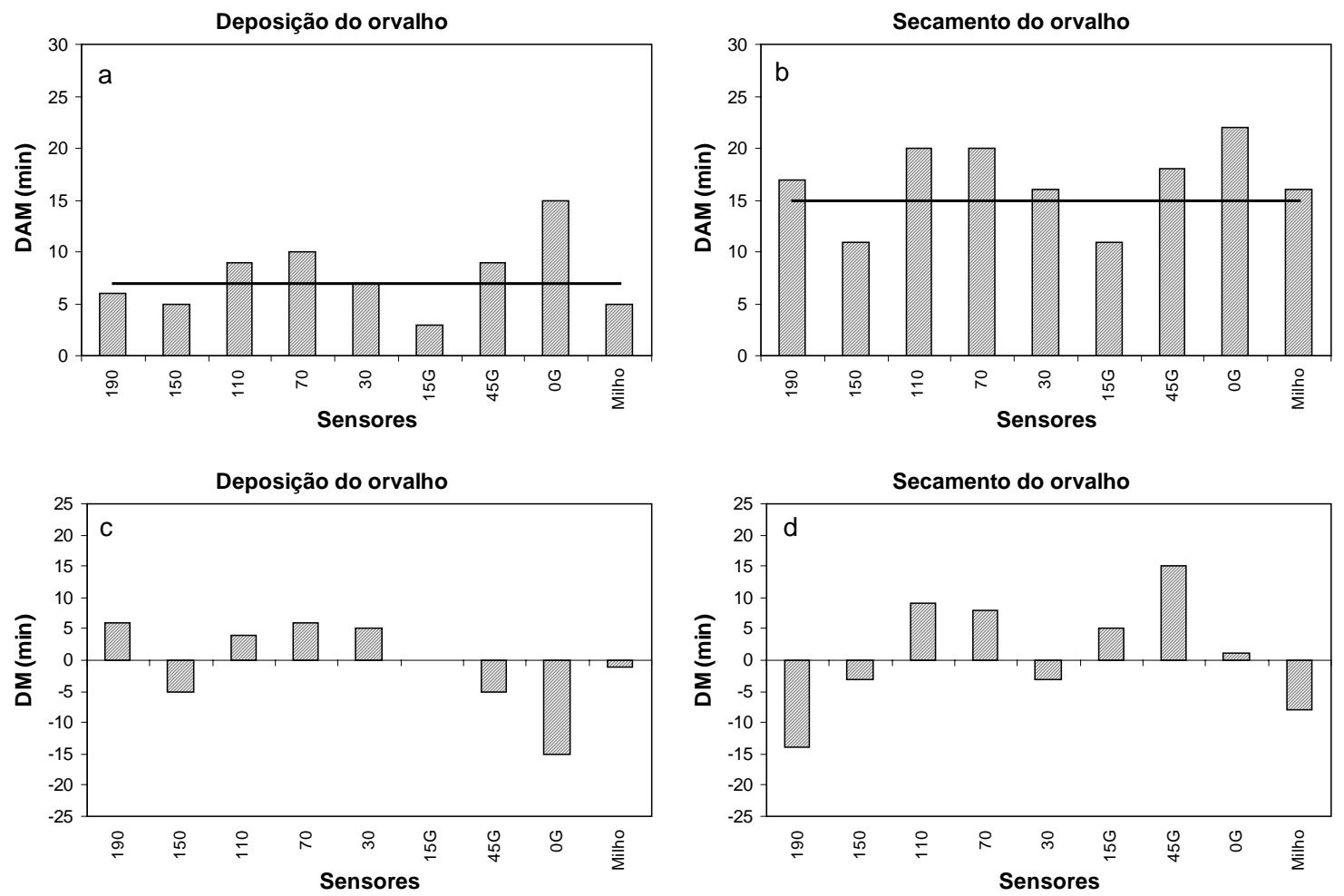

Figura 5.4 - Variabilidade entre os sensores de DPM quando foram instalados à mesma altura $(30 \mathrm{~cm})$ e ângulo $\left(30^{\circ}\right)$. No eixo $\mathrm{X}$ têm-se as posições em que esses sensores foram utilizados durante o período de medidas: $190=190 \mathrm{~cm}$ e $30^{\circ} ; 150=150 \mathrm{~cm}$ e $30^{\circ}$; $110=110 \mathrm{~cm}$ e $30^{\circ} ; 70=70 \mathrm{~cm}$ e $30^{\circ} ; 30=30 \mathrm{~cm}$ e $30^{\circ} ; 15 \mathrm{G}=30 \mathrm{~cm}$ e $15^{\circ} ; 45 \mathrm{G}=30$ $\mathrm{cm}$ e $45^{\circ} ; 0 \mathrm{G}=30 \mathrm{~cm}$ e $0^{\circ}$; e Milho $=$ no topo da cultura do milho a $30^{\circ}$. A linha contínua representa a média. 


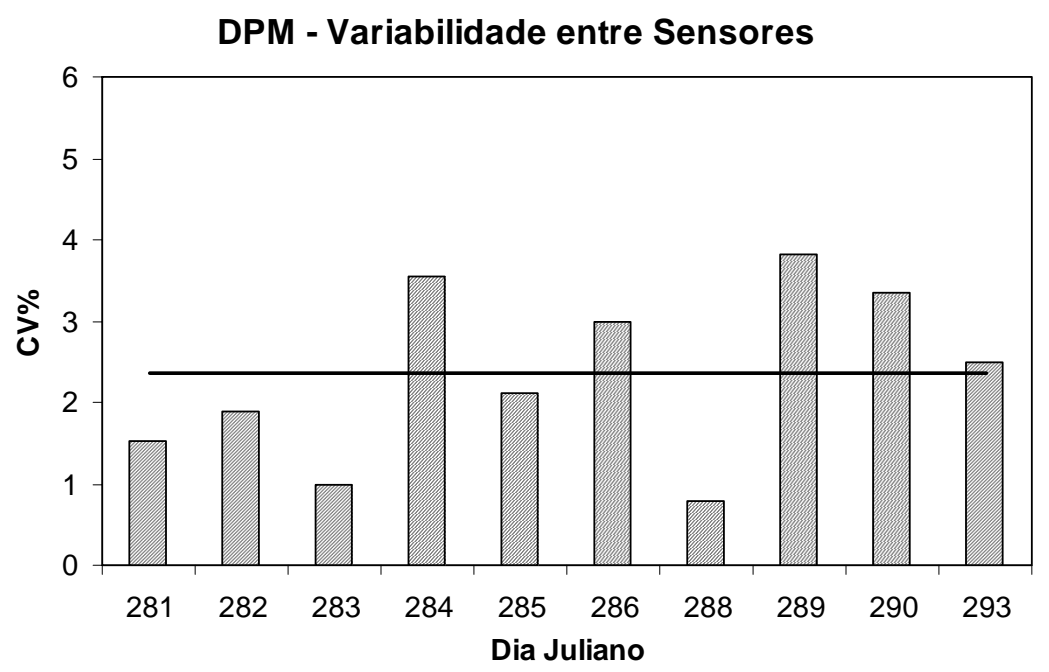

Figura 5.5 - Coeficientes de variação diários (barra) e médio (linha) da medida da DPM por todos os sensores instalados na mesma altura $(30 \mathrm{~cm})$ e ângulo $\left(30^{\circ}\right)$.

\subsubsection{Efeito das diferentes alturas e ângulos dos sensores na medida da DPM}

Considerando-se todo o período de medidas sobre o gramado, com um total de 71 dias em Elora, 69 dias em Ames e 50 dias em Piracicaba, comparou-se os dados de DPM obtidos com os sensores instalados a diferentes alturas e ângulos, assumindo-se o sensor a 30 cm de altura e com um ângulo de exposição de $30^{\circ}$ como referência (Figuras 5.6 e 5.7). Foi possível se identificar diferenças estatisticamente significativas entre as DPMs medidas com os sensores a diferentes alturas e ângulos, mostrando que a posição do sensor tem forte efeito na medida dessa variável.

Os sensores a 190 cm de altura mediram, em média, uma DPM mais curta - 97 minutos em Elora e 54 minutos em Piracicaba - do que os sensores a $30 \mathrm{~cm}$. Não foi observada diferença significativa entre os sensores a 30 e $70 \mathrm{~cm}$ em ambos os locais. Por 
outro lado, diferenças foram observadas em Elora entre os sensores instalados a 110, 150 e $190 \mathrm{~cm}$ de altura, enquanto que em Piracicaba nenhuma diferença foi observada entre esses sensores, exceto entre os sensores a 110 e $150 \mathrm{~cm}$ de altura (Figura 5.6). Em Ames, a diferença média de 33 minutos entre os sensores a 30 e $150 \mathrm{~cm}$ de altura, ambos $\operatorname{com} 45^{\circ}$ de inclinação, foi significativa.

a) Elora, ON, Canadá

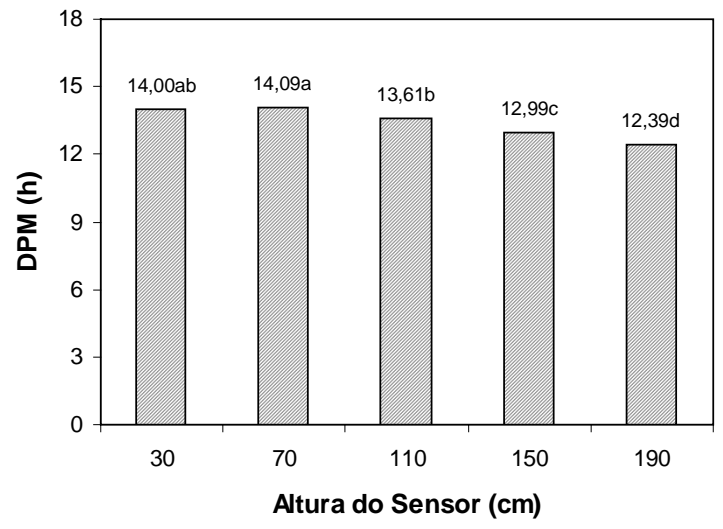

b) Piracicaba, SP, Brasil

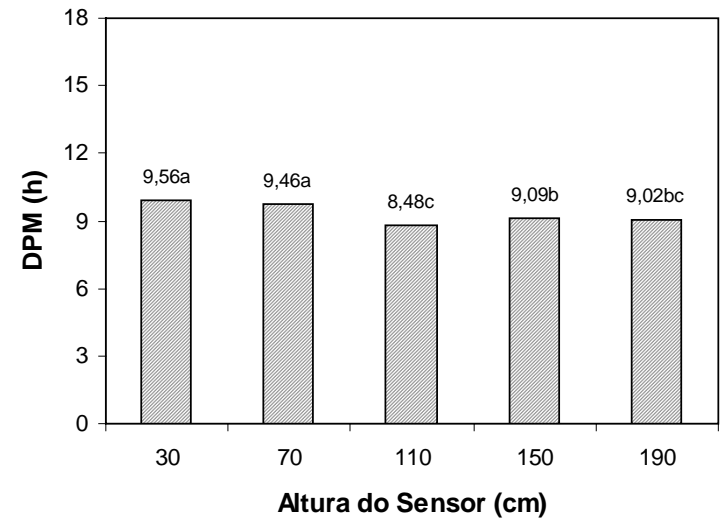

c) Ames, IA, Estados Unidos

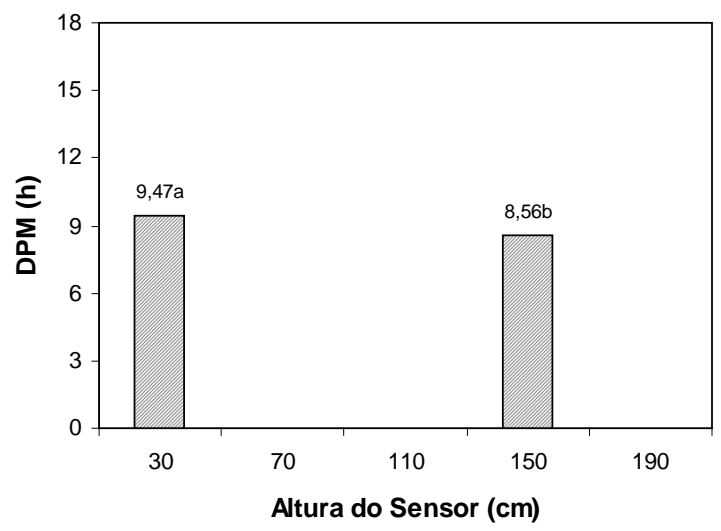

Figura 5.6 - DPM média obtida com os sensores instalados a diferentes alturas e com um ângulo de exposição de $30^{\circ}$ em Elora (a) e Piracicaba (b) e de $45^{\circ}$ em Ames (c). As médias de DPM, sobre as barras, seguidas da mesma letra não diferem significativamente entre si ao nível de $1 \%$ de probabilidade. 
Em relação ao ângulo de exposição dos sensores em relação à horizontal (Figura 5.7), os sensores com $0^{\circ}$ e $15^{\circ}$ de inclinação mediram, em média, uma DPM mais longa - 38 minutos em Elora e 56 minutos em Piracicaba - do que os sensores com $30^{\circ}$ e $45^{\circ}$. Os sensores instalados com menores ângulos em relação à horizontal normalmente ficam mais voltados para o céu do que aqueles com ângulos maiores, resultando em um processo de resfriamento mais intenso durante a noite e, conseqüentemente, em uma maior deposição de orvalho. Esses ângulos de exposição também permitem que os sensores acumulem uma maior quantidade de água, requerendo mais tempo para a sua evaporação durante a manhã seguinte. Em Elora, nenhuma diferença significativa foi observada entre os sensores com $30^{\circ}$ e $45^{\circ}$ de inclinação (Figura 5.7a), mas em Piracicaba a diferença entre os sensores com esses ângulos de inclinação foi significativa e ao redor de 25 minutos (Figura 5.7b).

a) Elora, ON, Canadá

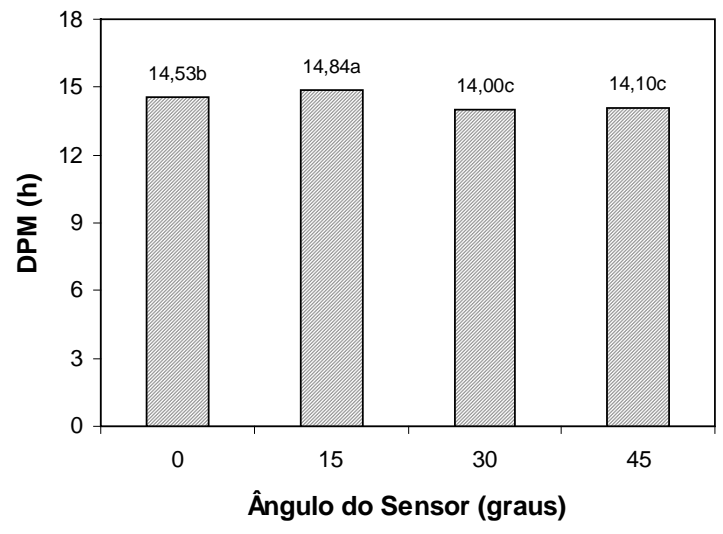

b) Piracicaba, SP, Brasil

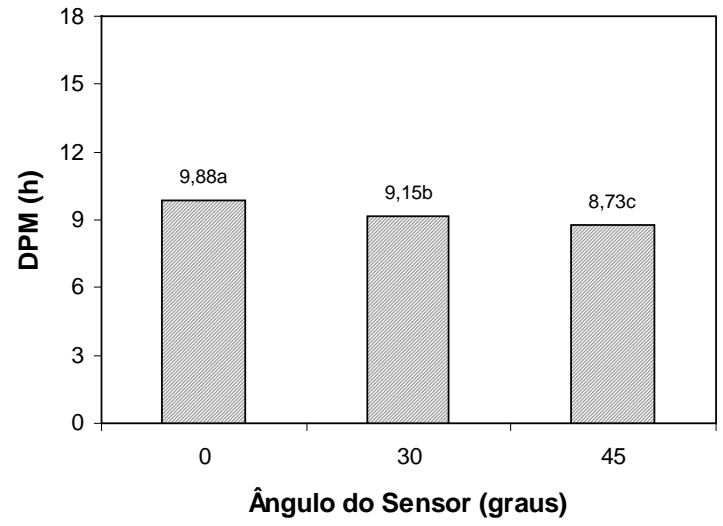

Figura 5.7 - DPM média obtida com os sensores instalados com diferentes ângulos de exposição em relação à horizontal e a uma altura de 30 cm em Elora (a) e Piracicaba (b). As médias de DPM, sobre as barras, seguidas da mesma letra não diferem significativamente entre si ao nível de $1 \%$ de probabilidade. 


\subsubsection{Relação entre a DPM medida na estação meteorológica e em três diferentes culturas}

Uma escolha óbvia para se instalar um sensor “padrão” de medida da DPM em uma estação meteorológica seria na mesma altura do abrigo, onde se encontram os sensores para a medida da temperatura e da umidade relativa. As regressões lineares entre os dados de DPM obtidos pelos sensores instalados na posição mencionada anteriormente, sobre o gramado em Elora $(190 \mathrm{~cm})$ e Ames $(150 \mathrm{~cm})$ e sobre solo nú em Piracicaba $(170 \mathrm{~cm})$, e aqueles medidos no topo das culturas do milho $(\sim 240 \mathrm{~cm})$, do melão ( $20 \mathrm{~cm})$ e do algodão $(\sim 100 \mathrm{~cm})$ são apresentadas na Figura 5.8. Principalmente para o milho e para o algodão, e em menor grau para o melão, as relações mostram uma correlação bem definida entre a DPM próxima do abrigo meteorológico e aquela medida junto às culturas, apesar das diferenças nas suas alturas, áreas foliares e estruturas. Para as culturas do milho e do algodão a dispersão dos dados $\left(\mathrm{R}^{2}\right.$ milho $=0,83$ e $\left.\mathrm{R}_{\text {algodão }}^{2} 0,92\right)$ foi menor do que aquela obtida para o melão $\left(\mathrm{R}^{2}\right.$ melão $=$ 0,65), o que se deve, provavelmente, às diferenças de altura entre os sensores na cultura e na estação meteorológica. Entretanto, todas as relações mostraram a mesma tendência, com as culturas apresentando maiores valores de DPM para os períodos com até 15 h de molhamento. Para os períodos com DPM > 15 h, causados principalmente por chuva (Figura 5.8), uma menor diferença foi observada entre a DPM medida na cultura e na estação meteorológica. 
a) Milho, Elora

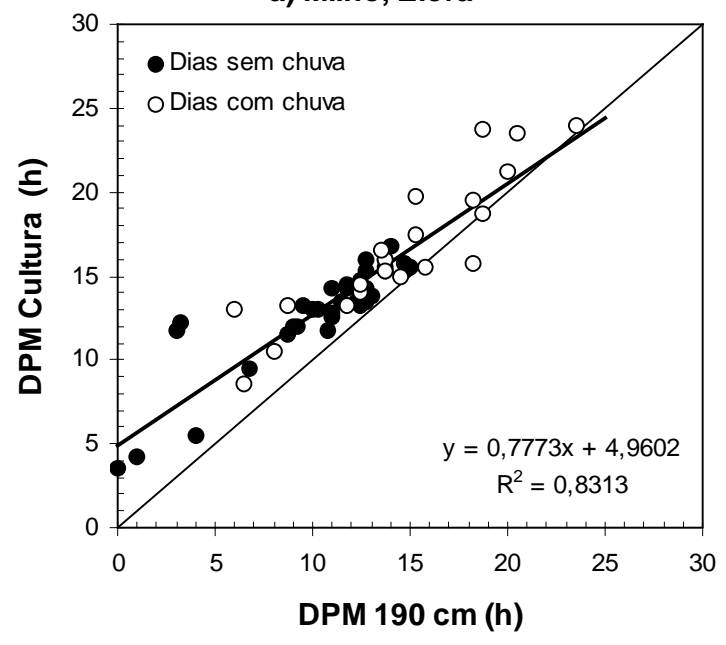

b) Algodão, Piracicaba

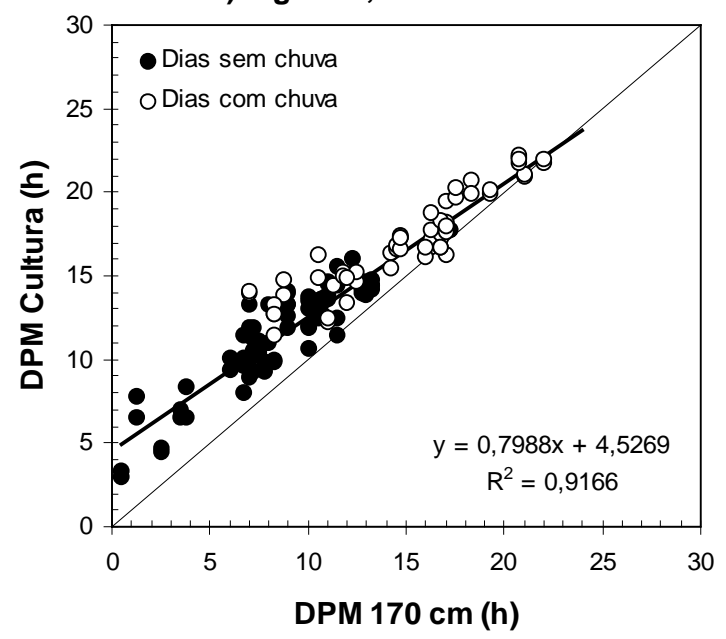

c) Melão, Ames

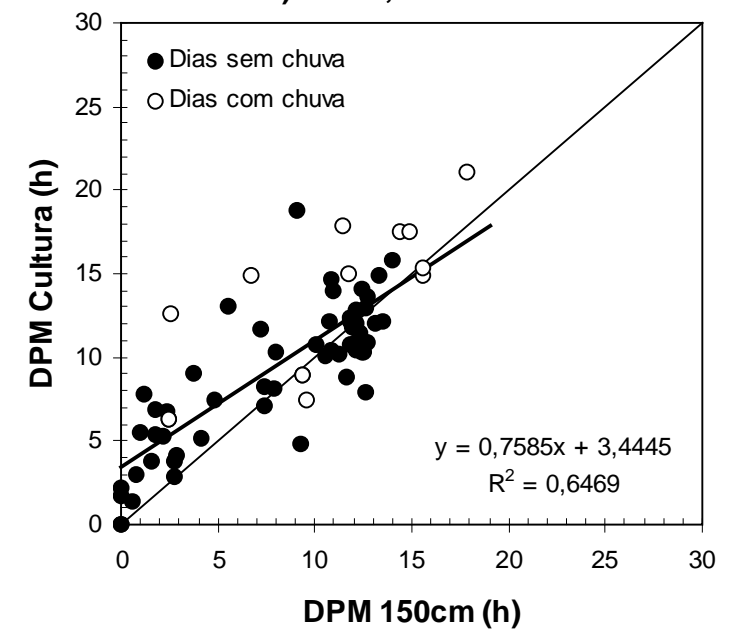

Figura 5.8 - Relação entre a DPM medida no topo da cultura e na posição mais alta sobre o gramado/solo em: a) Elora (gramado a $190 \mathrm{~cm}$ e milho a $240 \mathrm{~cm}$ ), b) Piracicaba (solo nú a 170 cm e algodão a 100 cm) e c) Ames (gramado a 150 cm e melão a 20 cm).

Quando os dados de DPM das culturas do milho e do melão foram comparadas com os dados de DPM obtidos a $30 \mathrm{~cm}$ sobre o gramado (Figura 5.9), as relações entre essas variáveis foi consideravelmente melhorada, com o coeficiente ângular (b) sendo de 
1,03 para o milho e de 1,02 para o melão, e os valores de $\mathrm{R}^{2}$ se elevando para 0,93 para o milho e 0,84 para o melão. A relação entre as DPMs, causadas tanto pelo orvalho como pela chuva, observada na cultura e a $30 \mathrm{~cm}$ sobre gramado mostrou ser pouco influenciada pelas grandes diferenças na arquitetura das plantas, especialmente tamanho e área das folhas e altura da cultura.

a) Milho, Elora

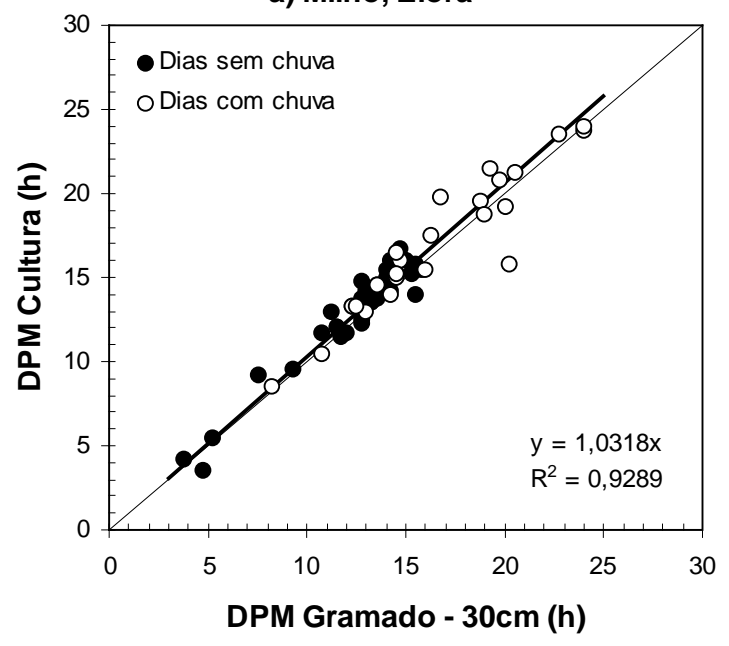

b) Melão, Ames

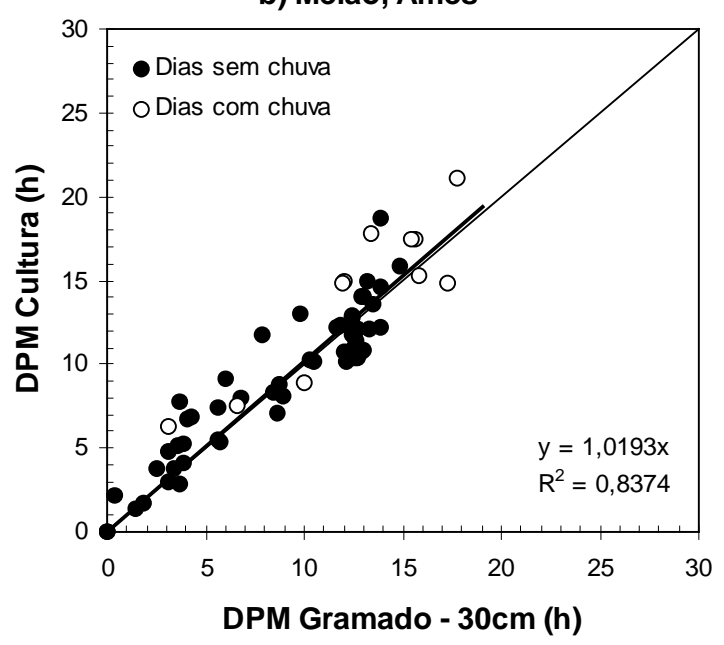

Figura 5.9 - Relação entre a DPM medida no topo da cultura e a $30 \mathrm{~cm}$ sobre o gramado em: a) Elora (milho a $240 \mathrm{~cm}$ ) e b) Ames (melão a $20 \mathrm{~cm}$ ).

\subsection{Discussão}

As análises apresentadas neste estudo mostraram que a altura e ângulo de exposição dos sensores de DPM têm um forte efeito nas medidas sobre o gramado. Comparando-se os dados dos sensores com as observações visuais, foi verificado que a altura de instalação do sensor tem muito mais influência na medida da DPM do que o 
seu ângulo de inclinação. Baseando-se nessa comparação, os sensores instalados a 30 cm de altura e com $15^{\circ}, 30^{\circ}$ ou $45^{\circ}$ de inclinação foram os que apresentaram os menores erros. Esses resultados são similares aos encontrados por Lau et al. (2000), que identificaram o ângulo de $45^{\circ}$ como sendo o melhor para a medida da DPM na cultura do tomate, e por Gillespie e Kidd (1978) que também testaram diferentes ângulos de inclinação dos sensores de DPM na cultura da cebola e concluíram que o sensor com $20^{\circ}$ de inclinação foi melhor do que aquele com $60^{\circ}$. No caso deste estudo, para noites e manhãs de observação visual, o sensor com $15^{\circ}$ de inclinação mediu o secamento do orvalho com elevada acurácia ( $\mathrm{EM}=$ 5,4 minutos), porém mostrou medir a deposição do orvalho muito cedo $(\mathrm{EM}=-19,3 \mathrm{~min})$. Considerando-se todo o período de medidas, o sensor exposto com $15^{\circ}$ mediu DPMs mais longas (40 a 50 minutos) do que os sensores a $30^{\circ}$ e $45^{\circ}$ (Figura 5.7), provavelmente por causa da sua maior exposição ao céu durante a noite.

Considerando-se o sensor instalado a $30 \mathrm{~cm}$ e com $30^{\circ}$ de inclinação como referência e que a variabilidade entre os sensores usados foi muito pequena $(\mathrm{CV}=$ 2,35\%), quando instalados na mesma altura e ângulo, foi possível se identificar claramente o efeito das diferentes posições dos sensores na medida da DPM. Esse efeito já havia sido relatado anteriormente na medida da DPM em diferentes culturas (Davis e Hughes, 1970; Gillespie e Kidd, 1978; Lau et al., 2000), porém esse é o primeiro estudo que documenta a influência de diferentes alturas e ângulos dos sensores para a escolha de uma condição padrão de observação da DPM em estação meteorológica. Baseando-se nos resultados aqui apresentados, foi observado que o ângulo de inclinação dos sensores, 
exceto a $0^{\circ}$, é menos crítico para a medida da DPM do que a altura e que há uma relação inversa entre a altura do sensor e a DPM nos locais estudados.

A DPM obtida por sensores instalados sobre o gramado, tanto próximo do abrigo meteorológico como a 30 cm de altura, mostrou correlação bem definida com a DPM medida no topo de diferentes culturas, para os locais deste estudo, porém a relação com a DPM medida a $30 \mathrm{~cm}$ foi muito maior. Para as culturas do milho e do melão, o uso das observações de DPM feitas a $30 \mathrm{~cm}$ de altura sobre o gramado para estimar a DPM ao nível das culturas resultou em superestimativas médias de apenas 2 a 3\% (Figura 5.9), as quais são similares em magnitude à variabilidade apresentada pelos sensores. Gleason et al. (1994), visando evitar interferência nas práticas de campo dos agricultores, usaram dados de DPM, obtidos por sensores instalados a $30 \mathrm{~cm}$ de altura sobre o gramado, em um sistema de controle de doenças. Os resultados aqui apresentados confirmam que Gleason et al. (1994) fizeram uma boa escolha para o posicionamento dos sensores de DPM em seus estudos. O fato de que a DPM medida por sensores expostos a $30 \mathrm{~cm}$ de altura e com $30^{\circ}$ de inclinação também simularam bem a DPM de culturas altas, como a do milho, foi uma surpresa.

Baseando-se nesses resultados, sugere-se que um sensor a $30 \mathrm{~cm}$ e com ângulo de inclinação variando de $30^{\circ}$ a $45^{\circ}$ deva ser considerado como uma possível referência para a medida da DPM em estações meteorológicas. No entanto, mais comparações entre observações, envolvendo outras culturas e regiões climáticas, são recomendáveis. Além disso, tal exposição de referência do sensor de DPM não deve ser adequada quando as culturas nas proximidades são irrigadas e a área da estação meteorológica não. 
Poucos trabalhos na literatura têm tentado correlacionar a DPM sobre gramado, em uma estação meteorológica, com a DPM obtida em culturas em áreas adjacentes. Por outro lado, os modelos mais precisos e exatos para a estimativa da DPM, como Pedro Jr. e Gillespie (1982a, 1982b), Zhang e Gillespie (1990), Gleason et al. (1994), Rao et al. (1998) e Magarey (1999), utilizam dados de estações meteorológicas padrões. A forte correlação obtida neste estudo entre a DPM a $30 \mathrm{~cm}$ sobre gramado e a DPM no topo das culturas reforça a idéia de que se adotar um modelo de base física para estimar a DPM a uma altura de $30 \mathrm{~cm}$ sobre gramado (Madeira et al., 2002) é uma alternativa viável às medidas diretas dessa variável. Esse procedimento é uma forma de modelagem menos complexa do que a de se tentar levar em conta todas as características das diferentes culturas e será objeto de estudo de um dos próximos capítulos.

\subsection{Conclusões}

Os sensores eletrônicos de DPM de placa de circuito impresso, quando propriamente tratados com pintura e calor, dão medidas que são tão precisas e acuradas quanto os limites da amostragem espacial relatados em estudos prévios (Magarey, 1999). Entretanto, a posição, altura e ângulo dos sensores de DPM têm efeito sobre as medidas. Nas posições mais altas a DPM foi menor do que aquela medida a $30 \mathrm{~cm}$ e nos menores ângulos ela foi maior do que nos ângulos maiores. Como padrão para a medida da DPM em uma estação meteorológica, sugere-se uma altura de $30 \mathrm{~cm}$ e ângulo variando entre $30^{\circ}$ e $45^{\circ}$. Quando os dados de DPM do sensor de referência (30 cm sobre gramado e com $30^{\circ}$ de inclinação) foram correlacionados com os dados de DPM medida na parte 
superior de culturas com diferentes características estruturais, uma forte relação foi obtida, o que sugere que a DPM da cultura possa ser suficientemente bem estimada para propósitos operacionais a partir da DPM medida em condição padrão em uma estação meteorológica. 


\section{VARIABILIDADE ESPACIAL DA DURAÇÃO DO PERÍODO DE MOLHAMENTO FOLIAR EM DIFERENTES CULTURAS}

\section{Resumo}

A variabilidade espacial da duração do período de molhamento foliar (DPM) foi avaliada em seis culturas com diferentes alturas e características estruturais: maçã, café, milho, uva, tomate e melão. As medidas de DPM foram feitas usando-se sensores eletrônicos de placa de circuito impresso, instalados em diferentes posições das culturas, com ângulo de inclinação variando de $30^{\circ}$ a $45^{\circ}$ em relação à horizontal. Para a macieira, os sensores foram instalados em doze posições no sentido leste-oeste, sendo quatro de cada um deles no topo (3,3 m), no meio (2,1 m) e em baixo (1,1 m). No cafeeiro jovem, com 80 cm de altura, quatro sensores foram instalados próximos das folhas a 20, 40, 60 e $80 \mathrm{~cm}$ de altura. Nas culturas do milho, da uva e do tomate, os sensores de DPM foram instalados em duas posições, sendo uma logo abaixo do topo das plantas e outro no interior da cultura. Na cultura do melão, apenas um sensor foi instalado logo abaixo do topo da cultura. Ao mesmo tempo e nas proximidades dessas culturas, com exceção para o experimento com tomate, a DPM foi medida sobre gramado, com o mesmo tipo de 
sensor instalado a $30 \mathrm{~cm}$ e com sua inclinação variando entre $30^{\circ}$ e $45^{\circ}$ em relação à horizontal. A avaliação das médias, usando-se o teste "t" para dados pareados, mostrou que a DPM variou entre as diferentes posições nas culturas, especialmente na macieira, no cafeeiro e na cultura do milho. Entretanto, o padrão de variação dependeu da altura e arquitetura das plantas. Para as árvores de maçã e para as plantas de milho, a DPM média foi maior no topo enquanto que para o cafeeiro ela foi maior na parte mais baixa da cultura (saia). Para a videira, cultivada no sistema de espaldeira, e no tomateiro, conduzido sem estaqueamento, a DPM não diferiu entre o topo da cultura e seu interior,

o que também foi assumido para a cultura do melão. A comparação pela análise de regressão entre a DPM medida nas culturas e no gramado mostraram que o sensor a 30 cm de altura sobre o gramado (condição de referência) permitiu uma acurada estimativa da DPM no topo das culturas, apesar das grandes diferenças estruturais entre elas, porém não possibilitou uma boa estimativa da DPM no interior das mesmas.

SPATIAL VARIABILITY OF LEAF WETNESS DURATION IN DIFFERENT CROP CANOPIES

\section{Summary}

The spatial variability of leaf wetness duration (LWD) was evaluated in six different height-architecture crop canopies: apple, coffee, corn, grape, tomato and muskmelon. LWD measurements were made using painted flat plate, printed-circuit wetness sensors deployed in different positions above and inside the crops, with angles 
ranging from $30^{\circ}$ to $45^{\circ}$ to horizontal. For apple trees, the sensors were installed in twelve east-west positions: four at each of the top $(3.3 \mathrm{~m})$, middle $(2.1 \mathrm{~m})$, and bottom (1.1 m) levels. For young coffee plants (80 cm tall), four sensors were installed close to the leaves at heights of 20,40,60, and $80 \mathrm{~cm}$. For the corn, grape, and tomato crops, LWD sensors were installed in two positions, one just below the canopy top and another inside the canopy; while for muskmelon there was one sensor placed near the canopy top. At the same time and places, LWD was measured above nearby mowed turfgrass with the same kind of flat plate sensor, deployed at $30 \mathrm{~cm}$ between $30^{\circ}$ and $45^{\circ}$ to horizontal. The evaluation of averages, using a t-test for paired data, showed that LWD varied among positions in the canopies, especially for apples, coffee, and corn. However, the pattern of variation depended on the plant height and architecture. For apple trees and corn plants the average LWD was longer at the top while for young coffee plants LWD was longer at the bottom. For grapes, cultivated in a hedgerow system, and for tomatoes, grown unstaked, average LWD did not differ between the top and inside the canopy, what was also considered to happen to muskmelon. The comparison by regression analysis between crop and turfgrass LWD measurements, except for tomatoes, showed that sensors at $30 \mathrm{~cm}$ over turfgrass provided quite accurate estimates of LWD at the top of the crops, despite large differences in crop height and structure, but poorer estimates for wetness within leaf canopies. 


\subsection{Introdução}

O microclima da cultura é um fator muito importante na epidemiologia das doenças de plantas. A duração do período de molhamento foliar (DPM), provocada por orvalho, chuva, neblina ou irrigação, junto com a temperatura do ar são os dois mais importantes fatores micrometeorológicos que influenciam a maioria dos fitopatossistemas. Conseqüentemente, eles são usados como variáveis de entrada em diversos sistemas de alerta fitossanitários, os quais aconselham os produtores com relação à real necessidade de uso de defensivos em suas lavouras (Huber e Gillespie, 1992; Gillespie et al., 1993).

A temperatura do ar é muito fácil de ser monitorada, porém a DPM é uma variável de difícil medida ou estimativa, em razão dela não estar relacionada apenas às variáveis atmosféricas, mas também às propriedades ópticas da superfície e ao microclima (Magarey, 1999; Magarey et al., 2001; Madeira et al., 2002). A variabilidade da DPM dentro da cobertura vegetal é um dos principais desafios em se obter uma medida representativa nas diferentes culturas para fins operacionais. O microclima da cobertura vegetal de uma cultura é influenciado por fatores como: área foliar, arquitetura das plantas, sistema de plantio ou arranjo das plantas no campo, altura das plantas, entre outros. Esses fatores controlam a interceptação e o balanço de radiação, determinando os regimes de temperatura, umidade e vento dentro das culturas, que por sua vez irão influenciar a duração do molhamento, permitindo que várias partes das plantas se tornem úmidas ou secas em diferentes momentos (Monteith e Unsworth, 1990; Huber e Gillespie, 1992). 
Apesar dos grandes esforços para se desenvolver precisos sensores eletrônicos para a medida da DPM e métodos para sua estimativa, a variabilidade da DPM em diferentes culturas não tem sido extensivamente estudada. A maioria dos estudos sobre DPM mede essa variável junto ao topo (Wittich, 1995; Francl e Panigrahi, 1997; Chtioui et al., 1999) ou logo abaixo do topo (Pedro e Gillespie 1982a; Pedro e Gillespie, 1982b; Gillespie e Barr, 1984; Sentelhas et al., 2004a) das culturas, considerando-se que essas posições são as mais favoráveis para a ocorrência de molhamento causado por orvalho. Entretanto, a DPM no interior das coberturas vegetais pode ser maior ou menor do que a que ocorre no topo, o que irá depender das características estruturais da cultura e, conseqüentemente, de seu microclima (Monteith e Unsworth, 1990).

Em geral, o microclima dentro das culturas é mais favorável à ocorrência de doenças fúngicas ou bacterianas do que o da parte externa, porém isso não é uma regra para os diferentes tipos de culturas, especialmente para eventos com orvalho. Pedro Jr. (1980), estudando a DPM em folhas de milho e soja ensolaradas e sombreadas, observou que a DPM foi $1 \mathrm{~h}$ mais longa nas folhas sombreadas em ambas as culturas. Por outro lado, Wittich (1995) observou que a DPM foi 2 h mais longa no topo de uma macieira do que no seu interior. Considerando-se essas diferenças, Huber e Gillespie (1992) sugeriram o uso de pelo menos dois sensores para se monitorar a variabilidade da DPM entre o topo e o interior das culturas, para fins operacionais.

Para se entender melhor a variabilidade da DPM em diferentes culturas, o presente estudo foi desenvolvido a partir da medida da DPM em diversas posições em seis diferentes culturas: maçã, café, milho, uva, tomate e melão. O objetivo foi estabelecer padrões de variabilidade e avaliar a influência da estrutura da cobertura 
vegetal dessas culturas na variabilidade espacial da DPM. A relação entre a DPM medida em diferentes posições nas culturas e a DPM medida em condição padrão, a 30 cm de altura sobre gramado, também foi estudada.

\subsection{Material e métodos}

\subsubsection{Sensores eletrônicos para medida da DPM}

Para a medida da DPM foram utilizados sensores eletrônicos de placa de circuito impresso (Campbell Scientific, Modelo 237). Esses sensores consistem de uma placa de circuito impresso de $1 \mathrm{~mm}$ de espessura com dois pentes de cobre intercalados, onde a condensação reduz a impedância que é registrada por sistema automático de aquisição de dados. Todos os sensores foram tratados com duas ou três camadas de tinta latex branca, para se aumentar a habilidade do sensor em detectar pequenas quantidades de molhamento, ou seja, gotículas com menos de $1 \mathrm{~mm}$ de diâmetro, e submetidos a tratamento térmico em estufa $\left(60-70^{\circ} \mathrm{C}\right.$ por $\left.12 \mathrm{~h}\right)$ para remoção ou desativação de componentes higroscópicos da tinta. O limiar de leitura no sistema de aquisição de dados para se considerar o sensor com molhamento foi determinado em laboratório, como descrito no capítulo 5. Valores maiores ou iguais ao valor dessa transição foram representados por 1 (molhado) e menores do que ele foram representados por 0 (seco). Cada sensor foi montado em uma secção de tudos de PVC ou de metal e instalado no campo em diferentes culturas e posições, assim como será descrito a seguir. 


\subsubsection{Experimentos de campo}

Os experimentos de campo foram conduzidos em quatro localidades, sob diferentes condições climáticas (Tabela 6.1), utilizando-se seis diferentes culturas: maçã, café, uva, milho, tomate e melão. A Figura 6.1 apresenta a posição e a altura dos sensores em cada uma das culturas estudadas.

Tabela 6.1 - Condições climáticas médias durante a realização dos experimentos de campo em Ames, IA, Estados Unidos (2000, 2001 e 2003), Elora, ON, Canadá (2003), Piracicaba, SP, Brasil (2003) e Jundiaí, SP, Brasil (2003/04).

\begin{tabular}{lcccccc}
\hline Local & Periodo & Ano & $\begin{array}{c}\mathrm{T} \\
\left({ }^{\circ} \mathrm{C}\right)\end{array}$ & $\begin{array}{c}\mathrm{UR} \\
(\%)\end{array}$ & $\begin{array}{c}\mathrm{P} \\
(\mathrm{mm})\end{array}$ & $\begin{array}{c}\text { U* } \\
\left(\mathrm{m} \mathrm{s}^{-1}\right)\end{array}$ \\
\hline Ames (Tomate) & $16 / 07-10 / 08$ & 2000 & 21,3 & 81,8 & 40 & 2,6 \\
Ames (Maçã) & $21 / 07-30 / 08$ & 2000 & 22,2 & 82,5 & 60 & 2,8 \\
Ames (Maçã) & $30 / 05-28 / 08$ & 2001 & 22,4 & 74,9 & 165 & 3,2 \\
Ames (Melão) & $23 / 07-07 / 10$ & 2003 & 20,5 & 75,1 & 197 & 3,0 \\
Elora (Milho) & $28 / 07-07 / 10$ & 2003 & 16,0 & 83,1 & 344 & 1,8 \\
Piracicaba (Café) & $11 / 10-22 / 12$ & 2003 & 18,6 & 65,7 & 45 & 1,4 \\
Jundiaí (Uva) & $24 / 10-14 / 01$ & $2003 / 04$ & 21,8 & 78,2 & 478 & 1,4 \\
\hline T = temperatura média do ar, UR = umidade relativa media, P = chuva total e U = velocidade média do \\
vento. * A velocidade do vento foi medida a 2 m de altura em Elora, Piracicaba e Jundiaí, e a 3m em \\
Ames.
\end{tabular}




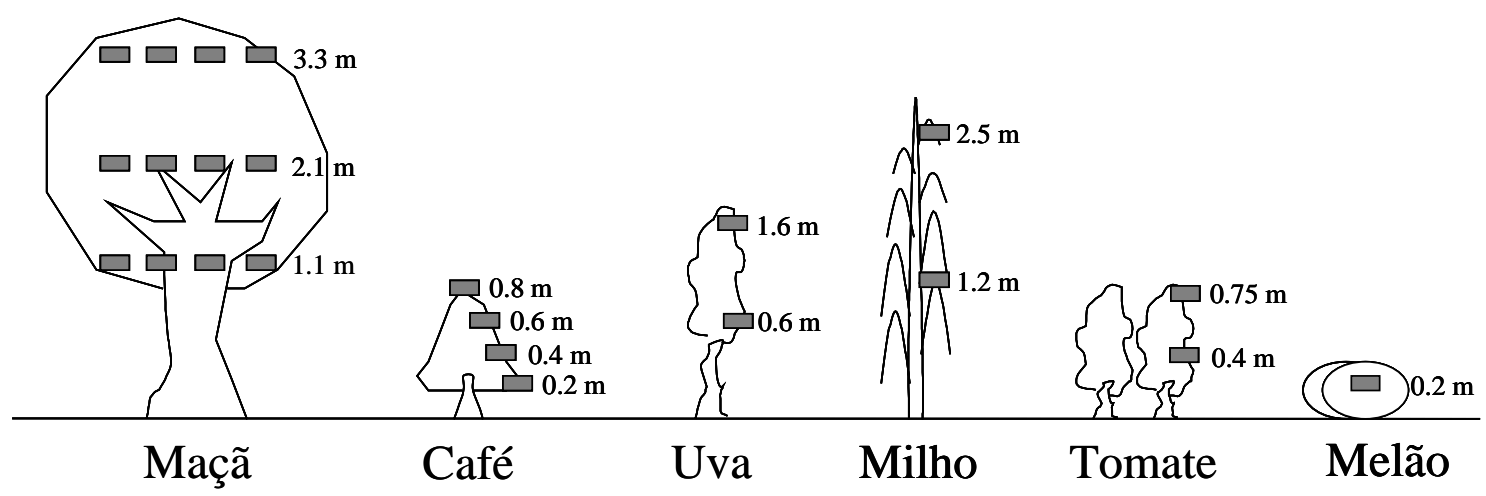

Figura 6.1 - Representação esquemática da posição dos sensores em cada uma das culturas estudadas.

Em Elora, ON, Canadá $\left(43^{\circ} 49^{\prime} \mathrm{N}, 80^{\circ} 35^{\prime} \mathrm{W}\right)$, os sensores de DPM foram instalados sobre um gramado ( 1 ha) a $30 \mathrm{~cm}$ de altura e em duas posições de uma cultura de milho bem desenvolvida, que se localizava a aproximadamente $200 \mathrm{~m}$ a noroeste da área gramada. As medidas foram realizadas entre 28 de julho e 07 de outubro de 2003, totalizando 71 dias. Na cultura do milho, um sensor foi instalado logo abaixo do topo da cultura entre as folhas, com sua altura variando de 1,8 a 2,5 m de acordo com o crescimento das plantas, e outro dentro da cobertura vegetal a 1,2 m de altura, sendo que ambos encontravam-se voltados para o norte com um ângulo de $30^{\circ} \mathrm{em}$ relação à horizontal, assim como os sensores sobre o gramado.

Em Ames, IA, Estados Unidos (42 $01^{\prime}$ N, $\left.93^{\circ} 46^{\prime} \mathrm{W}\right)$, os sensores de DPM foram instalados sobre uma área gramada a $30 \mathrm{~cm}$ de altura, voltados para o norte e com um ângulo de $45^{\circ}$ em relação à horizontal, e em três diferentes culturas. Um sensor foi instalado na cultura do melão, que ocupava uma área de aproximadamente 0,1 ha, logo abaixo do topo da mesma ( 0,20 m de altura), de 23 de julho a 07 de outubro de 2003, 
totalizando 69 dias de medidas. Na cultura da maçã (cv. Golden Delicious que ocupava uma área de 0,8 ha com as ruas dispostas no sentido N-S), foram instalados sensores de DPM em doze diferentes posições, no sentido E-W, sendo 4 no topo da árvore (3,3 m de altura), 4 no meio da árvore (2,1 m de altura) e 4 na parte mais baixa da copa (1,1 m de altura). Os sensores de DPM estavam voltados para o norte e com um ângulo de $45^{\circ} \mathrm{em}$ relação à horizontal, e as medidas foram feitas de 21 de julho a 30 de agosto de 2000, em três árvores, e de 30 de maio a 28 de agosto de 2001, em quatro árvores, totalizando 127 dias. Na cultura do tomate (cv. Roma), cultivado sem estaqueamento, os sensores de DPM foram instalados em quatro plantas após o florescimento e em duas posições em cada uma delas: no topo $(\sim 0,75 \mathrm{~m})$ e no inteior $(\sim 0,40 \mathrm{~m})$ da cultura, de 16 de julho a 10 de agosto de 2000, totalizando 24 dias de registros.

Em Piracicaba, SP, Brasil ( $\left.22^{\circ} 42^{\prime} \mathrm{S}, 47^{\circ} 30^{\prime} \mathrm{W}\right)$, os sensores foram instalados sobre um gramado a $30 \mathrm{~cm}$ de altura, voltados para o sul com uma inclinação de $30^{\circ} \mathrm{em}$ relação à horizontal, e em quatro diferentes alturas de uma planta de café jovem, no inteior de um cafezal ( 3 ha, cv. Obatã e com as ruas orientadas no sentido NW-SE) As medidas da DPM no cafeeiro foram feitas com os sensores instalados a $20 \mathrm{~cm}$ (parte baixa), $40 \mathrm{~cm}$ (meio-baixo), $60 \mathrm{~cm}$ (meio-alto) e $80 \mathrm{~cm}$ (topo), voltados para o sul e com uma inclinação de $30^{\circ}$ em relação à horizontal. As medidas foram feitas de 11 de outubro a 22 de dezembro de 2003, totalizando 58 dias de observações.

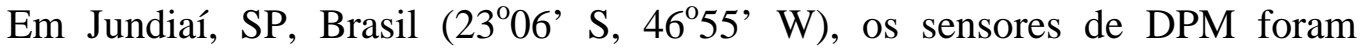
instalados sobre um gramado a $30 \mathrm{~cm}$ de altura, voltados para o sul com uma inclinação de $30^{\circ}$ em relação à horizontal, e em duas alturas na cultura da uva ( 0.2 ha, com a orientação das ruas no sentido N-S, cv. Niagara rosada). Um dos sensores na videira foi 
instalado no topo da cultura $(1,60 \mathrm{~m})$ e o outro na parte mais baixa da folhagem $(0,60$ m), ambos voltados para o sul e com ângulo de $30^{\circ}$. As medidas foram realizadas de 24 de outubro de 2003 a 14 de janeiro de 2004, totalizando 68 dias.

Todos os sensores de DPM estavam conectados a sistemas automáticos de aquisição de dados (Campbell Scientific, Modelos CR10, 21X e CR23X), programados para registrar a percentagem de tempo em que os sensores estiveram com molhamento durante o intervalo estabelecido para o armazenamento dos dados: 15 minutos em Elora e Piracicaba, 20 min em Jundiaí e 60 minutos em Ames.

\subsubsection{Análise dos dados}

Os dados diários de DPM das seis culturas, considerando-se o ínicio do período ao meio dia e o final às $11 \mathrm{~h} 00 \mathrm{~m}$ do dia seguinte, para a base de dados de 60 minutos, às 11h40m, para a base de dados de 20 minutos, e às $11 \mathrm{~h} 45 \mathrm{~m}$, para a base de dados de 15 minutos. Para os dados da cultura da maçã, foram determinadas as médias da DPM nas três posições: topo, meio e parte mais baixa, dada a baixa variabilidade observada entre os 4 sensores instalados em cada uma dessas posições em todas as árvores utilizadas. Para a cultura do melão, de porte muito baixo, o único sensor instalado logo abaixo do topo da cultura foi considerado como representativo também do interior da cultura.

Os dados diários de DPM, considerando-se todo o período e também separandose os dias com e sem chuva (chuva $>1 \mathrm{~mm}$ ), foram submetidos ao teste "t” para dados pareados de modo a se detectar as diferenças entre as medidas efetuadas nas diferentes posições em cada cultura, exceto para a cultura do melão. Esse teste é especialmente útil 
para efeito de comparação de dois tratamentos de dados pareados, quando cada grupo tem a mesma variância da população e a população das observações segue uma distribuição normal, assim como observado nos dados utilizados neste estudo.

Finalmente, os dados de DPM obtidos sobre o gramado (30 cm de altura) foram correlacionados, por meio de regressão linear simples, com os dados de DPM das culturas obtidos nas diversas posições da cobertura vegetal. Para esse propósito, a diferença média (DM), que descreve a direção da diferença predominante, e a diferença média absoluta (DAM), que indica a magnitude da diferença média, entre a DPM do gramado e a das culturas também foram determinadas. Essa análise final não foi conduzida para a cultura do tomate devido à falta de dados de DPM sobre o gramado no período em que as medidas na cultura foram feitas.

\subsection{Resultados e discussão}

A Tabela 6.2 apresenta a média da DPM considerando-se os dados de todos os períodos (com e sem chuva) para as seis culturas nas diferentes posições, assim como os resultados da análise estatística. A avaliação das médias, utilizando-se o teste "t” para dados pareados, mostrou que a DPM variou entre as diferentes posições no dossel das plantas, especialmente para as culturas da maçã, do café e do milho. Entretanto, o padrão de variação observado dependeu basicamente da altura e da arquitetura das plantas. Para as macieiras e para as plantas de milho, a DPM foi maior no topo, enquanto que para as plantas jovens de cafeeiro a DPM foi maior na parte mais baixa. Essas diferenças estão associadas não somente às distintas estruturas das plantas, mas também ao sistema de 
plantio, à idade e ao manejo da cultura. Em um pomar adulto de macieiras e em uma cultura bem desenvolvida de milho somente o topo das plantas está diretamente exposto ao céu, sendo geralmente a primeira parte do dossel a apresentar molhamento, tanto em dias somente com orvalho como também em dias com chuva. A diferença entre a DPM no topo e no interior da copa das macieiras foi ao redor de $2 \mathrm{~h}$, resultado similar ao observado por Wittich (1995). Para o milho, a DPM no topo do dossel foi $1 \mathrm{~h}$ maior do que no seu interior. Pedro Jr. (1980), estudando a DPM na cultura do milho, verificou uma diferença similar na DPM entre folhas ensolaradas e sombreadas próximas do topo da cultura, com as folhas sombreadas tendo maior DPM do que as folhas ensolaradas.

Ao contrário do que foi observado para as culturas da maçã e do milho, no cafeeiro jovem a DPM foi maior na parte mais baixa da cultura. A razão para essa resposta diferenciada está associada ao formato cônico das plantas (Figura 6.1), que permitiu que as folhas externas da planta, nas diferentes alturas, ficassem expostas ao céu, o que por sua vez possibilitou a formação do molhamento quase que simultânea em todas essas posições. Durante o período da manhã, entretanto, o topo das plantas recebe muito mais influência da radiação solar e do vento do que as outras posições, resultando no secamento mais rápido e, portanto, em menor DPM. Para as condições deste estudo, a DPM no cafeeiro foi, em média, aproximadamente 1,5 h maior na parte mais baixa do que no topo das plantas. Nenhuma diferença significativa foi observada entre a DPM nas duas posições intermediárias da planta, porém a DPM média nessas duas posições diferiram significativamente daquelas observadas no topo e na parte mais baixa das plantas, em cerca de 45 minutos. 
Tabela 6.2 - Duração do período de molhamento foliar (DPM) média nas diferentes posições nas cutluras da maçã, do café, do milho, da uva, do tomate e do melão, considerando-se todo o período.

\begin{tabular}{|c|c|c|c|c|}
\hline Cultura & \multicolumn{4}{|c|}{ Posição do sensor na cultura } \\
\hline \multirow{2}{*}{$\begin{array}{l}\text { Maçã } \\
\left(\mathrm{n}^{*}=127\right)\end{array}$} & Topo & \multicolumn{2}{|c|}{ Meio } & Parte Baixa \\
\hline & $8,67 \mathrm{a}$ & \multicolumn{2}{|c|}{$8,25 \mathrm{~b}$} & $6,78 \mathrm{c}$ \\
\hline \multirow{2}{*}{$\begin{array}{l}\text { Café } \\
(\mathrm{n}=58)\end{array}$} & Торо & Meio-alto & Meio-baixo & Parte Baixa \\
\hline & $7,84 \mathrm{c}$ & $8,50 \mathrm{~b}$ & $8,63 \mathrm{~b}$ & 9,29 a \\
\hline Milho & \multicolumn{2}{|c|}{ Tоро } & \multicolumn{2}{|c|}{ Interior } \\
\hline$(n=67)$ & \multicolumn{2}{|c|}{14,50 a } & \multicolumn{2}{|c|}{$13,53 \mathrm{~b}$} \\
\hline Uva & \multicolumn{2}{|c|}{ Tоро } & \multicolumn{2}{|c|}{ Parte baixa } \\
\hline$(n=68)$ & \multicolumn{2}{|c|}{8,48 a } & \multicolumn{2}{|c|}{$8,33 \mathrm{a}$} \\
\hline Tomate & \multicolumn{2}{|c|}{ Tоро } & \multicolumn{2}{|c|}{ Interior } \\
\hline$(\mathrm{n}=24)$ & \multicolumn{2}{|c|}{$10,41 \mathrm{a}$} & \multicolumn{2}{|c|}{$10,24 \mathrm{a}$} \\
\hline Melão & \multicolumn{4}{|c|}{ Topo/Interior } \\
\hline$(n=68)$ & \multicolumn{4}{|c|}{9,89} \\
\hline
\end{tabular}

As medias seguidas na linha pela mesma letra não diferem estatisticamente entre si ao nível de $5 \%$ de probabilidade. ${ }^{*} \mathrm{n}=$ número de dias com medidas de DPM.

Para a videira, cultivada em sistema de espaldeira com orientação das ruas no sentido N-S, a DPM média não diferiu significativamente entre as duas posições estudadas. A estrutura da planta associada ao sistema de espaldeira permitiu, que os sensores nas diferentes posições se resfriassem aproximadamente à mesma taxa durante à noite. Da mesma forma, durante o período da manhã houve suficiente espaço entre as ruas para que os dois sensores, no topo e na parte mais baixa, recebessem aproximadamente a mesma influência da radiação solar e do vento. A diferença 
observada entre o topo e a parte mais baixa da cultura foi de apenas 9 minutos, com as DPMs médias sendo de 8,48 h no topo e de 8,33 h na parte mais baixa. Para a cultura do tomate, de porte baixo e cultivada sem estaqueamento, a DPM também não diferiu significativamente entre o topo e o interior do dossel, o que também foi assumido ser válido para a cultura do melão, a qual contava com apenas um sensor de DPM.

Quando apenas os dias sem chuva foram considerados para a comparação, os mesmos padrões das diferenças entre as DPMs médias nas diferentes posições foram observados para todas as culturas (Tabela 6.3). Para os dias com chuva (Tabela 6.4), entretanto, esses padrões foram consideravelmente alterados, em decorrência das chuvas frequentemente promoverem o molhamento de todo o dossel, especialmente quando elas são intensas ou ocorrem por várias horas. Para as macierias, nenhuma diferença foi observada entre o topo e o meio das copas durante os dias chuvosos, porém na parte mais baixa a DPM média ainda foi cerca de $1 \mathrm{~h}$ menor do que nas demais posições. Para o cafeeiro, a DPM média no topo e na parte mais baixa do dossel não diferiram significativamente da DPM média obtida nas posições meio-alto e meio-baixo, respectivamente. Para as culturas do milho e da uva, em dias com chuva, nenhuma diferença foi observada entre a DPM média no topo e no interior do dossel. Para a cultura do milho, isso representa mudança em relação ao padrão observado anteriormente (Tabela 6.2 e Tabela 6.3), porém para a videira o mesmo padrão já havia sido observado considerando-se os dias sem chuva e todo o período. 
Tabela 6.3 - Duração do período de molhamento foliar (DPM) média nas diferentes posições nas cutluras da maçã, do café, do milho, da uva, do tomate e do melão, considerando-se apenas os dias sem chuva.

\begin{tabular}{|c|c|c|c|c|}
\hline Cultura & \multicolumn{4}{|c|}{ Posição do sensor na cultura } \\
\hline \multirow{2}{*}{$\begin{array}{l}\text { Maçã } \\
\left(n^{*}=90\right)\end{array}$} & Торо & \multicolumn{2}{|c|}{ Meio } & Parte Baixa \\
\hline & $8,32 \mathrm{a}$ & \multicolumn{2}{|c|}{$7,79 \mathrm{~b}$} & $6,14 \mathrm{c}$ \\
\hline \multirow{2}{*}{$\begin{array}{l}\text { Café } \\
(\mathrm{n}=36)\end{array}$} & Topo & Meio-alto & Meio-baixo & Parte Baixa \\
\hline & $5,06 \mathrm{~d}$ & $5,64 \mathrm{c}$ & $6,16 \mathrm{~b}$ & $6,65 \mathrm{a}$ \\
\hline \multirow{2}{*}{$\begin{array}{l}\text { Milho } \\
(\mathrm{n}=43)\end{array}$} & \multicolumn{2}{|c|}{ Topo } & \multicolumn{2}{|c|}{ Interior } \\
\hline & \multicolumn{2}{|c|}{13,05 a } & \multicolumn{2}{|c|}{$11,23 \mathrm{~b}$} \\
\hline Uva & \multicolumn{2}{|c|}{ Торо } & \multicolumn{2}{|c|}{ Parte baixa } \\
\hline$(n=44)$ & \multicolumn{2}{|c|}{$6,34 \mathrm{a}$} & \multicolumn{2}{|c|}{$5,88 \mathrm{a}$} \\
\hline Tomate & \multicolumn{2}{|c|}{ Topo } & \multicolumn{2}{|c|}{ Interior } \\
\hline$(n=18)$ & \multicolumn{2}{|c|}{9,39 a } & \multicolumn{2}{|c|}{9,15 a } \\
\hline Melão & \multicolumn{4}{|c|}{ Topo/Interior } \\
\hline$(n=56)$ & \multicolumn{4}{|c|}{8,95} \\
\hline
\end{tabular}

As medias seguidas na linha pela mesma letra não diferem estatisticamente entre si ao nível de $5 \%$ de probabilidade. ${ }^{*} \mathrm{n}$ = número de dias sem chuva e com medidas de DPM.

A comparação entre as medidas diárias de DPM, pela análise de regressão, obtidas junto às culturas e na condição padrão, a $30 \mathrm{~cm}$ sobre o gramado, mostrou que os sensores de DPM na condição padrão instalados nas proximidades das culturas promoveram estimativas bastante acuradas da DPM no topo das culturas, apesar das grandes diferenças nas suas alturas e estruturas. Porém, a estimativa da DPM nas demais posições no interior das culturas teve menor acurácia, o que mostra que outros fatores, 
tais como sombreamento e redução da velocidade do vento, afetam a formação e o secamento do molhamento.

Tabela 6.4 - Duração do período de molhamento foliar (DPM) média nas diferentes posições nas cutluras da maçã, do café, do milho, da uva, do tomate e do melão, considerando-se apenas os dias com chuva.

\begin{tabular}{|c|c|c|c|c|}
\hline Cultura & \multicolumn{4}{|c|}{ Posição do sensor na cultura } \\
\hline \multirow{2}{*}{$\begin{array}{l}\text { Maçã } \\
\left(n^{*}=36\right)\end{array}$} & Topo & \multicolumn{2}{|c|}{ Meio } & Parte Baixa \\
\hline & $9,55 \mathrm{a}$ & \multicolumn{2}{|c|}{$9,38 \mathrm{a}$} & $8,39 \mathrm{~b}$ \\
\hline \multirow{2}{*}{$\begin{array}{l}\text { Café } \\
(n=22)\end{array}$} & Topo & Meio-alto & Meio-baixo & Parte Baixa \\
\hline & $12,39 \mathrm{~b}$ & $13,18 \mathrm{a}$ & $12,66 \mathrm{~b}$ & $13,62 \mathrm{a}$ \\
\hline \multirow{2}{*}{$\begin{array}{l}\text { Milho } \\
(\mathrm{n}=24)\end{array}$} & \multicolumn{2}{|c|}{ Topo } & \multicolumn{2}{|c|}{ Interior } \\
\hline & \multicolumn{2}{|c|}{16,99 a } & \multicolumn{2}{|c|}{$17,43 \mathrm{a}$} \\
\hline \multirow{2}{*}{$\begin{array}{l}\text { Uva } \\
(n=24)\end{array}$} & \multicolumn{2}{|c|}{ Topo } & \multicolumn{2}{|c|}{ Parte baixa } \\
\hline & \multicolumn{2}{|c|}{$12,41 \mathrm{a}$} & \multicolumn{2}{|c|}{$12,83 \mathrm{a}$} \\
\hline \multirow{2}{*}{$\begin{array}{l}\text { Tomate } \\
(\mathrm{n}=6)\end{array}$} & \multicolumn{2}{|c|}{ Topo } & \multicolumn{2}{|c|}{ Interior } \\
\hline & \multicolumn{2}{|c|}{$13,63 \mathrm{a}$} & \multicolumn{2}{|c|}{13,57 a } \\
\hline \multirow{2}{*}{$\begin{array}{l}\text { Melão } \\
(\mathrm{n}=12)\end{array}$} & \multicolumn{4}{|c|}{ Topo/Interior } \\
\hline & \multicolumn{4}{|c|}{14,30} \\
\hline
\end{tabular}

As medias seguidas na linha pela mesma letra não diferem estatisticamente entre si ao nível de 5\% de probabilidade. ${ }^{*} \mathrm{n}=$ número de dias com chuva e com medidas de DPM.

A Figura 6.2 apresenta a relação entre as DPMs da cultura da maçã nas diferentes posições e a DPM padrão. Observa-se que tanto os coeficientes de determinação como os coeficientes angulares dessas relações decresceram do topo para a parte mais baixa da 
copa das árvores. Para o topo das macieiras, o coeficiente angular (b) foi de aproximadamente 0,92, representando que a DPM no gramado é cerca de $8 \%$ maior que a DPM no topo das macierias. Essa diferença aumentou para 12\% para a DPM medida no meio das copas e para 27\% na parte mais baixa. Essa tendência de superestimativa da DPM na macieria a partir da DPM observada na condição padrão também pode ser observada pelas diferenças médias apresentadas na Tabela 6.5. Do topo para a parte mais baixa da copa das macieiras, a DM aumentou de 0,68 para 2,56 h e a DAM aumentou de 1,51 para 2,93 h. Para a cultura do café, a mesma tendência com relação aos coeficientes de determinação e ângular foi observada (Figura 6.3 e Tabela 6.5), porém com a DPM no gramado sendo 5\% menor que a DPM da cultura no topo, 9 a $10 \%$ no meio e $17 \%$ na parte mais baixa.

Para a cultura do milho (Figura 6.4 e Tabela 6.5), a correlação entre a DPM no topo do dossel e na condição padrão foi similar à observada na cultura do café, sendo a DPM no gramado, em média, cerca de 3\% menor do que a da cultura. O mesmo foi observado para a cultura do melão (Figura 6.5 e Tabela 6.5), onde a DPM do gramado foi, em média, 2\% menor do que a da cultura. Dentro da cultura do milho, no entanto, a relação entre as DPMs da cultura e do gramado mostraram que essa variável na condição padrão foi, em média, 3\% maior que a observada na cultura, porém com uma maior dispersão dos dados $\left(\mathrm{R}^{2}=0,74\right)$ do que foi observado para o topo da cultura $\left(\mathrm{R}^{2}=0,93\right)$. 

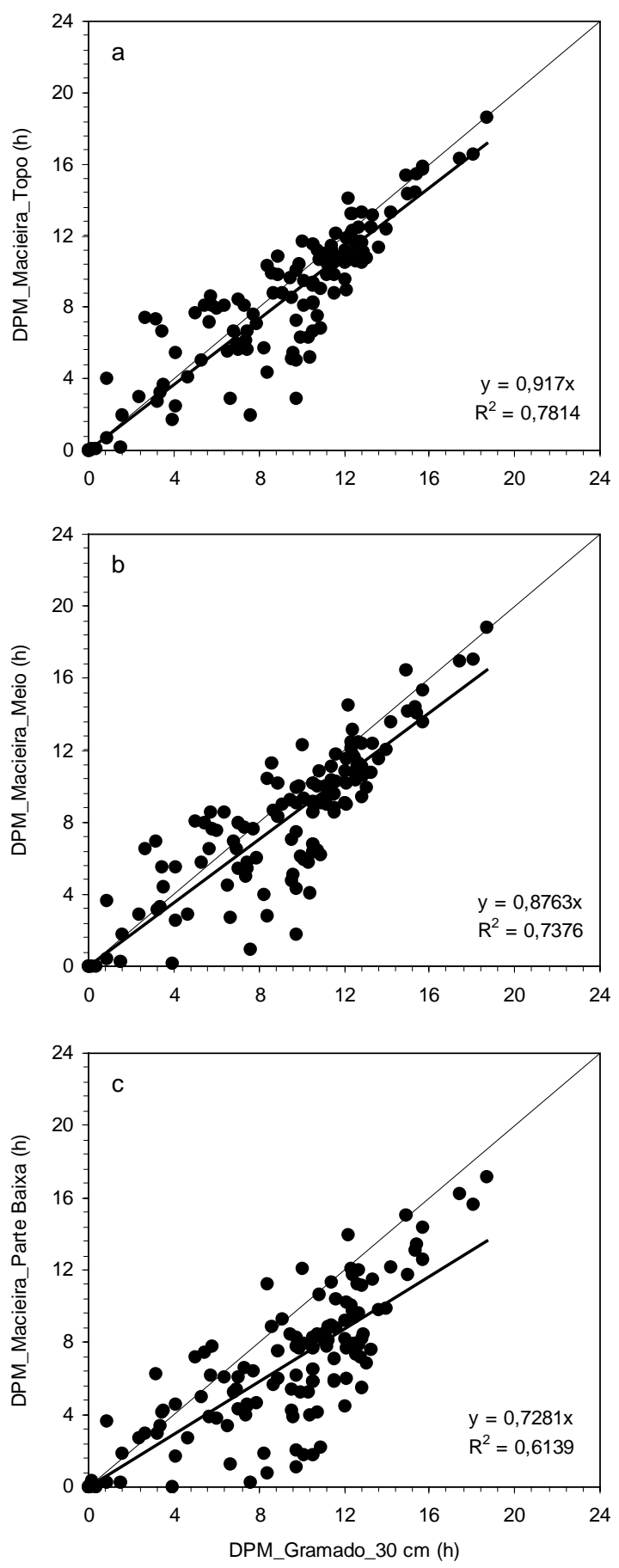

Figura 6.2 - Relação entre a DPM medida no topo (a), no meio (b) e na parte baixa (c) da cultura da maçã e a DPM medida a 30 cm de altura sobre o gramado, em Ames, IA, Estados Unidos. 

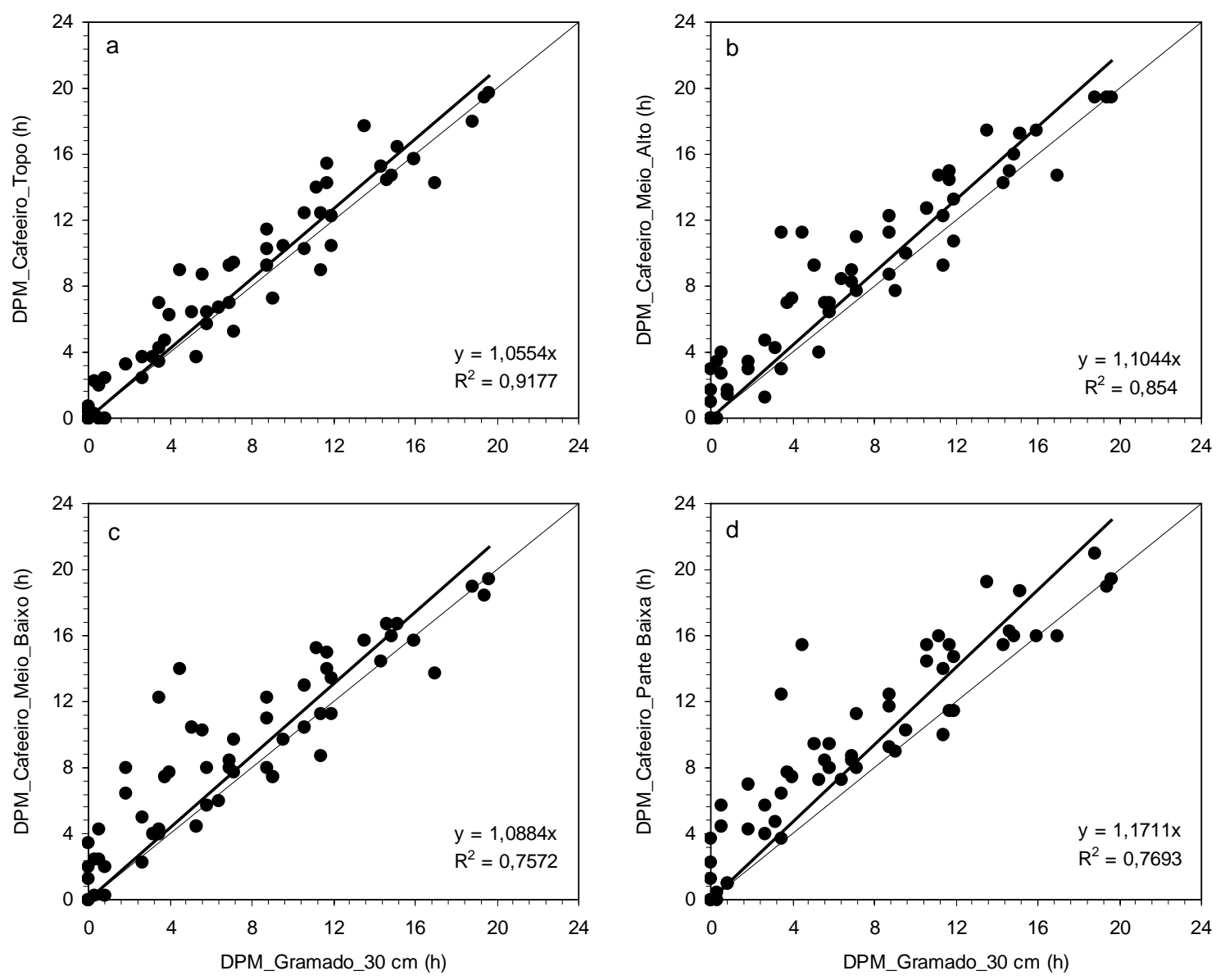

Figura 6.3 - Relação entre a DPM medida no topo (a), no meio_alto (b), no meio_baixo (c) e na parte baixa (d) da cultura do café e a DPM medida a $30 \mathrm{~cm}$ de altura sobre o gramado, em Piracicaba, SP, Brasil.

Finalmente, para a cultura da uva (Figura 6.6 e Tabela 6.5), a correlação entre as DPMs observadas na cultura e na condição padrão mostrou que a DPM no gramado foi, em média, cerca de 6\% maior do que as observadas no topo e no interior da cultura. Entretanto, a dispersão da relação DPM gramado x DPM cultura aumentou consideravelmente na parte baixa do dossel da videira, com $\mathrm{R}^{2}=0,68$ contra 0,96 para a 
tal relação no topo da cultura, mostrando que outros fatores que não influenciam a DPM sobre o gramado afetam o molhamento nessa posição dessa cultura.
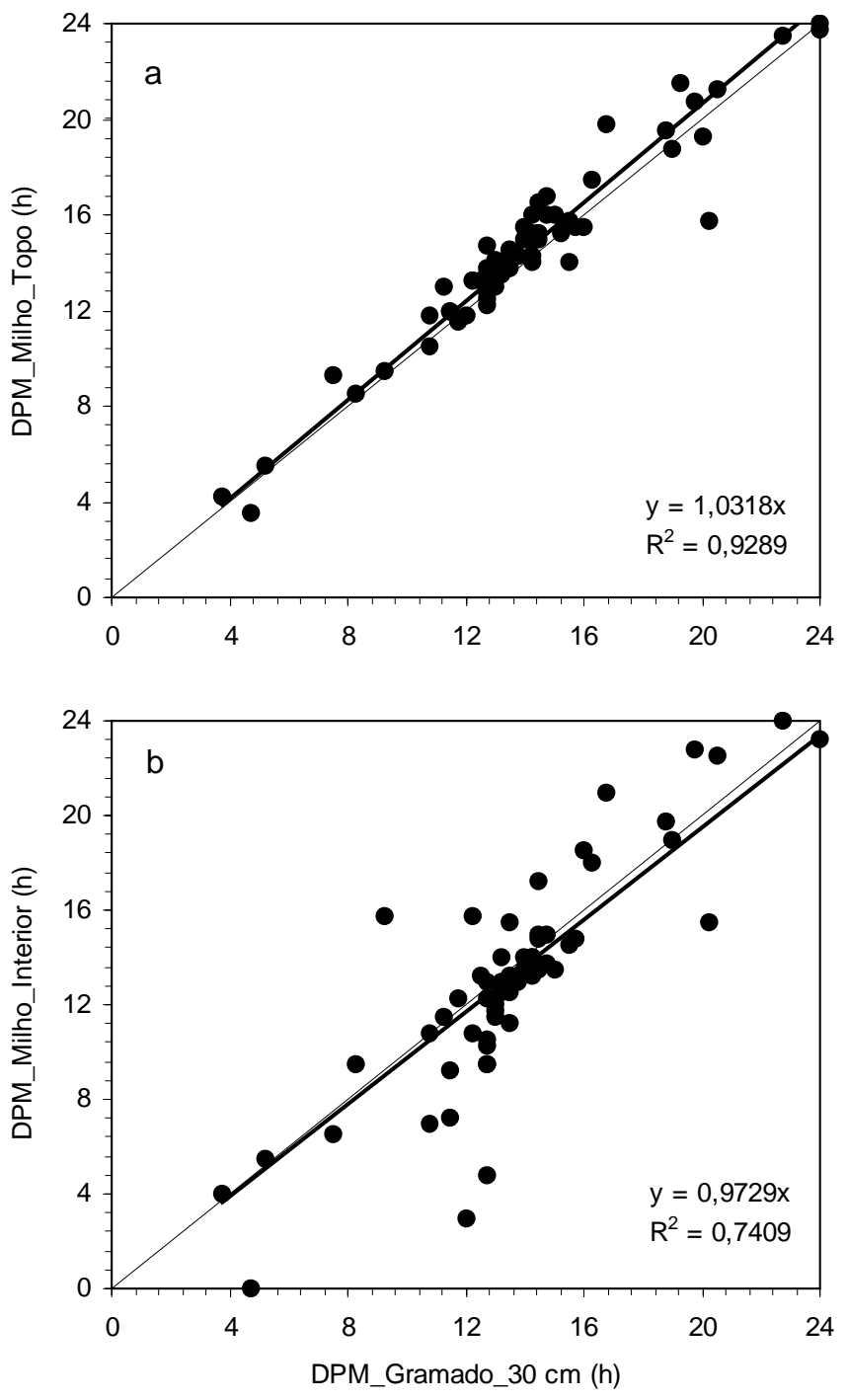

Figura 6.4 - Relação entre a DPM medida no topo (a) e no interior (b) da cultura do milho e a DPM medida a 30 cm de altura sobre o gramado, em Elora, ON, Canadá. 


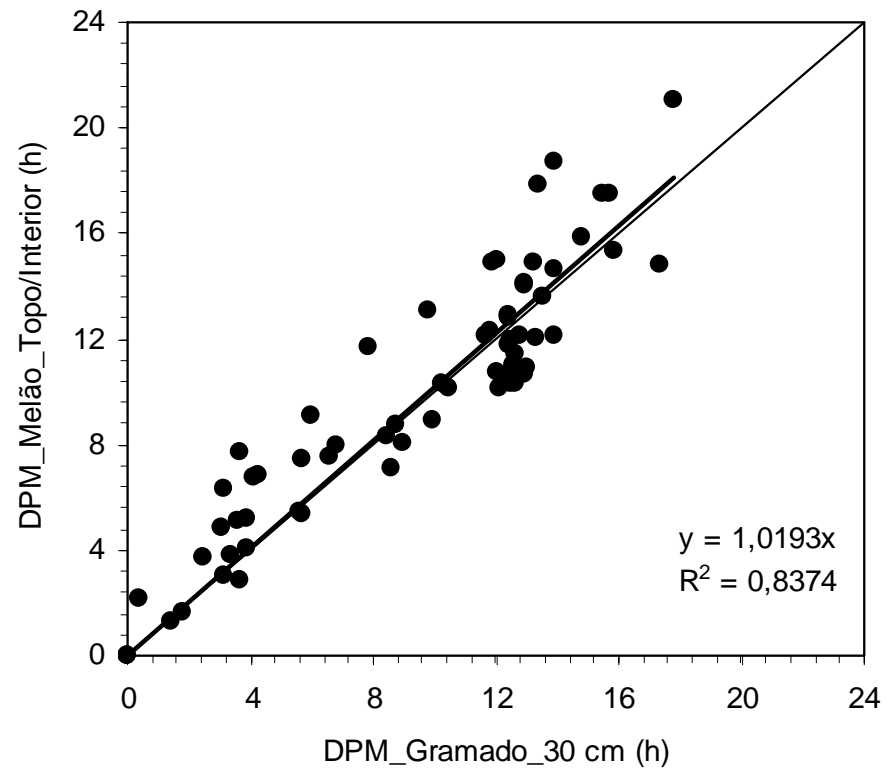

Figura 6.5 - Relação entre a DPM medida no topo/interior da cultura do melão e a DPM medida a $30 \mathrm{~cm}$ de altura sobre o gramado, em Ames, IA, Estados Unidos.

Poucos trabalhos na literatura nacional e internacional têm tentado correlacionar a DPM medida sobre gramado, em uma estação meteorológica padrão, com dados da DPM de culturas adjacentes, especialmente em várias posições do dossel. Por outro lado, os modelos mais acurados e precisos para a estimativa da DPM, como Pedro Jr. e Gillespie (1982a, 1982b), Zhang e Gillespie (1990), Gleason et al. (1994), Rao et al. (1998) e Magarey (1999), utilizam dados de estações meteorológicas. A forte correlação obtida neste estudo entre a DPM a $30 \mathrm{~cm}$ sobre gramado e aquela medida no topo das culturas reforça a idéia de que a adoção de modelos de base física para a estimativa da DPM a 30 cm sobre gramado, como empregado por Madeira et al. (2002), é uma alternativa viável para a medida direta dessa variável ao nível da cultura. Entretanto, 
esse procedimento é apenas operacionalmente aplicável para estimar a DPM no topo das culturas. Se essa posição for a que apresenta a maior DPM no dossel, como observado neste estudo para as culturas da maçã, do milho, da uva, do tomate e do melão, o procedimento de estimativa da DPM da cultura a partir de medidas na estação meteorológica ou de modelos de estimativa torna-se uma ferramenta muito útil. Por outro lado, se a maior DPM ocorre no interior da cultura, como foi observado para a cultura do café, isso irá requerer o uso de sensores posicionados em locais específicos da cultura, ou de correções empíricas para a DPM na condição padrão ou, ainda, de uma modelagem mais complexa. Se a medida tiver que ser feita especificamente na cultura, a partir dos dados obtidos neste estudo, sugere-se que seja adotada a recomendação de Huber e Gillespie (1992) de que se utilizem pelo menos dois sensores, sendo um no topo e outro na parte mais baixa ou interior da cultura, especialmente quando o propósito for se aplicar esses dados em um sistema de alerta fitossanitário.

\subsection{Conclusões}

A medida da DPM em diversas posições e em diferentes culturas mostrou que essa variável é afetada não somente pelas condições climáticas, mas também pela estrutura, arquitetura, arranjo e altura das plantas, fatores esses que controlam o microclima. O padrão de variação da DPM no interior das culturas diferiu de acordo com as características mencionadas acima. Para pomares, como o da macieira, e para culturas anuais bem desenvolvidas, como a do milho, onde somente o topo da cultura está diretamente exposto ao céu, a DPM causada pelo orvalho foi maior no topo do que 
no interior da vegetação. Para plantas jovens de café, as quais têm formato cônico, o padrão de variação da DPM em dias com orvalho foi o oposto, com maior DPM na parte baixa das plantas. Para uma cultura bem ventilada, como a da uva cultivada em sistema de espaldeira, ou de porte baixo, como o tomateiro, nenhuma diferença significativa foi observada, tanto para dias com ou sem chuva, entre o topo e a parte baixa do dossel. Por outro lado, durante os dias chuvosos a DPM mostrou variar menos entre o topo e o interior das culturas da maçã, do café e do milho. O uso da DPM medida sobre o gramado (a $30 \mathrm{~cm}$ de altura e com inclinação de $30^{\circ}$ ou $45^{\circ}$ ) mostrou ser uma opção bastante viável para se estimar a DPM no topo das diferentes culturas, especialmente para aquelas que tem nessa posição as maiores DPMs. Os erros absolutos médios associados a essas estimativas variaram de 50 a 95 minutos, os quais são suficientemente pequenos para permitir o uso dessas estimativas em sistemas de alerta fitossanitários (Magarey, 1999). Para as culturas em que a maior DPM ocorre no interior da vegetação, o uso de pelo menos dois sensores (um no topo e outro no interior) deve ser considerado, especialmente quando o propósito dessas medidas for que essas sejam utilizadas em sistemas de alerta fitossanitário. 

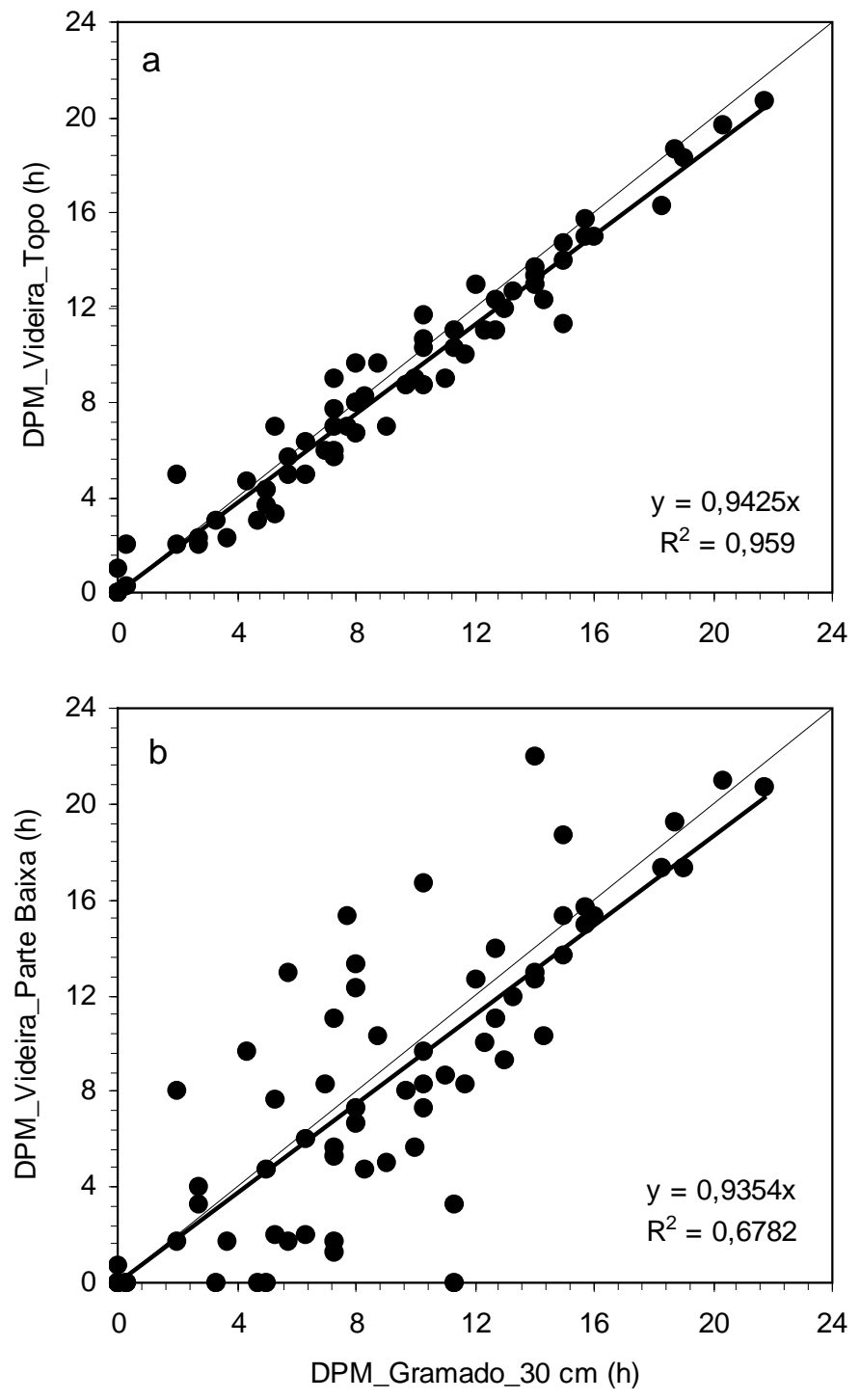

Figura 6.6 - Relação entre a DPM medida no topo (a) e na parte baixa (b) da cultura da uva e a DPM medida a 30 cm de altura sobre o gramado, em Jundiaí, SP, Brasil. 
Tabela 6.5 - Diferença média (MD) e diferença absoluta média (DMA) entre a DPM medida pelo sensor na condição padrão (sobre gramado, a $30 \mathrm{~cm}$ de altura e com ângulo de $30^{\circ}$ ) e nas diferentes posições nas culturas.

\begin{tabular}{|c|c|c|c|c|}
\hline Cultura & \multicolumn{4}{|c|}{ Posição do sensor na cultura } \\
\hline Maçã & \multicolumn{2}{|c|}{ Tоро } & Meio & Parte Baixa \\
\hline $\mathrm{DM}$ & \multicolumn{2}{|c|}{0,68} & 1,10 & 2,56 \\
\hline DAM & \multicolumn{2}{|c|}{1,51} & 1,84 & 2,93 \\
\hline Café & \multicolumn{2}{|r|}{ Meio-alto } & Meio-baixo & Parte Baixa \\
\hline DM & \multicolumn{2}{|l|}{$-0,76$} & $-1,53$ & $-2,19$ \\
\hline DAM & \multicolumn{2}{|l|}{1,25} & 1,94 & 2,31 \\
\hline Milho & \multicolumn{2}{|c|}{ Tоро } & \multicolumn{2}{|c|}{ Interior } \\
\hline $\mathrm{DM}$ & \multicolumn{2}{|c|}{$-0,50$} & \multicolumn{2}{|c|}{0,47} \\
\hline DAM & \multicolumn{2}{|c|}{0,83} & \multicolumn{2}{|c|}{1,67} \\
\hline Uva & \multicolumn{2}{|c|}{ Tоро } & \multicolumn{2}{|c|}{ Parte baixa } \\
\hline DM & \multicolumn{2}{|c|}{0,47} & \multicolumn{2}{|c|}{0,62} \\
\hline DAM & \multicolumn{2}{|c|}{0,92} & \multicolumn{2}{|c|}{2,65} \\
\hline Melão & \multicolumn{4}{|c|}{ Topo/Interior } \\
\hline DM & \multicolumn{4}{|c|}{$-0,60$} \\
\hline DAM & \multicolumn{4}{|c|}{1,58} \\
\hline
\end{tabular}




\section{AVALIAÇÃO DO MODELO DE PENMAN-MONTEITH PARA A ESTIMATIVA DA DURAÇÃO DO PERÍODO DE MOLHAMENTO FOLIAR EM CONDIÇÃO PADRÃO E DE CULTURA}

\section{Resumo}

Neste estudo, foi investigado o uso da equação de Penman-Monteith para se estimar a duração do período de molhamento foliar (DPM) de um sensor localizado em uma estação meteorológica. Isso foi considerado porque recentes observações revelaram que um sensor de DPM instalado a $30 \mathrm{~cm}$ acima do gramado proporcionou estimativas acuradas e precisas da DPM em várias culturas nas adjacências. Portanto, a modelagem de tal sensor na referida posição pode ser uma forma alternativa de se modelar a DPM em culturas. A DPM foi medida sobre um gramado em uma estação meteorológica a diferentes alturas (30, 110 e 190 cm) e no topo de três diferentes culturas: café, milho e uva, utilizando-se sensores eletrônicos de placa de circuito impresso. Ao mesmo tempo e nos mesmos locais, estações meteorológicas automáticas mediram, em condições padrões, a temperatura (T) e a umidade relativa do ar (UR), a velocidade do vento a $2 \mathrm{~m}$ $\left(U_{2 m}\right)$ e o saldo de radiação (Rn). A equação de Penman-Monteith foi capaz de estimar a 
DPM sobre o gramado com boa acurácia e precisão, utilizando para tanto uma resistência aerodinâmica adicional, baseada na velocidade do vento, para estimar a DPM a 30 e 110 cm de altura. O modelo, em média, superestimou a DPM em 3,4\% a 190 cm $\left(\mathrm{R}^{2}=0,92\right), 1,1 \%$ a $110 \mathrm{~cm}\left(\mathrm{R}^{2}=0,84\right)$ e $5,3 \%$ a $30 \mathrm{~cm}\left(\mathrm{R}^{2}=0,87\right)$. Quando a DPM estimada para o gramado a uma altura de $30 \mathrm{~cm}$ foi correlacionada com a DPM no topo das culturas, uma boa concordância foi observada, com uma superestimativa de $6,5 \%$ e um coeficiente de determinação de 0,90, considerando-se as três culturas conjuntamente. Quando adotou-se uma redução de 20\% nos valores negativos do saldo de radiação observou-se uma redução nas superestimativas obtidas pelo modelo de PenmanMonteith, especialmente na condição de $190 \mathrm{~cm}$ sobre gramado $\left(\mathrm{b}=1,0018\right.$ e $\mathrm{R}^{2}=$ 0,90). No caso das culturas, a superestimativa caiu para 4,4\% A necessidade da estimativa do saldo de radiação $(\mathrm{Rn})$ é uma desvantagem para o uso operacional dos modelos físicos de estimativa da DPM, já que essa variável é raramente medida diretamente. Assim, testou-se o efeito de diferentes estimativas de Rn na acurácia e precisão da DPM estimada pelo modelo aqui proposto. Quatro diferentes métodos de estimativa da $\mathrm{Rn}$ foram usados, os quais empregam diferentes combinações das variáveis radiação solar, T, UR, cobertura e altura de nuvens. Quando essas estimativas de Rn foram usadas no modelo de Penman-Monteith, ao invés dos dados medidos, não houve mudanças significativas na acurácia das estimativas da DPM, enquanto que a precisão $\left(\mathrm{R}^{2}\right)$ variou entre 0,85 e 0,92, dependendo da complexidade do modelo de estimativa de Rn empregado. Baseando-se nesses resultados, concluiu-se que o modelo de Penman-Monteith, aplicado a um sensor de DPM de tamanho e albedo fixos e 
exposto sobre um gramado a $30 \mathrm{~cm}$ de altura, pode ser uma ferramenta muito útil para a estimativa dessa variável em sistemas de alerta fitossanitário.

\section{EVALUATION OF A PENMAN-MONTEITH APPROACH TO PROVIDE A “STANDARD” AND CROP LEAF WETNESS DURATION ESTIMATE}

\section{Summary}

In this study, a Penman-Monteith approach to modeling LWD on a wetness sensor located in a weather station was investigated. It was undertaken because recent observations revealed that an LWD sensor located about $30 \mathrm{~cm}$ above a turf surface provided useful estimates of LWD in various nearby crops, therefore modeling such a sensor and location may be a simpler "standard" alternative to modeling LWD in a crop canopy. LWD was measured over turfgrass at different heights $(30,110,190 \mathrm{~cm}$ from the ground) and at the top of three different crops: coffee, corn, and grape, using painted flat-plate sensors. At the same times and places, automatic weather stations measured air temperature, RH, wind speed, and net radiation at $190 \mathrm{~cm}$ above turf. A PenmanMonteith approach was able to estimate sensor LWD over turfgrass with good accuracy and precision, using an aerodynamic resistance based on the wind speed to estimate wetness duration at 110 and $30 \mathrm{~cm}$. The model overestimated LWD by $3.4 \%$ at $190 \mathrm{~cm}$ $\left(\mathrm{R}^{2}=0.92\right), 1.1 \%$ at $110 \mathrm{~cm}\left(\mathrm{R}^{2}=0.84\right)$, and $5.3 \%$ at $30 \mathrm{~cm}\left(\mathrm{R}^{2}=0.87\right)$. When modeled LWD for a $30 \mathrm{~cm}$ sensor over turfgrass was correlated with crop LWD, good agreement was observed, with an overestimation of $6.5 \%$ and a coefficient of determination of 0.90 
for all three crops combined. When a reduction of $20 \%$ was adopted for the negative values of net radiation, overestimations diminished especially for the condition over

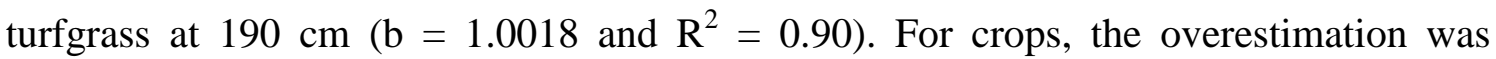
reduced to $4.4 \%$. The requirement for an estimation of net radiation $(\mathrm{Rn})$ is a disadvantage for operational physical models, since this variable is seldom measured directly. The effect of different estimates of Rn on the accuracy and precision of LWD estimates from our model was tested. Four different available methods to estimate Rn were used, based on combinations of incoming solar radiation, air temperature, $\mathrm{RH}$, cloud cover and cloud height. When these estimates were used in place of measured Rn in the Penman-Monteith model there was no significant degradation in the accuracy of the LWD estimates, while the precision of the estimates ( $\mathrm{R}^{2}$ values) varied between 0.85 and 0.92, depending on the complexity of the Rn models. We conclude that PenmanMonteith model for a fixed sensor size, albedo and exposure over turf may be a very useful "standard” tool to estimate LWD for use in plant disease management schemes.

\subsection{Introdução}

O molhamento foliar é reconhecido como um dos mais importantes fatores que condicionam a epidemiologia de doenças de plantas (Pedro, 1980; Huber e Gillespie, 1992; Gleason et al., 1994; Kim et al., 2002). O tempo em que tal molhamento permanece sobre a superfície das folhas das plantas, denominado de duração do período de molhamento foliar (DPM), é fundamental para o desenvolvimento de doenças fúngicas e bacterianas e o risco de infecção da maioria dos fitopatossistemas é 
diretamente proporcional a ela (Madeira et al., 2002). Baseado nesse fato, a DPM juntamente com a temperatura do ar vem sendo utilizada com muito sucesso em vários sistemas de alerta fitossanitário, como o Downcast (Jesperson e Sutton, 1987), para a cultura da cebola, o Tomcast (Pitblado, 1992), para a cultura do tomate, e o Melcast (Latin e Evans, 1996; Latin e Egel, 2001), para a cultura do melão.

Como a DPM não é amplamente medida nas estações meteorológicas, diversos métodos de estimativa dessa variável, a partir de dados meteorológicos, têm sido desenvolvidos (Pedro e Gillespie, 1982a,b; Huber e Gillespie, 1992; Gleason et al., 1994; Rao et al., 1998; Sentelhas et al., 2004b). Os métodos baseados nos princípios físicos da deposição do orvalho e da evaporação do orvalho ou da chuva interceptada têm mostrado boa adaptação e resultados suficientemente acurados para seu uso em sistemas operacionais, assim como apresentado para as culturas do milho, da soja e da maçã por Pedro Jr. e Gillespie (1982a,b), para a cultura da cebola por Gillespie e Barr (1984), para a cultura do girassol por Garín et al. (1997), para a cultura da banana por Lhommes e Jimenez (1992), para a macieira por Wittich (1995), para espigas de milho por Rao et al. (1998), para a videira por Magarey (1999), para a cultura do arroz por Luo e Goudrian (1999, 2000), e para a cultura da canola por Papastamati et al. (2004). Entretanto, o fato de tais modelos requererem dados de saldo de radiação $(R n)$ é uma desvantagem para empregá-los em sistemas operacionais, já que essa variável é raramente medida diretamente sobre as culturas e mesmo nas estações meteorológicas padrões (Madeira et al., 2002). Como solução para esse problema, o saldo de radiação pode ser estimado a partir da combinação de variáveis meteorológicas, como a radiação 
solar, T, UR, cobertura e altura de nuvens (Pedro, 1980; Jegede, 1997; Iziomon et al., 2000; Madeira et al., 2002).

Entre os diversos modelos físicos utilizados para estimar a deposição e a evaporação do molhamento, aquele baseado na equação de Penman-Monteith (Monteith e Unsworth, 1990) tem algumas vantagens em relação àqueles baseados na equação geral do balanço de energia, como o modelo apresentado por Pedro Jr. e Gillespie (1982a,b). A principal vantagem do modelo de Penman-Monteith é a de que este não requer dados de temperatura ao nível da cultura. Para isso, assume-se que a temperatura do ar, a uma dada altura acima do gramado em uma estação meteorológica, é representativa das condições à mesma altura acima da cultura e que uma resistência adicional nesse modelo, denominada resistência aerodinâmica, é suficiente para contabilizar a camada de ar entre a altura considerada e o topo da cultura (Rao et al., 1998). Resultados apresentados por Luo e Goudriaan (1999, 2000), na região tropical das Filipinas, por Jacobs et al. (2002), na região árida do Mediterrâneo, e por Rao et al. (1998), no sul de Ontário, Canadá, demonstraram que o modelo de Penman-Monteith teve uma boa performance sob uma grande diversidade de condições climáticas.

De acordo com Zhang e Gillespie (1990), a estimativa da DPM em uma cultura, a partir de dados meteorológicos obtidos fora dela, é um processo de dois passos. Entretanto, resultados recentes apresentados por Sentelhas (2004c,d) têm mostrado que a DPM medida a $30 \mathrm{~cm}$ sobre gramado foi muito similar àquelas obtidas no topo de cinco culturas com diferentes características estruturais (altura e arquitetura das plantas): maçã, café, milho, uva e melão. Baseando-se nessas evidências, este estudo teve como objetivo avaliar a equação de Penman-Monteith para modelar a DPM de um sensor 
localizado em uma estação meteorológica padrão e, desse modo, proporcionar uma alternativa simples, direta e útil para se estimar a DPM em culturas adjacentes. Também se estudou o efeito de diferentes estimativas do saldo de radição ( $R n)$ na precisão e acurácia das estimativas da DPM pelo método de Penman-Monteith, buscando-se alternativas para aqueles locais onde as medidas de Rn não são realizadas.

\subsection{Material e métodos}

\subsubsection{Experimentos de campo}

Os experimentos de campo foram conduzidos em três localidades (Tabela 7.1), com três diferentes culturas: café, uva e milho, além das medidas sobre o gramado.

Tabela 7.1 - Condições climáticas médias durante a realização dos experimentos de campo em Elora, ON, Canadá (2003), Piracicaba, SP, Brasil (2003) e Jundiaí, SP, Brasil (2003/04).

\begin{tabular}{|c|c|c|c|c|c|c|}
\hline Local (Cultura) & Período & Ano & $\begin{array}{c}\mathrm{T} \\
\left({ }^{\circ} \mathrm{C}\right)\end{array}$ & $\begin{array}{l}\text { UR } \\
(\%)\end{array}$ & $\begin{array}{c}\mathrm{P} \\
(\mathrm{mm})\end{array}$ & $\begin{array}{c}\mathrm{U}_{2 \mathrm{~m}} \\
\left(\mathrm{~m} \mathrm{~s}^{-1}\right)\end{array}$ \\
\hline Elora (Milho) & $28 / 07-07 / 10$ & 2003 & 16,0 & 83,1 & 344 & 1,8 \\
\hline Piracicaba (Café) & $11 / 10-22 / 12$ & 2003 & 18,6 & 65,7 & 45 & 1,4 \\
\hline Jundiaí (Uva) & $24 / 10-14 / 01$ & 2003/04 & 21,8 & 78,2 & 478 & 1,4 \\
\hline
\end{tabular}


Em Elora, ON, Canadá $\left(43^{\circ} 49^{\prime} \mathrm{N}, 80^{\circ} 35^{\prime} \mathrm{W}\right)$, os sensores de DPM foram instalados sobre um gramado ( 1 ha) e também no topo de uma cultura de milho, que se localizava a aproximadamente $200 \mathrm{~m}$ a noroeste da área gramada. As medidas foram realizadas entre 28 de julho e 07 de outubro de 2003, totalizando 71 dias. No gramado, os sensores de DPM foram instalados a três alturas (30, 110 e 190 cm) com um ângulo de exposição de $30^{\circ}$ em relação à horizontal e voltados para o norte. Na cultura do milho, um sensor foi instalado logo abaixo do topo da cultura, entre as folhas, com sua altura variando de 1,8 a 2,5 m de acordo com o crescimento das plantas, e voltado para o norte com um ângulo de $30^{\circ}$ em relação à horizontal.

Em Piracicaba, SP, Brasil ( $22^{\circ} 42^{\prime}$ S, 47 $30^{\circ}$ W), os sensores foram instalados sobre um gramado a $30 \mathrm{~cm}$ de altura e no topo de uma planta de café jovem $(80 \mathrm{~cm}$ de altura), no inteior de um cafezal ( 3 ha, cv. Obatã e com as ruas orientadas no sentido NW-SE), ambos voltados para o sul com uma inclinação de $30^{\circ}$ em relação à horizontal. As medidas foram feitas de 11 de outubro a 22 de dezembro de 2003, totalizando 58 dias de observações.

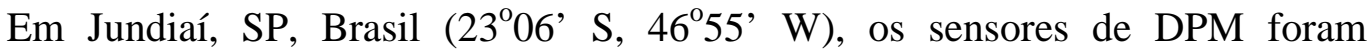
instalados sobre um gramado a $30 \mathrm{~cm}$ de altura e no topo $(1,60 \mathrm{~m})$ da cultura da uva ( 0,2 ha, com a orientação das ruas no sentido N-S, cv. Niagara rosada), ambos voltados para o sul e com ângulo de $30^{\circ}$ em relação à horizontal. As medidas foram realizadas de 24 de outubro de 2003 a 14 de janeiro de 2004, totalizando 68 dias.

Todos os sensores de DPM (Campbell Scientific, Modelo 237) foram pintados com duas ou três camadas de tinta branca e tratados termicamente, assim como descrito nos Capítulos 3 e 5, e estavam conectados a sistemas automáticos de aquisição de dados 
(Campbell Scientific, Modelos CR10, 21X e CR23X), programados para registrar a percentagem de tempo em que o sensor esteve com molhamento durante o intervalo estabelecido para o armazenamento dos dados: 15 minutos em Elora e Piracicaba e 20 min em Jundiaí.

Concomitantemente às medidas da DPM no gramado e nas culturas, estações meteorológicas automáticas instaladas nas três áreas experimentais resgistraram dados de temperatura (T) e umidade relativa do ar (UR), velocidade do vento a $2 \mathrm{~m}\left(\mathrm{U}_{2 \mathrm{~m}}\right)$, saldo de radiação (Rn) e chuva (Prec), em alturas que variaram de 1,5 a 2,0 m.

\subsubsection{Estimativa da DPM pelo modelo de Penman-Monteith}

O modelo de Penman-Monteith para estimativa da DPM, também denominado de modelo da resistência aerodinâmica (RES) por Rao et al. (1998), elimina a necessidade da medida da temperatura do ar na altura da cultura por assumir que a temperatura do ar medida sobre o gramado em uma estação meteorológica padrão, normalmente entre 1,5 e 2,0 m de altura, representa a temperatura do ar à mesma altura sobre a cultura e que uma resistência adicional nesse modelo, denominada resistência aerodinâmica, é suficiente para contabilizar a camada de ar entre a altura considerada e o topo da cultura (Rao et al., 1998). A resistência adicionada ao modelo (Figura 7.1), a qual assume-se ser a resistência aerodinâmica (ra), é descrita por Monteith e Unsworth (1990) como sendo: 
$r a=\frac{\ln \left[\frac{\left(z_{T}-0,65 z_{c}\right)}{\left(0,13 z_{c}\right)}\right]}{\left(0,4 u^{*}\right)}$

em que: $\mathrm{z}_{\mathrm{C}}$ é a altura da cultura, $\mathrm{z}_{\mathrm{T}}$ a altura da medida da temperatura e $\mathrm{u}^{*}$ a velocidade de fricção, dada pelo perfil logarítmico do vento (Monteith e Unsworth, 1990):

$$
u *=\frac{\left(0,4 U z_{T}\right)}{\left\{\ln \left[\frac{\left(z_{T}-0,65 z_{c}\right)}{\left(0,13 z_{c}\right)}\right]\right\}}
$$

sendo $\mathrm{U}_{\mathrm{ZT}}$ a velocidade do vento, em $\mathrm{ms}^{-1}$, à altura do abrigo meteorológico onde se encontra o sensor de temperatura.

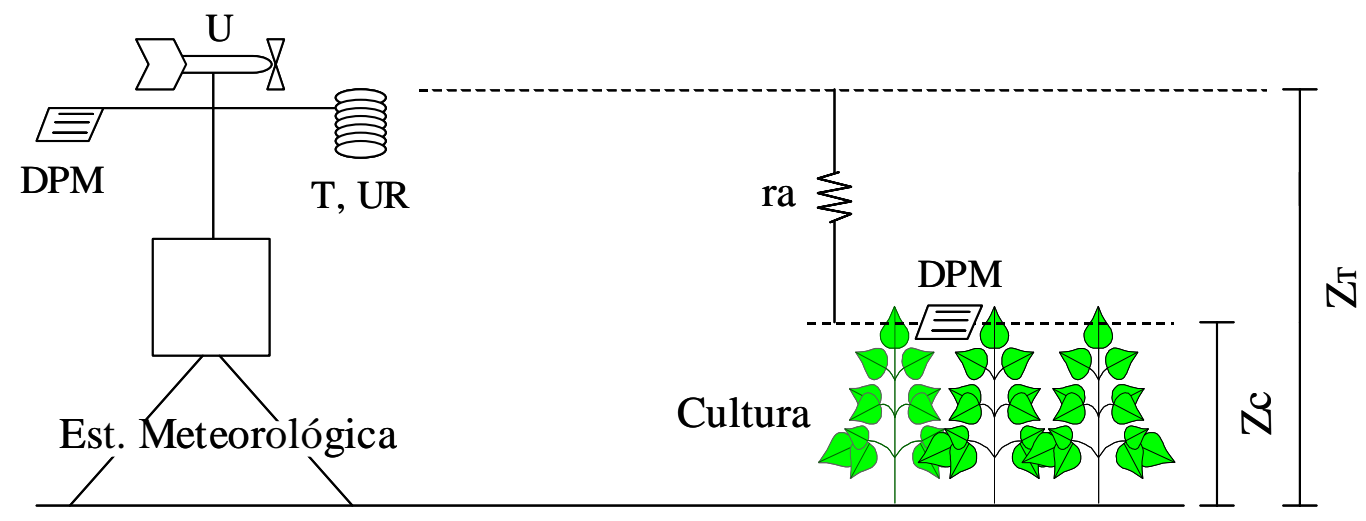

Figura 7.1 - Representação esquemática da altura dos sensores e da resistência aerodinâmica (ra) adicional requerida pelo modelo de Penman-Monteith. (Zc = altura da cultura e $\mathrm{Z}_{\mathrm{T}}=$ altura da medida de temperatura). 
Usando-se as relações apresentadas acima, o fluxo de calor latente (LE) para uma folha artificial pode ser estimado para cada intervalo de tempo usando-se a equação de Penman-Monteith (Monteith e Unsworth, 1990):

$L E=-\frac{\left\{s R n+\left[\frac{1200\left(e s_{T a}-e a\right)}{(r a+r b)}\right]\right\}}{\left(s+\gamma^{*}\right)}$

em que: s é a tangente à curva de pressão de saturação de vapor, es Ta $_{\text {a }}$ a pressão de saturação de vapor à temperatura do ar medida na estação meteorológica, ea a pressão atual de vapor, $\gamma^{*}$ a constante psicrométrica modificada $\left(=\gamma r_{V} / r_{H}\right)$, assumida como sendo 0,64 para período com orvalho $\left(\mathrm{r}_{\mathrm{V}}=\mathrm{r}_{\mathrm{H}}\right.$, os dois lados da folha com molhamento), e 1,28 para períodos com chuva ( $\mathrm{r}_{\mathrm{V}}=2 \mathrm{r}_{\mathrm{H}}$, apenas um lado da folha com molhamento), e rb a resistência da camada limite para o transporte de calor, dado por Campbell e Norman (1998) como sendo:

$r b=\frac{\left[307 *\left(\frac{d}{U z c}\right)^{1 / 2}\right]}{2}$

em que: d é a dimensão efetiva da folha artificial, ou seja, do sensor de DPM (= 0,07 m) e Uzs a velocidade do vento na altura do sensor. A máxima capacidade de retenção de água pela folha artificial (sensor) foi considerada igual a $0,8 \mathrm{~mm}$ para eventos com 
orvalho. O modelo admite que quando há ocorrência de chuva, esta inicia ou aumenta o molhamento e, portanto, é adicionada ao valor acumulado de LE (valores positivos) até um máximo de 0,6 mm. Para a estimativa da DPM na condição da estação meteorológica, onde o sensor de DPM estava na mesma altura dos sensores de T e UR (Figura 7.1), a resistência aerodinâmica adicional (ra) não foi necessária e a Equação (3) pode então ser escrita da seguinte forma:

$L E=-\frac{\left\{s R n+\left[\frac{1200\left(e s_{T a}-e a\right)}{(r b)}\right]\right\}}{\left(s+\gamma^{*}\right)}$

Para a estimativa da DPM nas condições dos sensores a 30 e $110 \mathrm{~cm}$, as resistências aerodinâmicas específicas para cada condição, empregadas na Eq. (3), foram determinadas pela diferença entre a ra a $190 \mathrm{~cm}$ e a ra à altura do sensor, assim como pode ser observado na Figura 7.2, resultando em:

$$
\begin{aligned}
& r a_{30 \mathrm{~cm}}=\frac{68,75}{U_{2 m}} \\
& r a_{110 \mathrm{~cm}}=\frac{19,79}{U_{2 m}}
\end{aligned}
$$

em que $U_{2 m}$ é a velocidade do vento, em $\mathrm{ms}^{-1}$, a $2 \mathrm{~m}$ de altura. No caso da resistência da camada limite (rb), esta foi calculada pela Eq. (4) considerando-se a velocidade do vento 
na altura dos sensores (30 e $110 \mathrm{~cm}$ ), as quais foram estimadas a partir da $\mathrm{U}_{2 \mathrm{~m}}$, utilizando-se o perfil logarítimico do vento, sendo:

$$
\begin{aligned}
& U_{30 \mathrm{~cm}}=0,651 U_{2 \mathrm{~m}} \\
& U_{110 \mathrm{~cm}}=0,893 U_{2 \mathrm{~m}}
\end{aligned}
$$

Seguindo-se o mesmo procedimento adotado por Pedro Jr. e Gillespie (1982a,b), a DPM, por esse modelo, foi considerada como sendo o intervalo de tempo entre a deposição de molhamento, quando LE > 0 (orvalho) ou quando inicía-se uma chuva, e o seu secamento, considerado quando a condensação e/ou a chuva acumuladas pelo modelo são consumidas pela quantidade equivalente de evaporação. O intervalo de tempo considerado para se obter a DPM diária foi entre as 12:15 h (Elora e Piracicaba) ou 12:20 h (Jundiaí) do dia n e as 12:00 h do dia n+1.

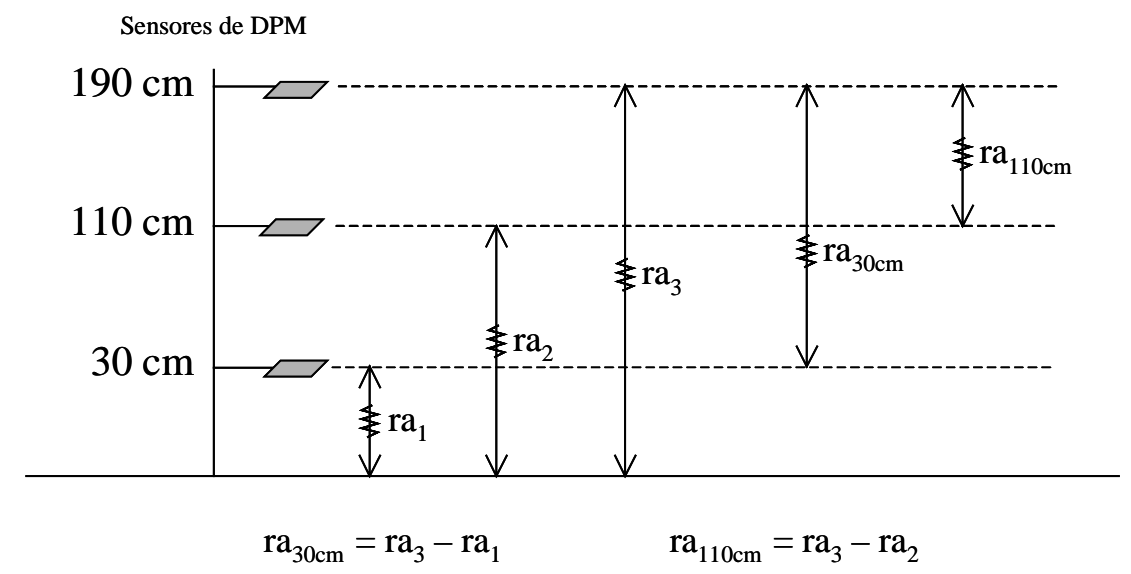

Figura 7.2 - Representação esquemática da posição relativa dos sensores de DPM e das resistências aerodinâmicas envolvidas na estimativa do fluxo de calor latente pelo método de Penman-Monteith nas alturas de 30 e $110 \mathrm{~cm}$ sobre gramado. 


\subsubsection{Estimativa do saldo de radiação}

O saldo de radiação é uma variável ambiental raramente medida diretamente nas estações meteorológicas, quer seja pelo custo do equipamento ou pela dificuldade de sua operação durante longos períodos. Assim, a estimativa dessa variável torna-se necessária, especialmente quando se deseja empregar modelos físicos para a estimativa da DPM, cujos cálculos tem que ser feitos no máximo na escala horária.

Neste estudo, testou-se o efeito de diferentes estimativas de Rn na acurácia e precisão da DPM estimada pelo modelo de Penman-Monteith. Quatro diferentes métodos de estimativa da Rn foram usados, os quais empregam diferentes combinações das variáveis radiação solar, T, UR, cobertura e altura de nuvens.

Este estudo foi conduzido apenas para a localidade de Elora, ON, Canadá, em razão da disponibilidade de dados horários de Rn e também da \% de cobertura e altura de nuvens, obtidos junto ao Aeroporto Internacional de Toronto, a cerca de $50 \mathrm{~km}$ da Estação Experimental de Elora, pertencente à Universidade de Guelph.

\subsubsection{Modelo I}

O primeiro modelo, denominado Modelo I, se baseia nos princípios físicos do balanço de radiação e em coeficientes empíricos apresentados na literatura (Pedro Jr., 1980). Esse modelo é o mais complexo aqui apresentado e envolve dados de radiação solar global (Rg), temperatura do ar (T), umidade relativa (UR), para a determinação da 
pressão parcial de vapor (ea), fração do céu coberto por nuvens (C) e altura das nuvens (H), combinados nas seguintes relações:

$\mathrm{Rn}=0,65 * \mathrm{Rg}+0,95 * \mathrm{RLc}-0,95 * 5,67 * 10^{-8} *(\mathrm{~T}+273)^{4}$

em que: Rg é a radiação solar global $\left(\mathrm{W} \mathrm{m}^{-2}\right), \mathrm{T}$ a temperatura do ar $\left({ }^{\circ} \mathrm{C}\right)$ e $\mathrm{RLc}$ a radiação atmosférica ajustada para a nebulosidade (equação 11):

$\mathrm{RLc}=\mathrm{RL} *\left(1+\mathrm{K} * \mathrm{C}^{2}\right)$

sendo RL a radiação atmosférica para condições de céu limpo (Equação 12) e K um parâmetro dependente da altura (tipo) de nuvem (Equação 13):

$\mathrm{RL}=5,67 * 10^{-8} *(\mathrm{~T}+273)^{4} *[0,82-0,25 \operatorname{EXP}(-0,2162 *$ ea $)]$

$\mathrm{K}=0,2462-0,02 * \mathrm{H} \quad(\mathrm{K}=0$ para períodos de céu limpo $)$

em que: ea é a pressão parcial de vapor (mb) e $\mathrm{H}$ a altura das nuvens (km).

\subsubsection{Modelo II}

O segundo modelo, denominado Modelo II, se baseia na temperatura do céu (Madeira et al., 2002), dada por: 
$\mathrm{Tsn}=\mathrm{T}-20^{\circ} \mathrm{C}$

Tcna $=\mathrm{T}-15^{\circ} \mathrm{C}$

$\mathrm{Tcnb}=\mathrm{T}-10^{\circ} \mathrm{C}$

em que: Tsn é a temperatura do céu sem nuvens, Tcna a temperatura do céu com nuvens altas (> $3 \mathrm{~km})$, Tcnb a temperatura do céu com nuvens baixas ( $\leq 3 \mathrm{~km})$ e $\mathrm{T}$ a temperatura do ar. A partir dessas temperaturas a radiação de ondas longas proveniente da atmosfera (Ld) foi calculada como sendo:

$\operatorname{Ld}=\left[5,67 * 10^{-8} *(1-\mathrm{C}) *(273+\mathrm{Tsn})^{4}\right]+\left[5,67 * 10^{-8} * \mathrm{C} *(273+\mathrm{Tcnx})^{4}\right]$

em que Tcnx representa a temperatura do céu com nuvens, sendo $\mathrm{x}=$ a para nuvens altas $\mathrm{e} \mathrm{x}=\mathrm{b}$ para nuvens baixas. Para a determinação da radiação de ondas longas proveniente da superfície (Lu) utilizou-se a equação de Stefan-Boltzman, assumindo-se que o sensor de DPM estava emitindo radiação como um corpo negro com temperatura similar à temperatura do ponto de orvalho (To):

$\mathrm{Lu}=5,67 * 10^{-8} *(273+\mathrm{To})^{4}$

sendo a To determinada a partir da pressão parcial de vapor, pela equação de Tetens. Finalmente, o saldo de radiação (Rn) foi obtido pela seguinte expressão: 
$\mathrm{Rn}=0,70 \mathrm{Rg}+\mathrm{Ld}-\mathrm{Lu}$

\subsubsection{Modelo III}

O terceiro modelo, denominado Modelo III, se baseia nas diferentes emissividades do céu para condições com ou sem nuvens. Para condições de céu sem nuvens a emissividade é dada por:

$\varepsilon s n=0,674+0,007 \mathrm{~T}$

e para condições de céu com nuvens essa variável é dada por:

$\varepsilon \mathrm{cn}=(1-\mathrm{C}) * \varepsilon \mathrm{sn}+\mathrm{C} *[1-(1-\varepsilon \mathrm{sn}) *(5 * \Delta \mathrm{T} / \mathrm{T}]$

em que $\Delta \mathrm{T}$ é a diferença de temperatura entre a base das nuvens e a temperatura do ar. Para este estudo, $\Delta \mathrm{T}$ foi admitido como sendo $5^{\circ} \mathrm{C}$, assim como empregado por Madeira et al. (2002).

Para a estimativa de Ld utilizou-se a equação de Stefan-Boltzman, com a temperatura do ar:

$\operatorname{Ld}=5,67 * 10^{-8} * \varepsilon *(273+\mathrm{T})^{4}$ 
em que $\varepsilon$ é igual a $\varepsilon s n$ para períodos sem nuvens e igual a $\varepsilon c n$ para períodos com nebulosidade. Para as estimativas de $\mathrm{Lu}$ e Rn adotou-se os mesmos procedimentos apresentados para o Modelo II, respectivamente, nas equações 18 e 19.

\subsubsection{Modelo IV}

O quarto modelo de estimativa de Rn, denominado Modelo IV, baseia-se na relação empírica entre o saldo de radiação e as variáveis independentes $\operatorname{Rg}$ e $\mathrm{T}$ para condições de meias-latitudes, apresentada por Iziomon et al. (2000):

$$
\mathrm{Rn}=0,837 *(\operatorname{Rg} * 0,77)-0,0275 *\left(5,67 * 10^{-8} *(273+\mathrm{T})^{4}\right)-37,7
$$

Os coeficientes empíricos dessa equação (0,837, -0,0275 e -37,7), foram determinados a partir da média dos coeficientes obtidos por Iziomon et al. (2000) para três localidades situadas à meias-latitudes ( 47 $\left.55^{\prime} \mathrm{N}\right)$ na Alemanha, em razão da proximidade entre os valores apresentados por esses autores.

\subsubsection{Análise dos dados}

As estimativas da DPM pelo modelo de Penman-Monteith foram feitas para as alturas de 30 e 110 cm (Equação 3) e 190 cm (Equação 5) acima da superfície gramada, para os dados coletados em Elora. Esses dados foram correlacionados, por meio da 
análise de regressão, com os dados obtidos pelos sensores eletrônicos de DPM nas mesmas alturas de modo a se avaliar a performance do modelo. Além disso, determinouse o erro médio (EM), o qual descreve a direção do erro predominante, e o erro absoluto médio (EAM), o qual indica a magnitude do erro médio, para os horários de início e de secamento do molhamento foliar para tais estimativas de DPM. Para tanto, levou-se em consideração todo o período de medidas assim como os dias com ou sem chuva separadamente.

O modelo de Penman-Monteith também foi avaliado para a estimativa da DPM a $30 \mathrm{~cm}$ de altura (condição padrão de referência), levando-se em consideração os dados das três localidades (Elora, Piracicaba e Jundiaí). Posteriormente, aplicou-se a análise de regressão entre a DPM de referência estimada e a DPM observada no topo das culturas do café, da uva e do milho. Para ambas as análises, o EM, o EAM e o erro absoluto máximo (EMAX) foram determinados.

Essas mesmas análises, no gramado e nas culturas, foram feitas para uma condição de redução do saldo de radiação noturno (valores negativos). Considerou-se que estando o sensor de DPM inclinado com um ângulo de $30^{\circ}$ em relação à horizontal, a sua área voltada para o céu era cerca de $80 \%$ da área do sensor. Portanto, adotou-se arbitrariamente uma redução de $20 \%$ nos valores negativos de Rn. Esse saldo de radiação negativo reduzido $\left(-\mathrm{Rn}^{*} 0.8\right)$ foi utilizado então na estimativa da DPM pelo modelo de Penman-Monteith, adotando-se os mesmos critérios citados no item 7.2.2, de modo a se avaliar o seu efeito.

As estimativas do saldo de radiação, pelos quatro modelos apresentados, foram comparadas, empregando-se a análise de regressão, aos dados observados em Elora com 
o saldo radiômetro Zipp \& Zonen, modelo CNR1, na escala horária. O efeito dessas estimativas de Rn na estimativa da DPM pelo modelo de Penman-Monteith também foi avaliado, substituindo-se neste os valores de Rn medidos pelos valores estimados pelos diferentes modelos e comparando-se a DPM horária estimada com a observada pelo sensor. O EM, o EAM e o EMAX das estimativas feitas com cada um dos modelos de Rn foram determinados.

\subsection{Resultados e discussão}

\subsubsection{Estimativa da DPM em condição padrão}

A Figura 7.3 apresenta a relação entre a DPM estimada pelo modelo de PenmanMonteith para as diferentes alturas sobre o gramado e os dados medidos pelos sensores eletrônicos. Observa-se que a equação de Penman-Monteith foi capaz de estimar a DPM sobre o gramado com boa acurácia (coeficientes angulares entre 1,01 e 1,06) e precisão (coeficientes de determinação entre 0,84 e 0,92), utilizando para tanto uma resistência aerodinâmica adicional, baseada na velocidade do vento a 2m, para estimar a DPM a 30

e $110 \mathrm{~cm}$ de altura. O modelo superestimou a DPM em cerca de 3,4\% a $190 \mathrm{~cm}\left(\mathrm{R}^{2}=\right.$ $0,92)$, de $1,1 \%$ a $110 \mathrm{~cm}\left(\mathrm{R}^{2}=0,84\right)$ e de $5,3 \%$ a $30 \mathrm{~cm}\left(\mathrm{R}^{2}=0,87\right)$. Rao et al. (1998) também observaram bom desempenho do modelo de Penman-Monteith na estimativa da DPM para a cultura do milho, porém com subestimativas, o que também foi obtido por Luo e Goudriaan (2000) na cultura do arroz inundado. Por outro lado, Pedro Jr. e Gillespie (1982b), empregando um modelo físico baseado na equação geral do balanço 
de energia, observaram superestimativas da DPM para as culturas do milho e da soja, o que segundo esses autores podem estar relacionadas à determinação do saldo de radiação, especialmente no caso das folhas sombreadas. No presente estudo, erros associados ao saldo de radiação também podem ter ocorrido, especialmente pelo fato do modelo considerar que o sensor se encontrava na horizontal. No entanto, tais superestimativas provavelmente se devem também às diferenças na capacidade de retenção do molhamento pelos sensores de DPM, em razão de seu ângulo de inclinação de $30^{\circ}$, em relação ao valor assumido pelo modelo.

Os erros observados para a DPM podem ser melhor analisados ao se avaliar os erros das estimativas para os horários de início e de secamento do molhamento foliar (Tabela 7.2).

Verificou-se que para o secamento do orvalho não houve muitas diferenças entre as estimativas nas três alturas, com o horário estimado sendo consistentemente mais tarde do que o observado pelos sensores (EMs +) e com o EAM sendo da ordem de 38 a 39 minutos para todo o período analisado. A mesma tendência foi observada quando analisou-se somente os dias com ou sem chuvas, ou seja, com o secamento sendo estimado tardiamente (EMs +). Porém, neste caso, os erros foram ligeiramente menores nos dias em que o molhamento foliar foi provocado apenas pelo orvalho (EAMs entre 24 e 27 minutos) e substancialmente maiores nos dias em que a chuva também contribuiu para a DPM (EAMs entre 55 e 63 minutos). Tais erros estão associados ao fato de que os sensores normalmente têm sua capacidade de retenção de água variável, especialmente em dias chuvosos ou com muito vento, enquanto o modelo admite uma capacidade constante de retenção de água. 

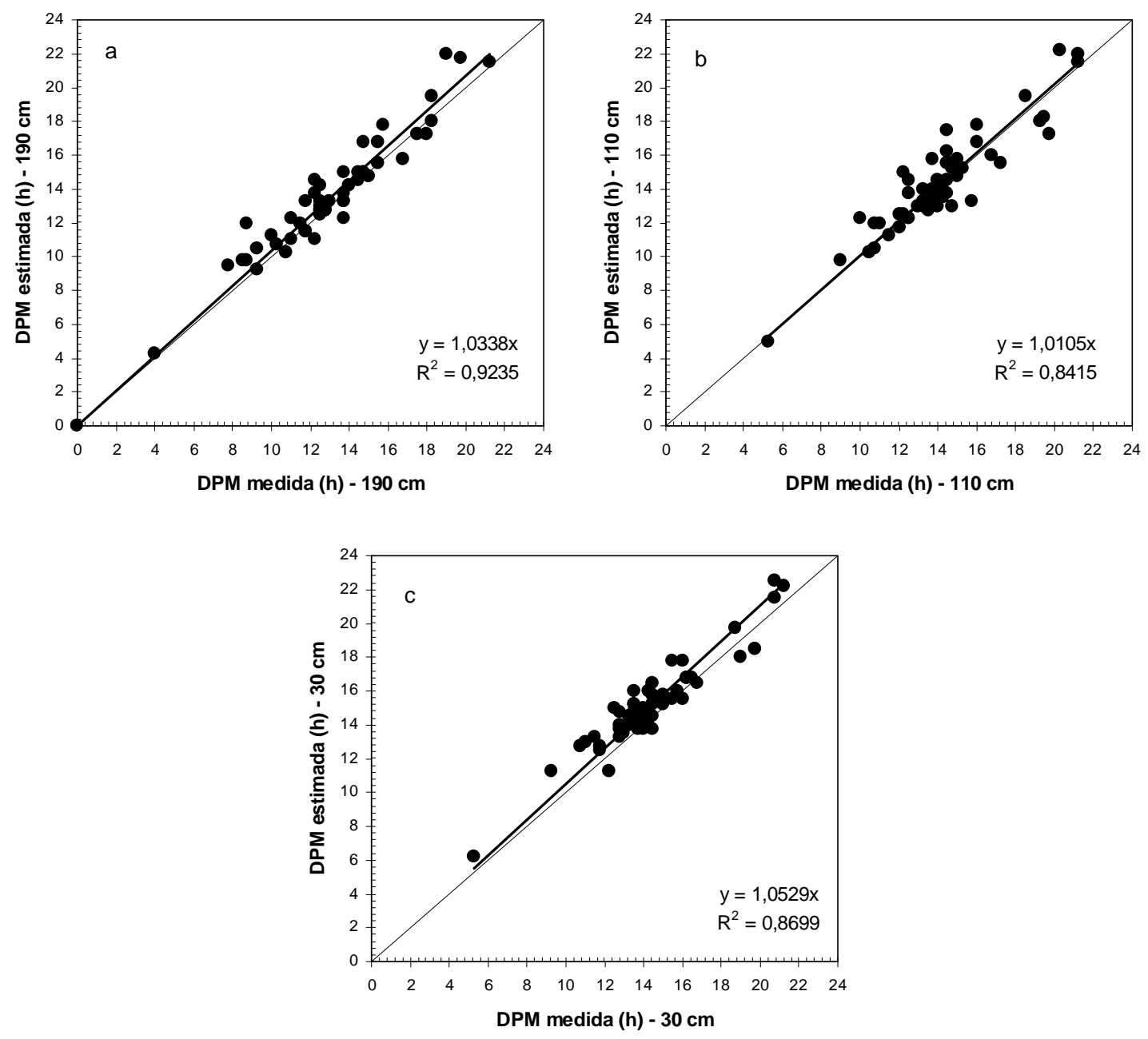

Figura 7.3 - Relação entre a DPM estimada pelo modelo de Penman-Monteith, para as alturas de $190 \mathrm{~cm}$ (a), $110 \mathrm{~cm}$ (b) e $30 \mathrm{~cm}$ (c), e a DPM medida pelos sensores eletrônicos, em Elora, ON, Canadá, de julho a outubro de 2003. 
Tabela 7.2 - Erro médio (EM) e erro absoluto médio (EAM), em minutos, para o início e para o fim do molhamento foliar estimados pelo modelo de Penman-Monteith, para alturas de 190, 110 e 30 cm acima da superfície gramada, considerando-se todo o período e os dias com e sem chuva separadamente.

\begin{tabular}{lcccc}
\hline Sensor & \multicolumn{2}{c}{ Início do molhamento } & \multicolumn{2}{c}{ Fim do molhamento } \\
\cline { 2 - 5 } & EM (min.) & EAM (min.) & EM (min.) & EAM (min.) \\
\hline Todo o período & & & & \\
\hline $190 \mathrm{~cm}$ & $+6,00$ & 18,50 & $+32,25$ & 39,25 \\
$110 \mathrm{~cm}$ & $+6,00$ & 24,50 & $+20,75$ & 37,25 \\
$30 \mathrm{~cm}$ & $-17,66$ & 29,76 & $+27,58$ & 38,22 \\
\hline Dias sem chuva & & & & \\
\hline $190 \mathrm{~cm}$ & $+3,60$ & 15,80 & $+19,05$ & 24,73 \\
$110 \mathrm{~cm}$ & $+1,97$ & 22,50 & $+10,26$ & 26,84 \\
$30 \mathrm{~cm}$ & $-27,75$ & 33,00 & $+18,37$ & 25,12 \\
\hline Dias com chuva & & & & \\
\hline $190 \mathrm{~cm}$ & $+8,49$ & 22,83 & $+53,48$ & 62,61 \\
$110 \mathrm{~cm}$ & $+12,95$ & 27,95 & $+38,86$ & 55,23 \\
$30 \mathrm{~cm}$ & $+0,68$ & 23,86 & $+44,32$ & 62,04 \\
\hline
\end{tabular}

Para o início do molhamento, as estimativas dos horários apresentaram erros de menor magnitude do que aqueles para os horários de secamento (Tabela 7.2), o que também foi observado em outros estudos com modelos físicos de estimativa da DPM (Pedro Jr. e Gillespie, 1982b; Francl e Panigrahi, 1997; Rao et al., 1998). Esses erros no horário de início do molhamento foram crescentes com a diminuição da altura da posição dos sensores para todo o período de dados e também para os dias sem chuva, o que era esperado em função das variáveis meteorológicas estarem sendo observadas a 190 cm de altura. Para os dias com chuva, tal tendência só foi observada entre os erros 
das estimativas a 190 e 110 cm de altura. De um modo geral, os horários de início do molhamento estimados pelo modelo de Penman-Monteith mostraram-se antecipados (EMs -) para a altura de $30 \mathrm{~cm}$, exceto para os dias chuvosos. Para as demais condições (190 e $110 \mathrm{~cm})$ tais estimativas foram ligeiramente tardias, com EM variando entre $+1,97$ e $+12,95$ minutos.

De um modo geral, o modelo de Penman-Monteith estimou a DPM nas três alturas com erros absolutos médios inferiores a $1,1 \mathrm{~h}$ e com erros máximos não superiores a 3,25 h (Tabela 7.3). Esses valores de EAM são inferiores aos obtidos com o mesmo modelo por Rao et al. (1998), da ordem de 1,77 h, e com modelos similares por Luo e Goudriaan (2000), da ordem de 2,11 h, e por Madeira et al. (2002), da ordem de 1,5 h, quando empregados, respectivamente, na cultura do milho, na cultura do arroz inundado e sobre gramado. Além disso, os resultados aqui obtidos, para os erros das estimativas da DPM pelo modelo de Penman-Monteith, são da mesma ordem de grandeza daqueles obtidos por modelos mais complexos, como os apresentados por Pedro e Gillespie (1982a,b) e Francl e Panigrahi (1997), da ordem de 1,0 a 1,5 h.

Tabela 7.3 - Erro médio (EM), erro absoluto médio (EAM) e erro absoluto máximo (EMAX), em horas, da estimava da DPM pelo modelo de Penman-Monteith para as alturas de 190, 110 e 30 cm sobre gramado, em Elora.

\begin{tabular}{rccc}
\hline Posição & EM & EAM & EMAX \\
\hline $190 \mathrm{~cm}$ & $+0,47$ & 0,76 & 3,25 \\
$110 \mathrm{~cm}$ & $+0,20$ & 0,89 & 3,00 \\
$30 \mathrm{~cm}$ & $+0,78$ & 1,05 & 2,50 \\
\hline
\end{tabular}




\subsubsection{Estimativa da DPM de referência e da cultura em diferentes localidades}

A partir das estimativas da DPM pelo modelo de Penman-Monteith para a condição de referência, avaliou-se a possibilidade de se estimar a DPM da cultura. A Figura 7.4a apresenta a relação entre a DPM medida a $30 \mathrm{~cm}$ de altura sobre um gramado e a DPM estimada para essa condição, levando-se em consideração os dados obtidos em Elora, Jundiaí e Piracicaba. Assim como observado para a relação apresentada na Figura 7.3c, para Elora, a DPM estimada para a condição de referência também apresentou valores superiores aos medidos pelos sensores, quando os dados de duas outras localidades foram levados em consideração (Figura 7.4a e Tabela 7.4). A superestimativa média, neste caso, foi da ordem de $7,4 \%\left(\mathrm{R}^{2}=0,92\right)$, mostrando que o modelo manteve seu desempenho estável e aceitável, indicando que este tem aplicabilidade universal sem a necessidade de ajustes ou calibrações.

Os erros absolutos médios associados a essas estimativas (Tabela 7.4) foram da ordem de 1,0 h em Elora, de 1,5 h em Jundiaí, de 1,9 h em Piracicaba e de 1,46 h considerando-se as três localidades conjuntamente. Erros dessa ordem de magnitude, de

1 a 2 h, vêm sendo obtidos por outros estudos envolvendo modelos físicos para a estimativa da DPM (Pedro Jr. e Gillespie, 1982b; Francl e Panigrahi, 1997; Rao et al., 1998; Luo e Goudriaan, 2000; Madeira et al., 2002), sendo aceitáveis do ponto de vista operacional, já que erros dessa grandeza também podem ser observados entre medidas feitas pelos sensores eletrônicos e observações visuais (Magarey, 1999; Magarey et al., 2001). 
Tabela 7.4 - Erro médio (EM), erro absoluto médio (EAM) e erro absoluto máximo (EMAX), em horas, da estimava da DPM pelo modelo de Penman-Monteith para a condição de referência (30 cm sobre gramado), em Elora, Jundiaí e Piracicaba.

\begin{tabular}{lcccc}
\hline Erro (horas) & Elora & Jundiaí & Piracicaba & Geral \\
\hline EM & $+0,77$ & $+1,29$ & $+1,74$ & $+1,22$ \\
EAM & 1,04 & 1,55 & 1,92 & 1,46 \\
EMAX & 2,50 & 4,70 & 4,50 & 4,70 \\
\hline
\end{tabular}

Quando a DPM estimada para o gramado a uma altura de $30 \mathrm{~cm}$ foi correlacionada com a DPM medida no topo das culturas, uma boa concordância foi observada, com uma superestimativa média de 6,5\% e um coeficiente de determinação de 0,90, considerando-se as três culturas conjuntamente (Figura 7.4b). Novamente, os erros associados a essas estimativas foram da ordem de 0,9 a 1,9 h, considerando-se as culturas separadamente, e de 1,4 h para todo o conjunto de dados (Tabela 7.5). Esses erros são similares àqueles apresentados na literatura, como já discutido anteriormente, porém salienta-se que na parametrização aqui apresentada esse modelo não exige ajustes ou calibrações, assim como a medida da temperatura ou de outras variáveis junto à superfície da cultura, ao contrário do modelo proposto por Pedro Jr. e Gillespie (1982a,b) e empregado por diversos autores (Gillespie e Barr, 1984; Lhomme e Jimenez, 1982; Scherm e Bruggen, 1993; Wittich, 1995; Francl e Panigrahi, 1997; Rao et al., 1998; Papastamati et al., 2004). Novamente, isso mostra a estabilidade do modelo de Penman-Monteith para a estimativa da DPM, quando empregado para diferentes condições climáticas, e a potencialidade desse procedimento direto de estimativa da 
DPM da cultura a partir da DPM de referência para uso em sistemas de alerta fitossanitário, à semelhança do que atualmente é utilizado para a estimativa da evapotranspiração de referência e de cultura (Allen et al., 1998).
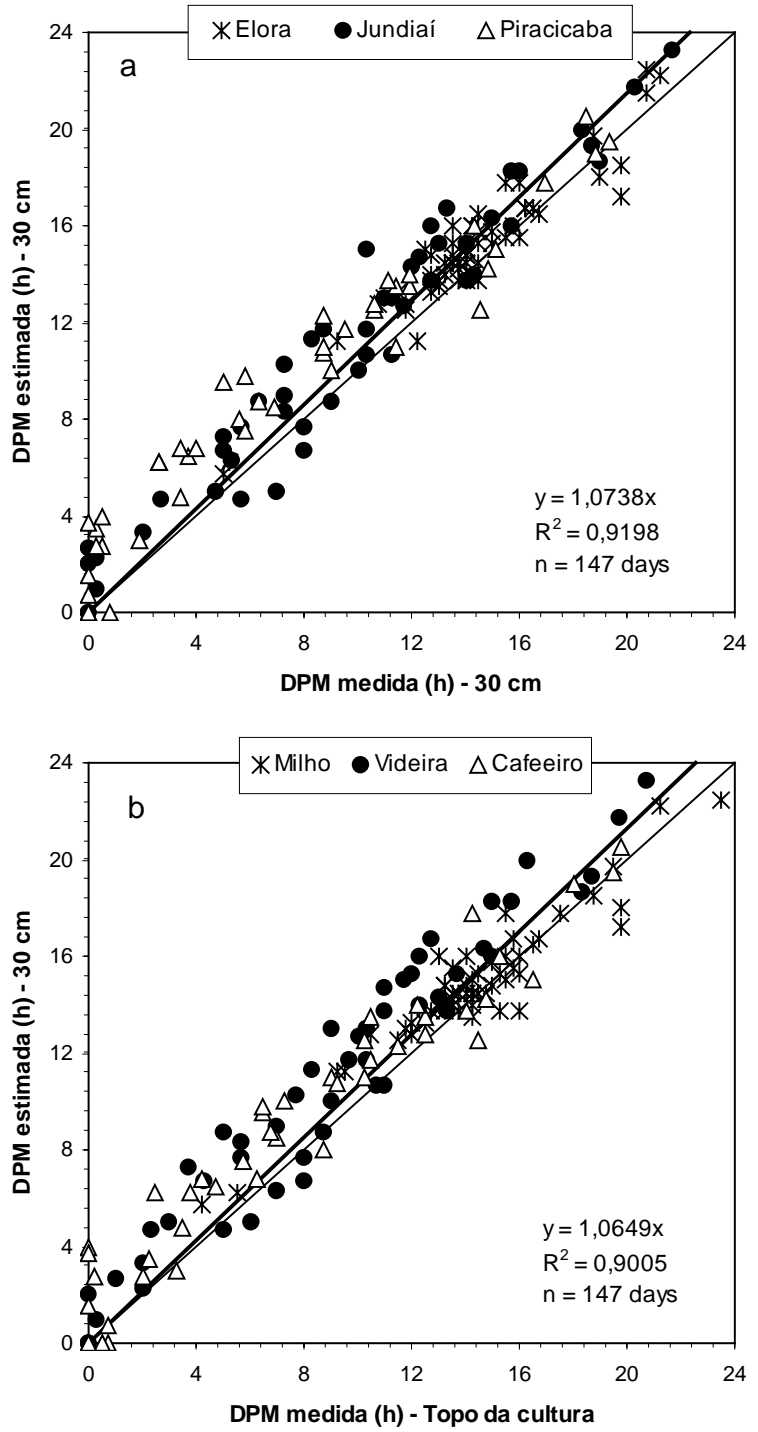

Figura 7.4 - Relação entre a DPM estimada pelo modelo de Penman-Monteith, para a altura de 30 cm sobre superfície gramada, e a DPM medida pelo sensor eletrônico na mesma posição em Elora, Piracicaba e Jundiaí (a) e no topo das culturas do milho, da uva e do café (b). 
Quando a DPM estimada para o gramado a uma altura de $30 \mathrm{~cm}$ foi correlacionada com a DPM medida no topo das culturas, uma boa concordância foi observada, com uma superestimativa média de 6,5\% e um coeficiente de determinação de 0,90, considerando-se as três culturas conjuntamente (Figura 7.4b). Novamente, os erros associados a essas estimativas foram da ordem de 0,9 a 1,9 h, considerando-se as culturas separadamente, e de 1,4 h para todo o conjunto de dados (Tabela 7.5). Esses erros são similares àqueles apresentados na literatura, como já discutido anteriormente, porém salienta-se que na parametrização aqui apresentada esse modelo não exige ajustes ou calibrações, assim como a medida da temperatura ou de outras variáveis junto à superfície da cultura, ao contrário do modelo proposto por Pedro Jr. e Gillespie (1982a,b) e empregado por diversos autores (Gillespie e Barr, 1984; Lhomme e Jimenez, 1982; Scherm e Bruggen, 1993; Wittich, 1995; Francl e Panigrahi, 1997; Rao et al., 1998; Papastamati et al., 2004). Novamente, isso mostra a estabilidade do modelo de Penman-Monteith para a estimativa da DPM, quando empregado para diferentes condições climáticas, e a potencialidade desse procedimento direto de estimativa da DPM da cultura a partir da DPM de referência para uso em sistemas de alerta fitossanitário, à semelhança do que atualmente é utilizado para a estimativa da evapotranspiração de referência e de cultura (Allen et al., 1998).

A estimativa da DPM da cultura a partir da DPM de referência mostrou ser melhor para culturas com cobertura contínua, caso da cultura do milho, onde o EAM foi inferior a 1h. Nas culturas com cobertura descontínua, caso da uva conduzida em espaldeira e do cafeeiro jovem, os erros absolutos médios foram maiores, entre 1,5 e 1,9 
h, o que é consequência das diferenças estruturais e aerodniâmicas dessas em relação ao à cobertura de referência (gramado).

Uma outra constatação foi de que o modelo de Penman-Monteith acusou a ocorrência de DPM, entre 1 e 4 h, enquanto os sensores não registaram molhamento foliar. Isso ocorreu numa seqüência de 4 dias entre 16/10 e 29/11 no cafeeiro e em 2 dias (26/10 e 05/11) na videira, nos quais o molhamento acumulado durante à noite foi menor do que 0,01 $\mathrm{mm}$. Isso mostra a sensibilidade do modelo analisado na estimativa da condensação, sendo esses erros provavelmente associados à calibração dos sensores de umidade relativa, em razão de ser essa variável a de maior peso na formação do orvalho (Papastamati et al., 2004).

\subsubsection{Efeito da redução do saldo de radiação noturno na estimativa da DPM}

De forma a se avaliar as possíveis causas da tendência de superestimativa da DPM pelo modelo de Penman-Monteith, tanto para as condições de gramado (Tabelas 7.3 e 7.4 e Figuras 7.3 e 7.4a) como das culturas (Tabela 7.5 e Figura 7.4b), estimou-se a DPM para tais condições levando-se em consideração uma redução de $20 \%$ no saldo noturno de radiação (valores negativos).

Tal procedimento resultou em redução das superestimativas da DPM para todas as condições, como se pode observar nos coeficientes angulares das equações de regressão linear (Figuras 7.5 e 7.6) e nos valores de EM (Tabelas 7.6, 7.7 e 7.8). Para as estimativas feitas sobre o gramado a $190 \mathrm{~cm}$ de altura, mesma posição em que as variáveis meteorológicas utilizadas no modelo foram medidas, a reta da equação de 
regressão mostrou haver um ótimo ajuste entre os valores de DPM medidos e estimados ( $b=1,0018, \mathrm{R}^{2}=0,90, \mathrm{EM}=+0,01 \mathrm{~h}$ e EAM = 0,88 h). Por outro lado, com exceção apenas para a condição de gramado a 110 cm, a tendência de superestimativa da DPM se manteve, apesar de ser em menor grau, mostrando que outras variáveis podem estar condicionando essa superestimativa, sendo a mais provável a resistência aerodinâmica adicional utilizada para as estimativas a $30 \mathrm{~cm}$ de altura.

Tabela 7.5 - Erro médio (EM), erro absoluto médio (EAM) e erro absoluto máximo (EMAX), em horas, da estimava da DPM pelo modelo de Penman-Monteith para as culturas do milho, da uva e do café, a partir dos dados observados em uma estação meteorológica em Elora, Jundiaí e Piracicaba, respectivamente.

\begin{tabular}{lcccc}
\hline Erro (horas) & Milho & Uva & Café & Geral \\
\hline EM & $+0,47$ & $+1,71$ & $+1,23$ & $+1,12$ \\
EAM & 0,93 & 1,87 & 1,53 & 1,42 \\
EMAX & 3,00 & 4,00 & 4,00 & 4,00 \\
\hline
\end{tabular}

Tabela 7.6 - Erro médio (EM), erro absoluto médio (EAM) e erro absoluto máximo (EMAX), em horas, da estimava da DPM pelo modelo de Penman-Monteith para as alturas de 190, 110 e $30 \mathrm{~cm}$ sobre gramado, em Elora, considerando-se $80 \%$ do saldo de radiação noturno.

\begin{tabular}{rccc}
\hline Posição & EM & EAM & EMAX \\
\hline $190 \mathrm{~cm}$ & $+0,01$ & 0,88 & 3,25 \\
$110 \mathrm{~cm}$ & $-0,21$ & 1,01 & 2,75 \\
$30 \mathrm{~cm}$ & $+0,40$ & 0,83 & 2,50 \\
\hline
\end{tabular}



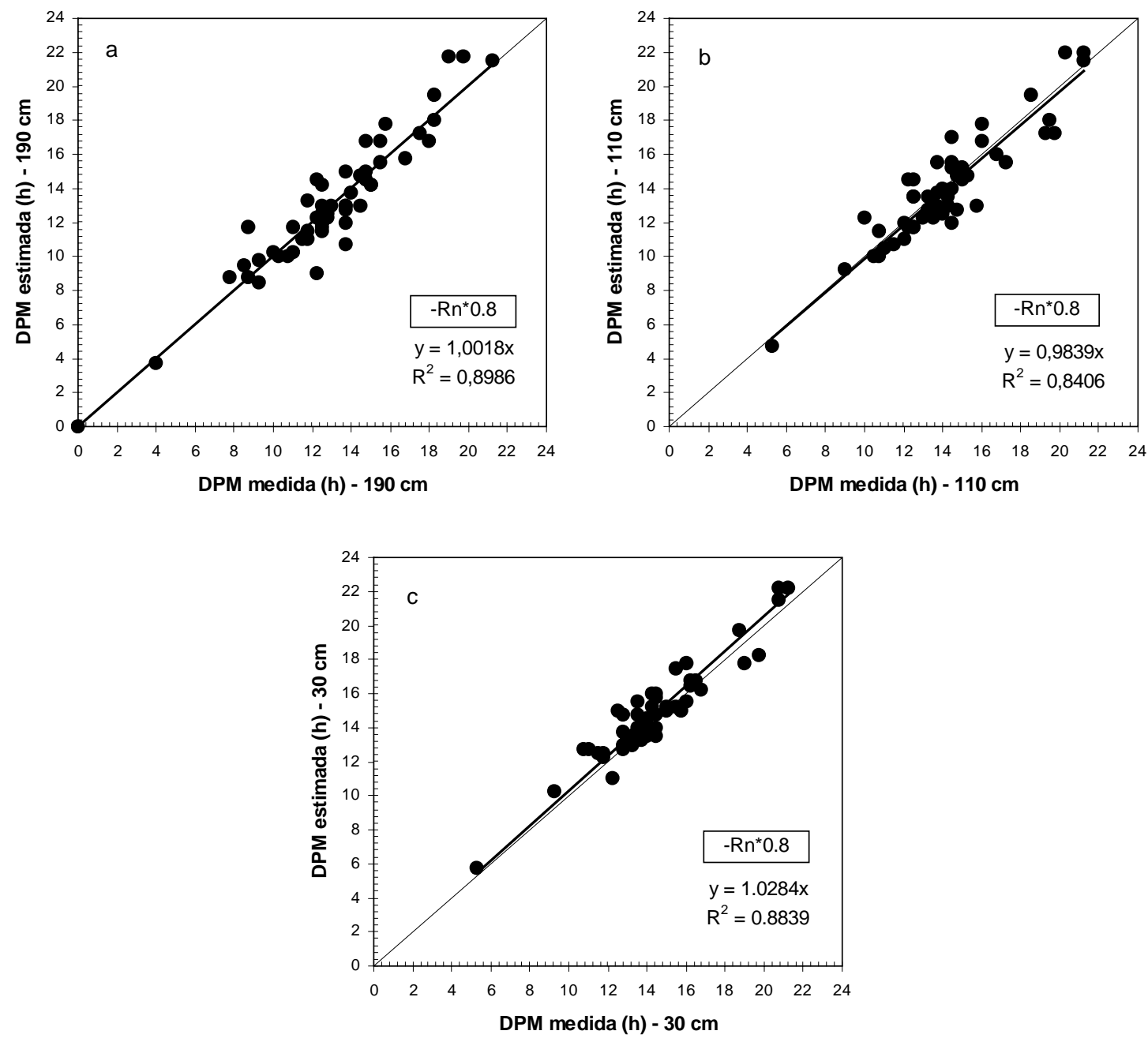

Figura 7.5 - Relação entre a DPM estimada pelo modelo de Penman-Monteith (considerando-se 80\% do saldo de radiação noturno), para as alturas de 190 cm (a), 110 cm (b) e 30 cm (c), e a DPM medida pelos sensores eletrônicos, em Elora, ON, Canadá, de julho a outubro de 2003. 
Tabela 7.7 - Erro médio (EM), erro absoluto médio (EAM) e erro absoluto máximo (EMAX), em horas, da estimava da DPM pelo modelo de Penman-Monteith para a condição de referência (30cm sobre gramado), em Elora, Jundiaí e Piracicaba, considerando-se $80 \%$ do saldo de radiação noturno.

\begin{tabular}{lcccc}
\hline Erro (horas) & Elora & Jundiaí & Piracicaba & Geral \\
\hline EM & $+0,40$ & $+0,67$ & $+1,49$ & $+0,77$ \\
EAM & 0,83 & 1,25 & 1,76 & 1,23 \\
EMAX & 2,50 & 4,40 & 4,95 & 4,95 \\
\hline
\end{tabular}

Tabela 7.8 - Erro médio (EM), erro absoluto médio (EAM) e erro absoluto máximo (EMAX), em horas, da estimava da DPM pelo modelo de Penman-Monteith para as culturas do milho, da uva e do café, a partir dos dados observados em estação meteorológica em Elora, Jundiaí e Piracicaba, respectivamente, e considerando-se 80\% do saldo de radiação noturno.

\begin{tabular}{lcccc}
\hline Erro (horas) & Milho & Uva & Café & Geral \\
\hline EM & $+0,07$ & $+1,09$ & $+0,92$ & $+0,67$ \\
EAM & 0,83 & 1,50 & 1,39 & 1,23 \\
EMAX & 2,50 & 4,00 & 4,50 & 4,50 \\
\hline
\end{tabular}



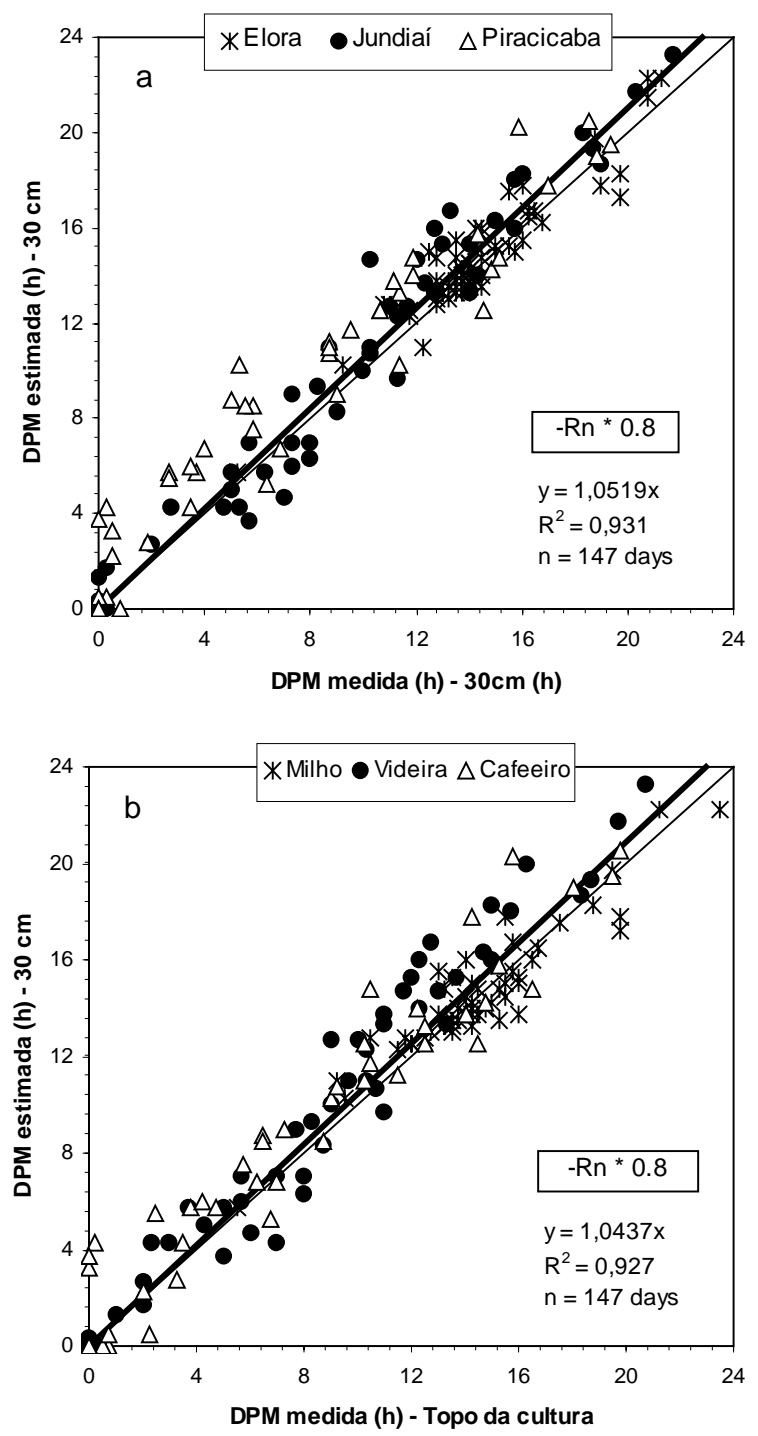

Figura 7.6 - Relação entre a DPM estimada pelo modelo de Penman-Monteith (considerando-se $80 \%$ do saldo de radiação noturno), para a altura de $30 \mathrm{~cm}$ sobre superfície gramada, e a DPM medida pelo sensor eletrônico na mesma posição em Elora, Piracicaba e Jundiaí (a) e no topo das culturas do milho, da uva e do café (b). 


\subsubsection{Efeito das estimativas do saldo de radiação na estimativa da DPM}

A necessidade da estimativa do saldo de radiação (Rn) é uma desvantagem para o uso operacional dos modelos físicos de estimativa da DPM, já que essa variável é raramente medida diretamente, até mesmo nas estações meteorológicas padrões. Assim, testou-se o efeito de diferentes estimativas de Rn na acurácia e precisão da DPM estimada pelo modelo de Penman-Monteith. Quatro diferentes métodos de estimativa da Rn foram usados, os quais empregam diferentes combinações das seguintes variáveis: radiação solar, T, UR, cobertura e altura de nuvens.

Na Figura 7.7 são apresentadas as relações entre os dados horários de Rn medidos sobre o gramado e estimados pelos quatro modelos. Observa-se que apesar da boa concordância entre as medidas e as estimativas, com os valores de $\mathrm{R}^{2}$ sempre acima de 0,95 e com o coeficiente ângular da reta significativamente não diferindo de 1 , os modelos não estimaram adequadamente o saldo de radiação noturno. O modelo I foi o que teve o melhor desempenho do ponto de vista estatístico, com os menores valores dos coeficientes linear $(\mathrm{a}=-4,09)$ e ângular $(\mathrm{b}=1,06)$ da equação da reta e com o maior valor de $\mathrm{R}^{2}(0,98)$. Por outro lado, o modelo III foi o que teve o pior desempenho, com a $=23,11, \mathrm{~b}=1,14$ e $\mathrm{R}^{2}=0,95$.

Quando essas estimativas de Rn, ao invés dos dados medidos, foram usadas no modelo de Penman-Monteith, não houveram mudanças significativas na acurácia das estimativas da DPM (b variando de 0,95 a 1,02), enquanto que a precisão $\left(\mathrm{R}^{2}\right)$ variou entre 0,85 e 0,92, dependendo da complexidade do modelo de estimativa de $\mathrm{Rn}$ empregado (Figura 7.8). Resultados similares foram obtidos por Madeira et al. (2002), 
que ao empregarem a Rn estimada pelos modelos II e III na estimativa da DPM não observaram diferenças significativas nos erros absolutos médios proporcionados (1,5 e 1,6 h, respectivamente). Esses resultados, concordam com as observações de Papastamati et al. (2004) que verificaram que o saldo de radiação tem um efeito cerca de seis vezes menor na estimativa da DPM por modelos físicos do que a umidade relativa do ar.

Os erros associados às estimativas de DPM, com diferentes formas de determinação do saldo de radiação, foram sempre inferiores a 1,6 h, porém com os Modelos I e II apresentando erros muito similares aos obtidos com o saldo de radiação medido (Tabela 7.9). Os modelos III e IV, por sua vez, resultaram nos maiores EAM, 1,29 e 1,53 h, e EMAX, 6,0 e 4,0 h, respectivamente.

O modelo IV, apesar da subestimativa da DPM e dos maiores erros, é um modelo bastante simples, baseado apenas na $\mathrm{T}$ e na Rg, possibilitando o emprego de modelos físicos de estimativa da DPM a partir de estações meteorológicas simples e sem a necessidade de dados de nuvens, os quais normalmente só estão disponíveis em aeroportos de grande porte. 

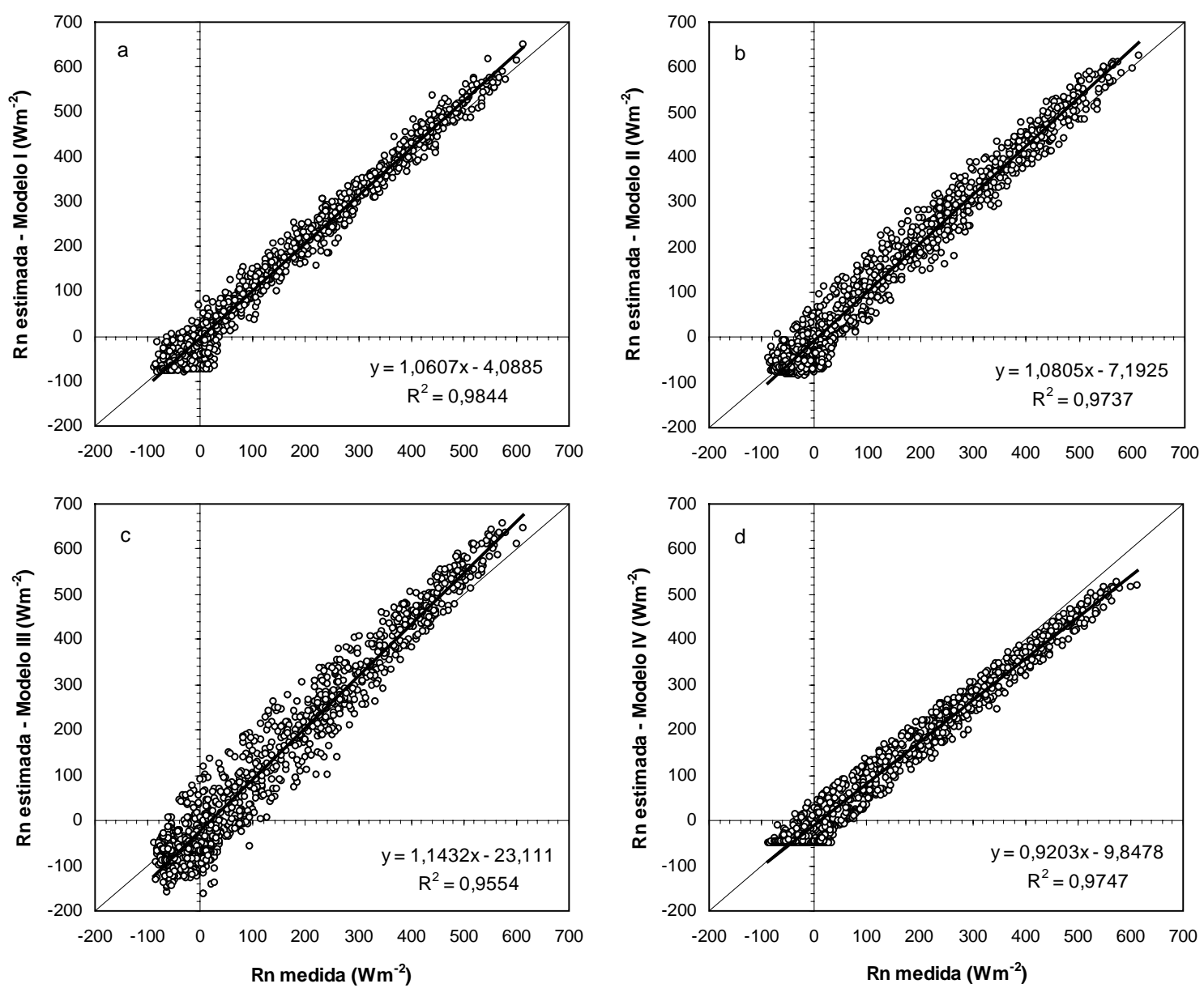

Figura 7.7 - Relação entre o saldo de radiação horário medido pelo sensor CNR1 sobre gramado e aqueles estimados a partir das variáveis meteorológicas pelos modelos I (a), II (b), III (c) e IV (d), para Elora, ON, Canadá. 

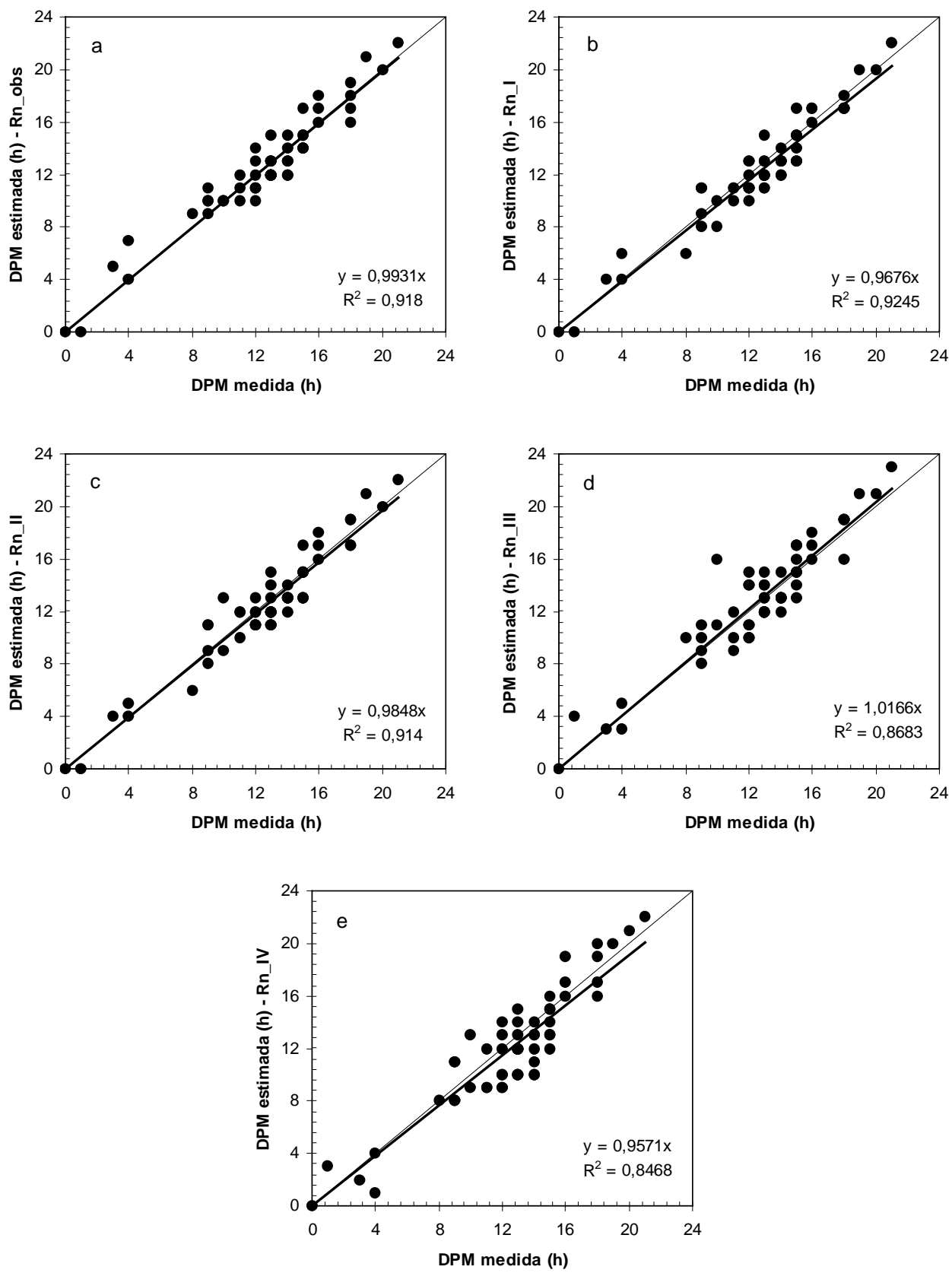

Figura 7.8 - Relação entre os dados diários da DPM medida por sensor eletrônico e as DPMs estimadas pelo modelo de Penman-Monteith, utilizando-se diferentes formas de obtenção do saldo de radiação: a) medido, b) estimado pelo Modelo I, c) estimado pelo Modelo II, d) estimado pelo Modelo III e e) estimado pelo Modelo IV. 
Tabela 7.9 - Erro médio (EM), erro absoluto médio (EAM) e erro absoluto máximo (EMax), em horas, da estimativa da DPM pelo modelo de Penman-Monteith, utilizandose diferentes métodos de determinação do saldo de radiação: medida pelo sensor CNR1 (Rn_obs) e estimada pelos modelos I (Rn_I), II (Rn_II), III (Rn_III) e IV (Rn_IV), e dados de uma estação meteorológica em Elora.

\begin{tabular}{lccccc}
\hline Erro & Rn_obs & Rn_I & Rn_II & Rn_III & Rn_IV \\
\hline EM & $-0,03$ & $-0,41$ & $-0,21$ & $+0,26$ & $-0,60$ \\
EAM & 0,93 & 1,00 & 1,07 & 1,29 & 1,53 \\
EMax & 3,00 & 2,00 & 3,00 & 6,00 & 4,00 \\
\hline
\end{tabular}

\subsection{Conclusões}

Conclui-se a partir deste estudo que o modelo de Penman-Monteith, aplicado a um sensor de DPM de tamanho e albedo fixos e exposto sobre gramado a $30 \mathrm{~cm}$ de altura, é uma ferramenta muito útil para a estimativa dessa variável em sistemas de alerta fitossanitário. Os resultados aqui apresentados mostraram que a DPM de referência estimada pelo modelo de Penman-Monteith, a partir de dados meteorológicos, é uma boa opção para a estimativa direta da DPM de diferentes culturas, mesmo para aqueles locais onde não há disponibilidade de dados de saldo de radiação, em razão dessa variável poder ser estimada, sem efeitos significativos nos resultados. As superestimativas da DPM da cultura obtidas pelo modelo de Penman-Monteith, da ordem de 6,5\%, são aceitáveis em termos operacionais, pois uma certa margem de segurança é desejável quando do uso da DPM em sistemas de alerta fitossanitário. 


\section{CONCLUSÕES GERAIS}

Os resultados deste estudo permitiram concluir que:

a) Os sensores eletrônicos para medida da DPM, com espaçamento típico de $1 \mathrm{~mm}$ entre os eletrôdos, devem ser pintados. Esse procedimento é necessário para reduzir as subestimativas e aumentar a precisão das medidas.

b) Os sensores eletrônicos de DPM de placa de circuito impresso, quando propriamente tratados com pintura e calor, dão medidas que são tão precisas e acuradas quanto os limites da amostragem espacial relatados em estudos prévios. Entretanto, a posição, altura e ângulo dos sensores de DPM têm efeito sobre as medidas. Nas posições mais altas a DPM foi menor do que aquela medida a $30 \mathrm{~cm}$ e nos menores ângulos ela foi maior do que nos ângulos maiores.

c) O padrão de instalação do sensor para a medida da DPM de referência em uma estação meteorológica deve ser a uma altura de 30 cm e com ângulo de inclinação em relação à horizontal variando entre $30^{\circ}$ e $45^{\circ}$. 
d) Em geral, todos os modelos de estimativa da DPM tiveram um bom desempenho na cultura do algodão, apresentando em média pequenas subestimativas pelo modelo do NHUR $>90 \%$ e superestimativas pelos modelos DPO, CART e RES.

e) Os modelos do NHUR>90\% e da DPO, sendo empíricos e de fácil aplicação, são uma ferramenta prática para a estimativa da DPM na cultura do algodão, especialmente quando dados de radiação solar e velocidade do vento não estão disponíveis. Porém, o modelo RES (Penman-Monteith) mostrou ser uma boa opção para a estimativa da DPM ao nível da cultura, tendo as estimativas boa concordância com as medidas obtidas pelas micro-estações. Além disso, o modelo RES foi capaz de reproduzir a mesma relação entre a DPM medida ao nível da cultura e na estação meteorológica.

f) O modelo da DPO também apresentou capacidade de reproduzir a relação de DPM entre a cultura e a estação meteorológica, porém, este método necessita de ajustes empíricos dependentes das condições da cultura e do clima do local.

g) A medida da DPM em diversas posições de diferentes culturas mostrou que essa variável é afetada não somente pelas condições climáticas, mas também pela estrutura, arquitetura, arranjo e altura das plantas, fatores esses que controlam o microclima. O padrão de variação da DPM no interior das culturas diferiu de acordo com as características mencionadas acima. 
h) Para pomares, como o da macieira, e para culturas anuais bem desenvolvidas, como a do milho, onde somente o topo da cultura está diretamente exposto ao céu, a DPM causada pelo orvalho foi maior no topo do que no interior da vegetação. Para plantas jovens de café, as quais tem formato cônico, o padrão de variação da DPM em dias com orvalho foi o oposto, com maior DPM na parte baixa das plantas. Para uma cultura bem ventilada, como a da uva cultivada em sistema de espaldeira, ou de baixo porte, como a do tomate, nenhuma diferença significativa foi observada, tanto para dias com ou sem chuva, entre o topo e a parte baixa do dossel. Por outro lado, durante os dias chuvosos a DPM mostrou variar menos entre o topo e o interior das culturas da maçã, do café e do milho.

i) O uso da DPM medida sobre o gramado (a $30 \mathrm{~cm}$ de altura e com inclinação de $30^{\circ}$ ou $45^{\circ}$ ) mostrou ser uma opção bastante viável para a estimativa da DPM no topo de diferentes culturas, especialmente para aquelas que tem nessa posição as maiores DPMs. Para as culturas em que a maior DPM ocorre no interior da vegetação, o uso de pelo menos dois sensores (um no topo e outro no inteior) deve ser considerado.

j) O modelo de Penman-Monteith aplicado a um sensor de DPM de tamanho e albedo fixos e exposto sobre gramado a $30 \mathrm{~cm}$ de altura pode ser uma ferramenta muito útil para a estimativa dessa variável em sistemas de alerta fitossanitário.

k) A DPM de referência estimada pelo modelo de Penman-Monteith, a partir de dados meteorológicos obtidos em estações padrões, é uma boa opção para a estimativa 
direta da DPM de diferentes culturas, mesmo para aqueles locais onde não há disponibilidade de dados de saldo de radiação, em razão dessa variável poder ser estimada sem efeitos significativos nos resultados. As superestimativas da DPM da cultura obtidas pelo modelo de Penman-Monteith, da ordem de 6,5\%, são aceitáveis em termos operacionais, pois uma certa margem de segurança é desejável quando do uso da DPM em sistemas de alerta fitossanitário. 


\section{REFERÊNCIAS BIBLIOGRÁFICAS}

Allen,R.G., Pereira, L.S., Raes, D., Smith, M. Crop evapotranspiration - guidlines for computing crop water requirements. Roma: FAO, 1998. 331p. (Paper 56).

Armstrong, R., Barthakur, N.N. and Norris, E. A comparative study of three leaf wetness sensors. International Journal of Biometeorology, v.37, p.7-10, 1993.

Baier, W. Studies on dew formation under semi-arid conditions. Agricultural Meteorology, v.3, p.103-112, 1966.

Bathakur, N.N. A comparative study of radiometric and electronic leaf wetness sensors. Agricultural and Forest Meteorology, v.36, p.83-90, 1985.

Bergamin Filho, A., Amorim, L. Doenças de plantas tropicais: epidemiologia e controle econômico. Piracicaba: Ed. Ceres. 1996. 299p.

Burrage, S.W. Dew on wheat. Agricultural Meteorology, v.10, p.3-12, 1972.

Burrage, S.W. Monitoring the environment in relation to epidemiology. In: Scott, P.R., Bainbridge, A. (ed). Plant disease epidemiology. Oxford, Blackwell Sci. Publ. p.93110. 1978.

Butler, D.R., Jadhav, D.R. Requirements of leaf wetness and temperature for infection of groundnut by rust. Plant Pathology, v.40, p.395-400, 1991. 
Byrne, J.M., Hausbeck, M.K., Meloche, C., Jarosz, A.M. Influence of dew period and temperature on foliar infection of greenhouse-grown tomato by Colletotrichum coccodes. Plant-Disease, v.82, n.6, p.639-641, 1998.

Campbell Sci. Model 237 - Leaf wetness sensor. Campbell Scientific, Inc., Logan, 1996. 4p.

Campbell, G.S., Norman, J.M. Introduction to environmental biophysics. 2ed. New York: Springer. 1998. 286p.

Canihos, Y, Peever, T.L., Timmer, L.W. Temperature, leaf wetness and isolate effects on infection of Minneola tangelo leaves by Alternaria sp. Plant-Disease, v.83, n.5, p.429-433, 1999.

Chtioui, Y., Panigrahi, S., Francl, L. A generalized regression neural network and its application for leaf wetness prediction to forecast plant disease. Chemometrics and Intelligent Laboratory Systems, v.48, p.47-58, 1999.

Ciarisse, O., Bourgeois, G., Duthie, J.A. Influence of temperature and leaf wetness duration on infection of strawberry leaves by Mycosphaerella fragariae. Phytopathology, v.90, n.10, p.1120-1125, 2000.

Crowe, M.J., Coakley, S.M, and Emge, R.G. Forecasting dew duration at Pendleton, Oregon, using simple weather observations. Journal of Applied Meteorology, v.17, p.1482-1487, 1978.

Davis, D.R., Hughes, J.E. A new approach to recording the wetting parameter by the use of electrical resistance sensors. Plant Disease Report, v.54, p.474-479, 1970. 
Deshpande, R.Y., Hubbard, K.G., Coyne, D.P., Steadman, J.R., and Pankhurst, A.M. Estimating leaf wetness in dry bean canopies as a prerequisite to evaluating white mold disease. Agronomy Journal, v.87, p.613-619, 1995.

Francl, L.J., Panigrahi, S. Artificial neural network models of wheat leaf wetness. Agricultural and Forest Meteorology, v.88, p.57-65, 1997.

Garín, A., Figueroa, P., Basualdo, A., Giavedoni, P., Oricchio, P., Skanky, M. Meteorological method based on wet foliage to determine areas at high risk of fungal epidemics. International Journal of Biometeorology, v.40, p.178-180, 1997.

Getz, R.R. Report on the measurement of leaf wetness. Report to WMO, Commission for Instruments and methods of Observation. 1991. 9p.

Giesler, L. J., Horst, G.L., Yuen, G.Y. A site-specific sensor for measuring leaf wetness duration within turfgrass canopies. Agricultural and Forest Meteorology, v.81, p.145156, 1996.

Gillespie, T.J., Kidd, G.E. Sensing duration of leaf moisture retention using electrical impedance grids. Canadian Journal of Plant Science, v.58, p.179-187, 1978.

Gillespie, T.J., Barr, A. Adaptation of a dew estimation scheme to a new crop and site. Agricultural and Forest Meteorology, v.31, p.289-295, 1984.

Gillespie, T.J., and Duan, R.X. A comparison of cylindrical and flat plate sensors. Agricultural and Forest Meteorology, v.40, p.61-70, 1987.

Gillespie, T.J., Brisco, B., Brown, R.J., and Sofko, G.J. Radar detection of a dew event in wheat. Remote Sensing Environment, v33, p.151-156, 1990. 
Gillespie, T.J., Srivastava, B., Pitblado, R.E. Using operational weather data to schedule fungicide sprays on tomatoes in southern Ontario, Canada. Journal of Applied Meteorology, v.32, p.567-573, 1993.

Goudriaan, J. Crop micrometeorology: a simulation study. Simulation Monograph, Pudoc, Wageningen. 1977.

Gleason, M.L., Taylor, S.E., Loughin, T.M., and Koehler, K.J. Development and validation of an empirical model to estimate the duration of dew periods. Plant Disease, v.78, p.1011-1016, 1994.

Gleason, M.L., Parker, S.K. Pitbaldo, R.E. Latin, R.X., Speranzini, D., Hazzard, R.V., Maletta, M.J., Cowgill, W.P., and Biederstedt, D.L. Validation of a commercial system for remote estimation of wetness duration. Plant Disease, v.81, p.825-829, 1997.

Grove, G.G. Powdery mildew of sweet cherry: influence of temperature and wetness duration on release and germination of ascospores of Podosphaera clandestina. Phytopathology, v.81, n.10, p.1271-1275, 1991.

Hijmans, R.J., Forbes, G.A., Walker, T.S. Estimating the global severity of potato late blight with GIS-linked disease forecast models. Plant Pathology, v.49, p.497-705, 2000.

Hoppmann, D., Wittich, K.P. Epidemiology-related modelling of the leaf wetness duration as an alternative to measurements, taking Plasmopara viticola as an example. Zeitschrift für Pflanzenkrankheiten und Pflanzenschutz, v.104, p.533-544, 1997.

Huber, L., Gillespie, T.J. Modeling leaf wetness in relation to plant disease epidemiology. Annual Review of Phytopathology, v.30, p.553-577, 1992. 
Iziomon, M.G., Mayer, H., Matzarakis, A. Empirical models for estimating net radiation flux: a case study for three mid-latitude sites with orographic variability. Astrophysics and Space Science, v.273, p.313-330, 2000.

Jacobs, A.F.G., Hesinkveld, B.G., Berkowicz, S.M. A simple model for potencial dewfall in an arid region. Atmospheric Research, v.64, p.285-295, 2002.

Jacome, L.H., Schuh, W. Effects of leaf wetness duration and temperature on development of black Sigatoka disease on banana nfected by Mycosphaerella fijiensis var. difformis. Phytopathology, v.82, n.5, p.515-520, 1992.

Jegede, O.O. Estimating net radiation from air temperature for diffusion modeling applications in a tropical area. Boundary-Layer Meteorology, v.85, p.161-173, 1997.

Jesperson, G.D., Sutton, J.C. Evaluation of a forcaster for downy mildew of onion (Allium cepa L.). Crop Protection, v.6, n.2, p.95-103, 1987.

Kim, K.S., Taylor, S.E., Gleason, M.L., Koehler, K.J. Model to enhance site-specific estimation of leaf wetness duration. Plant Disease, v.86, p.179-185, 2002.

Klemm, O., Milford, C., Sutton, M.A., Spindler, G., van Putten, E. A climatology of leaf surface wetness. Theoretical and Applied Climatology, v.71, p.107-117, 2002.

Latin, R.X., Evans, K.J. Development and delivery of a forcaster for Alternaria leaf blight of muskmelon. Phytopathology, v.86, p.S106, 1996. (Abstr.)

Latin, R.X., Egel, D.S. Melcast: melon disease forcaster. Purdue University. Coop. Ext. Bulletin. BP-64-W. 2001.

Lau, Y.F., Gleason, M.L., Zriba, N., Taylor, S.E., Hinz, P.N. Effects of coating, deployment angle, and compass orientation on performance of electronic wetness sensors during dew periods. Plant Disease, v.84, p.192-197, 2000. 
Lhomme, J.P., Jimenez, O.F. Estimating dew duration on banana and plantation leaves from standard meteorological observations. Agricultural and Forest Meteorology, v.62, p.263-274, 1992.

Lomas, J. Note on dew-duration recorders under semi-arid conditions. Agricultural Meteorology, v.2, p.351-359, 1965.

Lomas, J., Shashoua, Y. The performance of three types of leaf-wetness recorders. Agricultural Meteorology, v.7, p.159-166, 1970.

Lou, W.H., Goudriaan, J. Effects of altering water temperature on leaf wetness in paddy rice crops. Agricultural and Forest Meteorology, v. 97, p.33-42, 1999.

Lou, W.H., Goudriaan, J. Dew formation on rice under vaarying durations of nocturnal radiative loss. Agricultural and Forest Meteorology, v.104, p.303-313, 2000.

Madeira, A.C., Kim, K.S., Taylor, S.E., Gleason, M.L. A simple cloud-based energy balance model to estimate dew. Agricultural and Forest Meteorology, v.111, p.5563, 2002.

Magarey, R.D. A theoretical standard for estimation of surface wetness duration in grape. Ph.D. dissertation. Cornell University, Ithaca, NY, USA. 1999. 208p.

Magarey, R.D., Seem, R.C., Russo, J.M., Zack, J.W., Waight, K.T., Travis, J.W., Oudemans, P.V. Site-specific weather information without on-site sensors. Plant Disease, Saint Paul, v.85, n.12, p.1216-1226. 2001.

Melching, J.S., Dowler, W.M., Koogle, D.L., Royle, M.H. Effects of duration, frequency and temperature of leaf wetness periods on soybean rust. Plant Disease, v.73, p.117122, 1989. 
Miranda, R.A.C., Davies, D.D., and Cornell S.E. A laboratory assessment of wetness sensors for leaf, fruit and trunk surfaces. Agricultural and Forest Meteorology, v.102, p. 263-274, 2000.

Monteiro, J.E.B.A. Microclima e ocorrência de ramulose no algodoeiro em diferentes densidades populacionais. Piracicaba, 2002. 99p. Dissertação (Mestrado em Agronomia) - PPGFAA/ESALQ/USP.

Monteiro, J.E.B.A.; Sentelhas, P.C.; Pezzopane, J.R.M. Sensores eletrônicos de molhamento foliar: validade e aspectos práticos. In: Reunión Argentina de Agrometeorología, 9, 2002. Actas... Córdoba: AADA, 2002, p.15-16.

Monteith, J.L. Dew: Facts and fallacies. In: Rutter, A.J., Whitehead, F.H. (ed) The water relations of plants. 1961. p.35-56.

Monteith, J.L. Principles of environment physics. London: Ed Edward Arnold. 1973. 241p. Monteith, J.L., Unsworth, M.H. Principles of environmental physics. 2ed. New York: Edward Arnold. 1990. 291p.

Norman, J.M., and Campbell, G. Application of a plant environment model to problems in the environment. Advances in Irrigation, v.2, p.155-188, 1983.

Papastamati, K., McCartney, H.A., van den Bosch, F. Modelling leaf wetness duration during the rosette stage of oilseed rape. Agricultural and Forest Meteorology, v.123, p.69-78, 2004.

Pedro Jr., M.J. Relation of leaf surface wetness duration to meteorological parameters. Ph.D. dissertation. University of Guelph, Guelph, ON, Canada. 1980. 147p.

Pedro Jr., M.J., and Gillespie, T.J. Estimating dew duration. I. Utilizing micrometeorological data. Agricultural Meteorology, v.25, p.283-296, 1982a. 
Pedro Jr., M.J., and Gillespie, T.J. Estimating dew duration. II. Utilizing standard weather station data. Agricultural Meteorology, v.25, p.297-310, 1982b.

Pedro Jr., M.J. Aspectos microclimáticos e epidemiologia. In: Curso prático internacional de agrometeorologia para a otimização da irrigação. Campinas, IAC, 1989. 13p.

Pereira, A.R., Angelocci, L.R., Sentelhas, P.C. Agrometeorologia: fundamentos e aplicações práticas. Guaíba, Ed. Agropecuária. 2002. 480p.

Pitblado, R. The development and implementation of TOMCAST. Ontario Minist. Agric. Food. 1992. 25p.

Raman, C.R.V., Venkataraman, S., Krishnamurthy, V. Dew over India and its contribution to winter-crop water balance. Agricultural Meteorology, v.11, p.17-35, 1973.

Rao, P.S., Gillespie, T.J., Schaafsma, A.W. Estimating wetness duration on maize ears from meteorological observations. Canadian Journal of Soil Science, v.78, p.149154, 1998.

Scherm, H., Bruggen, A.H.C. Sensitivity of simulated dew duration to meteorological variations in different climatic regions of California. Agricultural and Forest Meteorology, v.66, p.229-245, 1993.

Schuh,W. Effect of pod development stage, temperature, and pod wetness duration on the incidence of purple seed strain of soybeans. Phytopathology, v.82, n.4, p.446451, 1992.

Schuh,W. Influence of interrupted dew periods, relative humidity, and light on disease severity and latent infections caused by Cercospora kikuchii on soybean. Phytopathology, v.83, n.1, p.109-113, 1993. 
Schuh, W., Adamowicz, A. Influence of assessment time and modeling approach on the relationship between temperature-leaf wetness periods and disease parameters of Septoria glycines on soybeans. Phytopathology, v.83, n.9, p.941-948, 1993.

Sentelhas, P.C. Ocorrência de helmintosporiose e de oídio na cultura do trigo sob diferentes condições microclimáticas. Dissertação de Mestrado, ESALQ/USP. 1992. 103p.

Sentelhas, P.C., Pedro, M.J., Felício, J.C. Estimativa da duração do período de molhamento para o trigo. Revista Brasileira de Agrometeorologia, v.1, n.1, p.117-122, 1993.

Sentelhas, P. C.; Pezzopane, J. E. M.; Ungaro, M. R. G.; Moraes, S. A.; Dudienas, C. Aspectos climáticos relacionados à ocorrência da mancha de Alternária em cultivares de girassol. Fitopatologia Brasileira, v.21, n.4, p.464-469, 1996.

Sentelhas, P.C., Monteiro, J.E.B.A., Gillespie, T.J. Electronic leaf wetness duration sensor: why it should be painted. International Journal of Biometeorology, v.48, p.202-205, 2004a.

Sentelhas, P.C., Gillespie, T.J., Monteiro, J.E.B.A., Rowlandson, T. Estimating leaf wetness duration on a cotton crop from meteorological data. Revista Brasileira de Agrometeorologia, 2004b. (In press)

Sentelhas, P.C., Gillespie, T.J., Gleason, M.L., Monteiro, J.E.B.A., Helland, S.T. Operational exposure of leaf wetness sensors. Agricultural and Forest Meteorology, 2004c. (In press)

Sentelhas, P.C., Gillespie, T.J., Batzer, J.C., Gleason, M.L., Monteiro, J.E.B.A., Pezzopane, J.R.M., Pedro Jr., M.J. Spatial variability of leaf wetness duration in different crop canopies. International Journal of Biometeorology, 2004d. (In press) 
Sharma, M.L. Contribution of dew in the hydrological balance of a semi-arid grassland. Agricultural Meteorology, v.17, p.321-331, 1976.

Smith, C.A., Gilpatrick, J.D. Geneva leaf-wetness detector. Plant Disease, v.64, p.286288, 1980.

Sutton, J.C., Gillespie, T.J., and Hildebrand, P.D. Monitoring weather factors in relation to plant disease. Plant Disease, v.68, p.78-84, 1984.

Turechek, W.W., Stevenson, K.L. Effects of host resistance, temperature, leaf wetness, and leaf age on infection and lesion development of pecan scab. Phytopathology, v.88, n.12, p.1294-1301, 1998.

Van der Wal, A.F. Moisture as a factor in epidemiology and forecasting. In: Koslowski, T.T. Water deficits and plant growth - Water and plant disease. NewYork: Academic Press. 1978. v.5, p.253-295.

Wallin, J.R. Agrometeorological aspects of dew. Agricultural Meteorology, v.42, p.85102, 1967.

Wei, Y.Q., Bailey, B.J., Stenning, B.C. A wetness sensor for detecting condensation on tomato plants in greenhouses. Journal of Agricultural Engineering Research, v.61, p.197-204, 1995.

Weiss, A., Lukens, D.L. Electronic circuit for detecting leaf wetness and comparison of two sensors. Plant Disease, v.65, p.41-43, 1981.

Weiss, A., Hagen, A.F. Further experiments on the measurement of leaf wetness. Agricultural Meteorology, v.29, p.207-212, 1983. 
Weiss, A., Lukens, A.F., Steadman, J.R. A sensor for the direct measurement of leaf wetness: construction techniques and testing under controlled conditions. Agricultural and Forest Meteorology, v.43, p.241-249, 1988.

Willmott, C.J.; Ackleson, S.G.; Davis, R.E.; Feddema, J.J.; Klink, K.M.; Legates, D.R.; O’donnell, J.; Rowe, C.M. Statistics for the evaluation and comparison of models. Journal of Geophysical Research, v.90, n.C5, p.8995-9005. 1985.

Wilson, T.B.; Bland, W.L.; Norman, J.M. Measurement and simulation of dew accumulation and drying in a potato canopy. Agricultural and Forest Meteorology, v.93, p.111-119, 1999.

Wittich, K.P. Some remarks on the dew duration on top of an orchard. Agricultural and Forest Meteorology, v.72, p.167-180, 1995.

Zangvil, A. Six years of dew observations in the Negev Desert, Israel. Journal of Arid Environment, v.32, p.361-371, 1996.

Zhang, Y., Gillespie, T.J. Estimating maximum droplet wetness duration on crops from nearby weather station data. Agricultural and Forest Meteorology, v.51, p.145-158, 1990.

Zheng, J., Sutton, J.C. Inoculum concentration, leaf age, wetness duration, and temperature in relation to infection of strawberry leaves by Diplocarpon earlianum. Canadian Journal of Plant Pathology, v.16, n.3, p.177-186, 1994. 